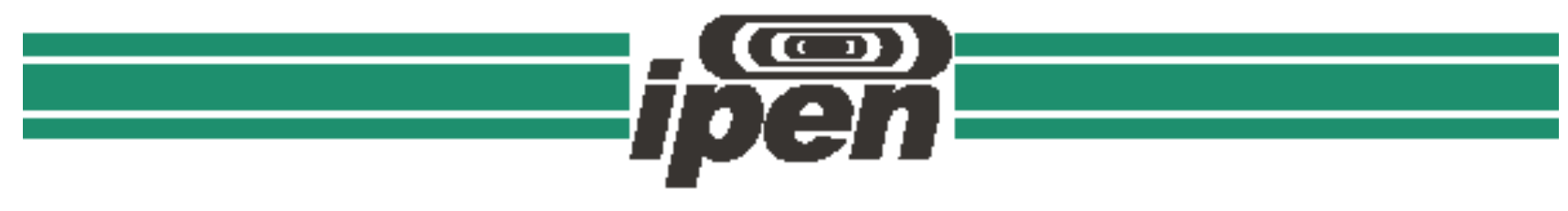

AUTARQUIA ASSOCIADA À UNIVERSIDADE DE SÃO PAULO

\title{
DESENVOLVIMENTO DE METODOLOGIAS UTILIZADAS NAS ÁREAS DE SALVAGUARDAS E FORENSE NUCLEAR BASEADAS NA TÉCNICA LA-HR-ICP-MS
}

Rafael Coelho Marin

Dissertação apresentada como parte dos requisitos para obtenção do Grau de Mestre em Ciências na Área de Tecnologia Nuclear - Materiais

Orientador:

Prof. Dr. Jorge Eduardo de Souza Sarkis 
INSTITUTO DE PESQUISAS ENERGÉTICAS E NUCLEARES

Autarquia associada à Universidade de São Paulo

\title{
DESENVOLVIMENTO DE METODOLOGIAS UTILIZADAS NAS ÁREAS DE SALVAGUARDAS E FORENSE NUCLEAR BASEADAS NA TÉCNICA LA-HR-ICP-MS
}

\author{
Rafael Coelho Marin
}

Dissertação apresentada como parte dos requisitos para obtenção do Grau de Mestre em Ciências na Área de Tecnologia Nuclear - Materiais

Orientador:

Prof. Dr. Jorge Eduardo de Souza Sarkis

Versão Corrigida

Versão Original disponivel no IPEN 


\section{Dedicatória}

Dedico este trabalho à toda minha família pelo seu apoio incondicional, sem o qual não chegaria ao final deste trabalho e desta etapa da minha vida. Em especial, gostaria de citar meus queridos pais Maria e Laércio pelo carinho, compreensão e apoio que foram determinantes para que eu concluísse essa etapa. Ao avô João por toda a companhia nesses meus anos de vida, que contaram com diversos ensinamentos e passeios pela cidade, contribuindo com o meu conhecimento de mundo. À avó Lourdes que infelizmente no pôde acompanhar esta etapa, mas teve grande contribuição durante meu caminho até aqui. Às tias Rosa, Selma, Ana e Gorette; aos tios Dorival e João pelo carinho com o qual cuidaram de mim e da molecada: Íris e Gael. A esses dois últimos pela alegria infinita que me trazem pelo simples sorriso e por me manterem firme na batalha de desenvolver a ciência no país. À Íris em especial, por desde cedo compreender minha ausência e me apoiar neste longo caminho. E não menos importante à Carla, minha mulher e companheira de tantas conquistas e frustrações que esta etapa nos trouxe e, principalmente, por ter mantido a fé no meu propósito.

Foi uma grande dedicatória, para uma família igualmente grande e que merece muito mais do que uma página - a gratidão de uma vida. 


\section{Agradecimentos}

Agradeço primeiramente a Deus pelo dom da vida, por Seu amor incondicional; sem Ele não teria a capacidade da compreensão, interpretação e conhecimento de parte da ciência, Sua criação.

Ao Prof. Dr. Jorge Eduardo de Souza Sarkis, orientador e responsável não só pelo laboratório de Caracterização Química e Isotópica - LCQ. Agradeço imensamente pela orientação que como fruto, gerou esse trabalho, publicações em revistas conceituadas na área de estudo e a participação de um curso oferecido pela Comunidade Européia para profissionais e estudantes de Salvaguardas e Ciência Forense Nuclear. Isso possibilitou um enorme crescimento profissional nesse fascinante mundo da ciência. Agradeço pelos pacientes conselhos que grandemente contribuíram para meu crescimento pessoal e intelectual, pois tive o privilégio de contar com sua disponibilidade.

Agradeço ainda Dr. João Cristiano Ulrich do LCQI, pelos treinamentos, explicações, estudos e orientação proporcionados.

À Dra. Elita Urano de Carvalho Frajndlic do Centro do Combustível Nuclear - CCN, pela colaboração direta com esse trabalho, cedendo seu tempo e o espaço para a coleta das amostras.

Ao Dr. Olívio Pereira de Oliveira Junior do Centro Tecnológico da Marinha em São Paulo - CTMSP, pelos ensinamentos e discussões sobre metrologia.

Ao companheirismo, discussões proveitosas e parceria dos colegas Tania Mateus Yoshimura, Isabella Bordon, Cristina Zampieri, Luciana Vieira de Santana e Ernesto Diaz, que forneceram bastante material e causos para inúmeras piadas de bom gosto, é claro! Agradeço em especial o colega Rafael C. B. Pestana pela parceria na coleta e análise das amostras, bem pelas discussões a respeito do trabalho. 
O auxílio financeiro foi fundamental para meu sustento ao longo desses anos. Agradeço a CAPES, Coordenação de Aperfeiçoamento de Pessoal de Nível Superior, pelo apoio na realização desse trabalho. Agradeço ainda ao IPEN, Instituto de Pesquisas Energéticas e Nucleares, por promover minha capacitação profissional. 
RESUMO

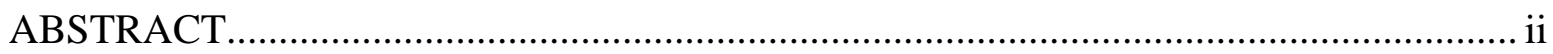

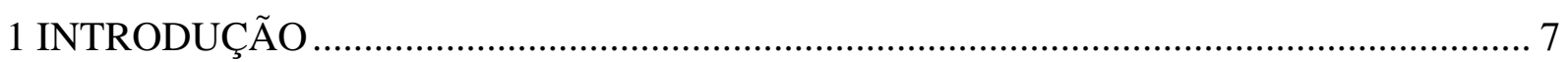

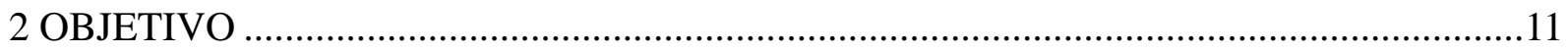

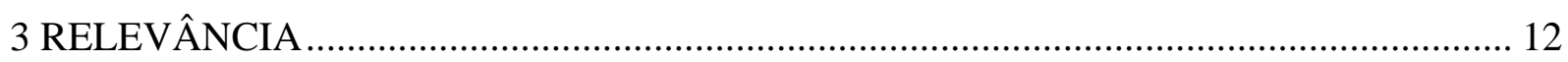

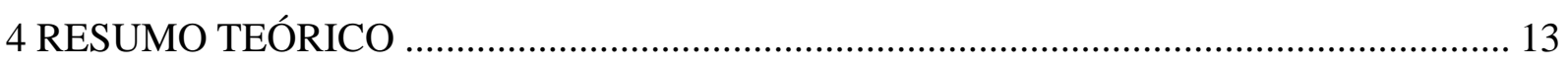

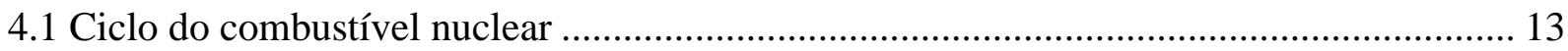

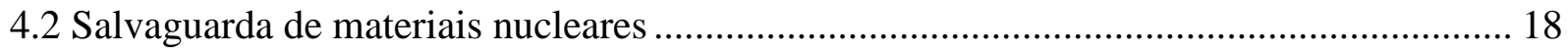

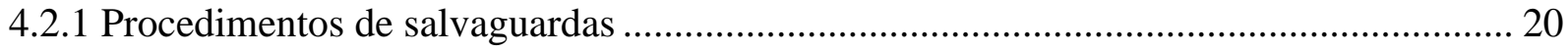

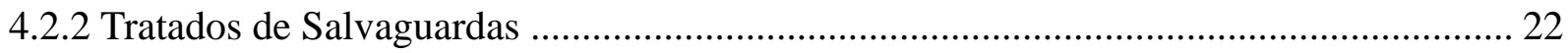

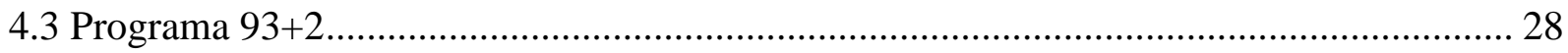

4.3.1 Amostras ambientais e as amostras de esfregaço (swipe samples) ................................... 30

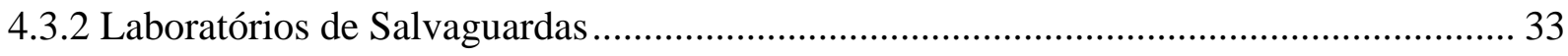

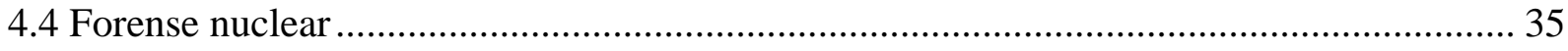

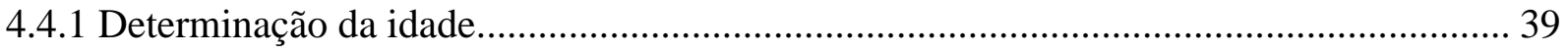

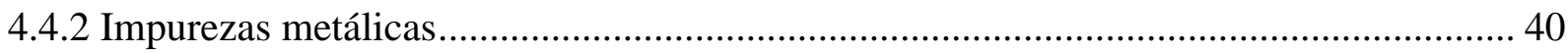

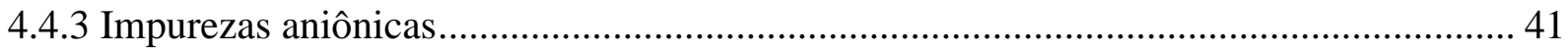

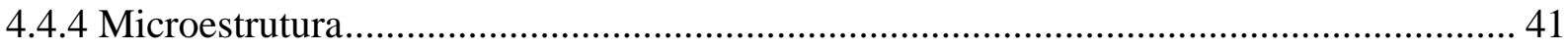

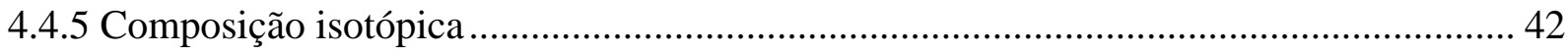

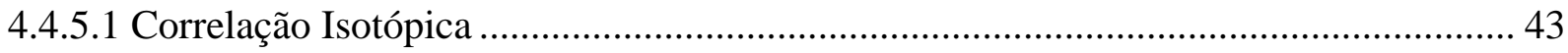

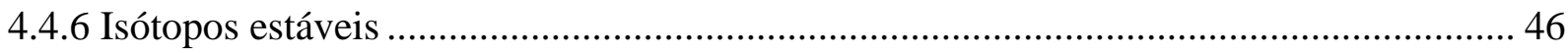

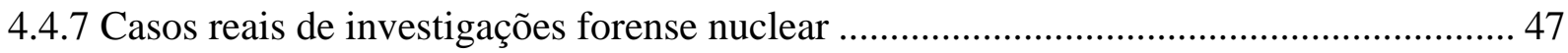

4.5 Salvaguarda de materiais nucleares e a área forense nuclear …………………............... 50

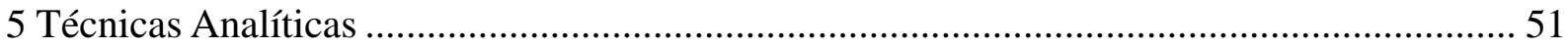

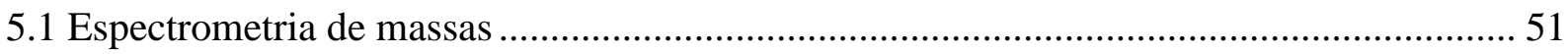

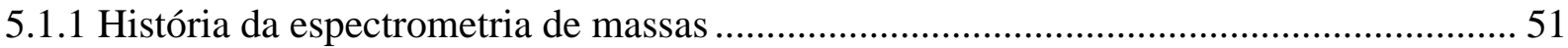

5.1.2 Espectrometria de massas com fonte de plasma indutivamente acoplado (Inductively

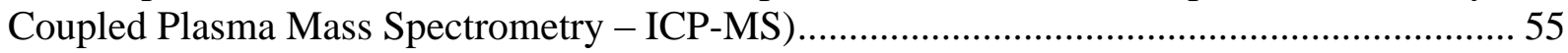

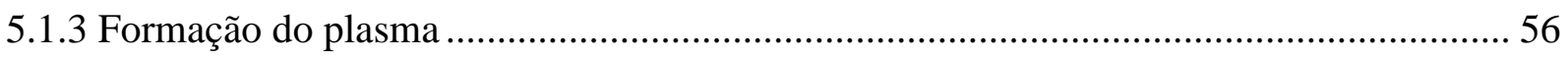

5.1.4 Espectrômetros de massa com fonte de plasma indutivamente acoplado de setor de campo (Sector Field Inductively Coupled Mass Spectrometry - SF-ICP-MS) …….................. 59

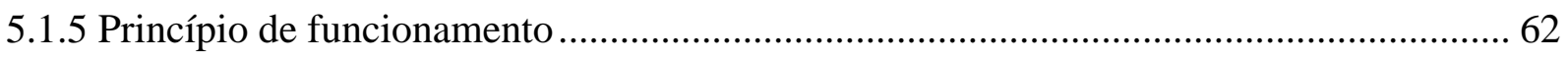

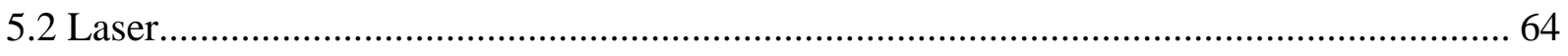

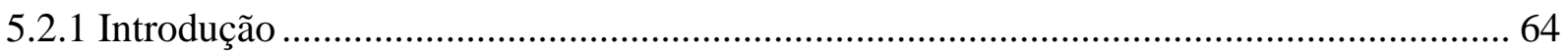

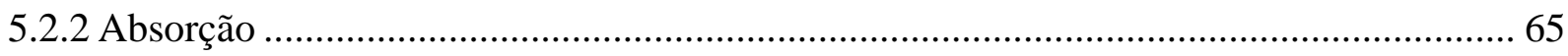




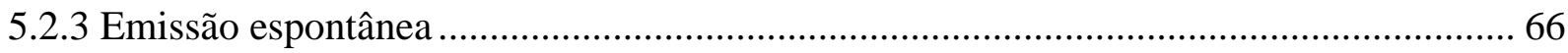

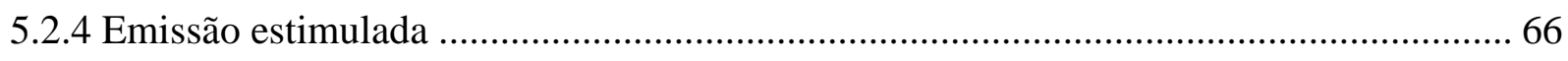

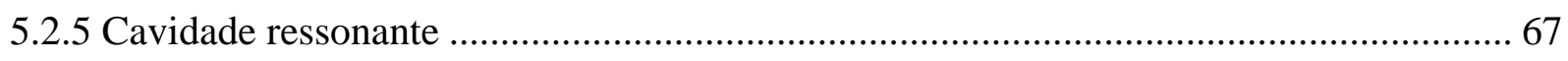

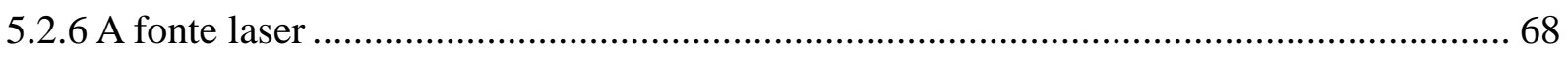

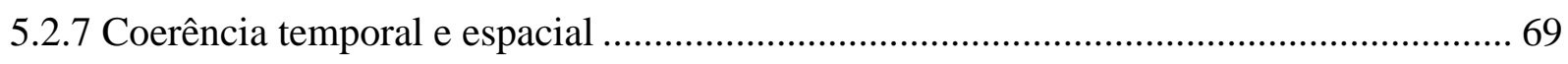

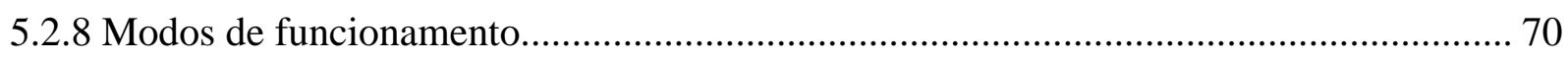

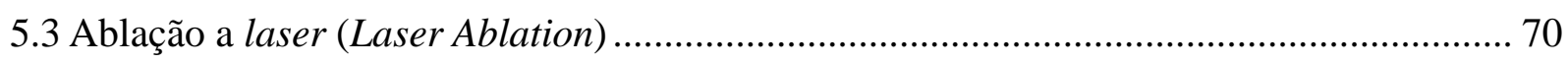

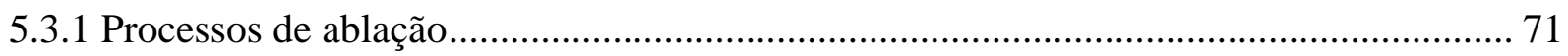

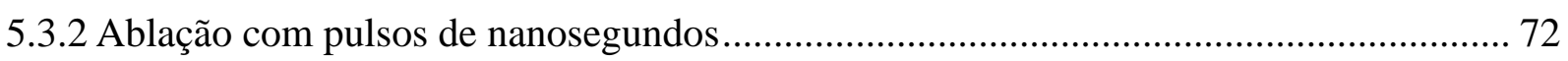

5.3.3 Comprimento de onda no processo de ablação................................................................ 73

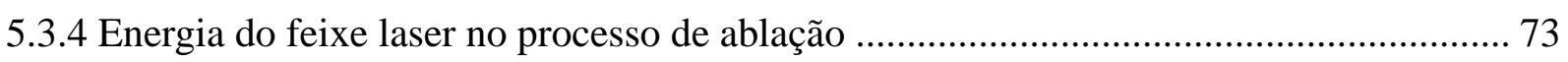

5.3.5 Laser Ablation Inductively Coupled Mass Spectrometry (LA-ICP-MS) ……………..... 74

5.3.6 Utilização da técnica LA-ICP-MS como metodologia de análise de materiais nucleares76

5.4 Técnicas complementares utilizadas na estratégia analítica ............................................... 77

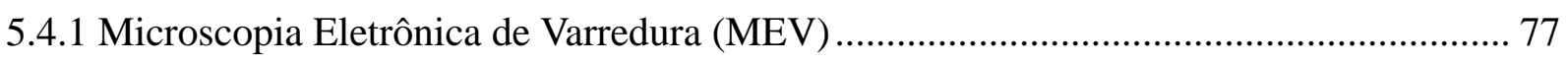

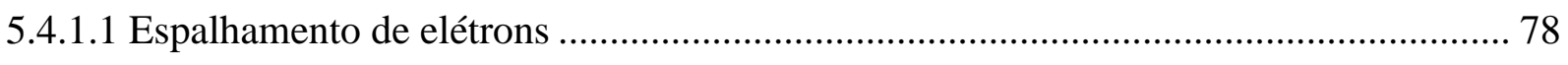

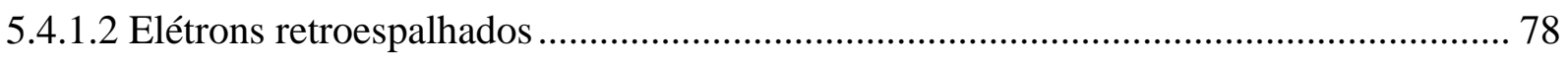

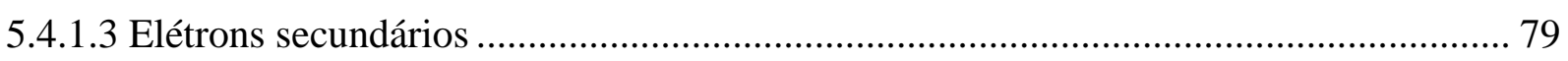

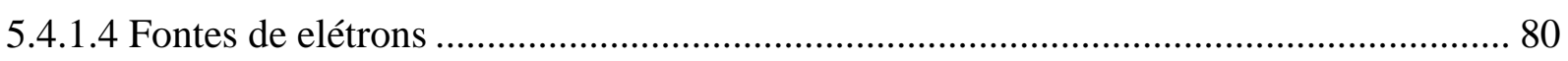

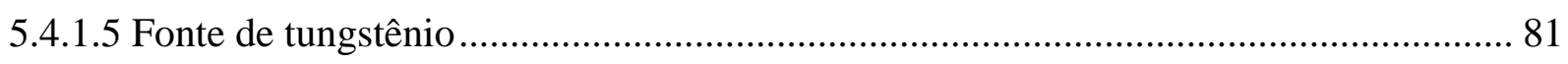

5.4.2 XEDS - Espectroscopia de Energia Dispersiva de Raios X.......................................... 82

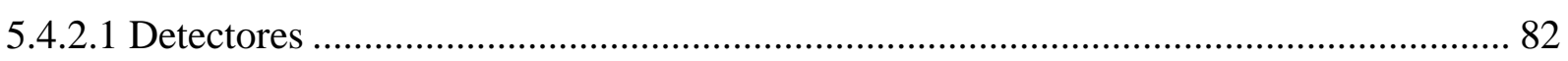

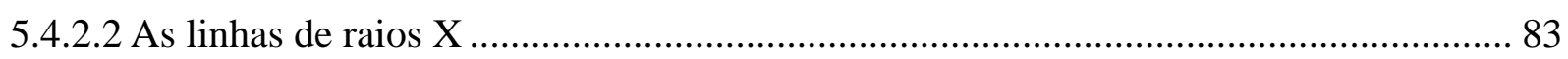

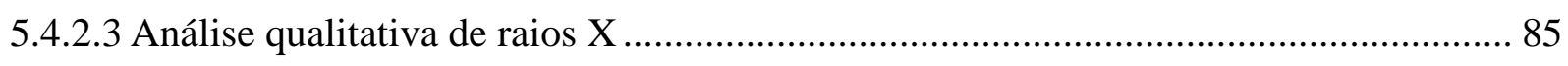

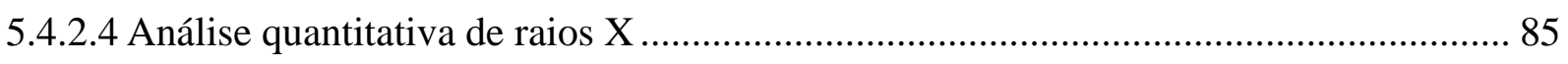

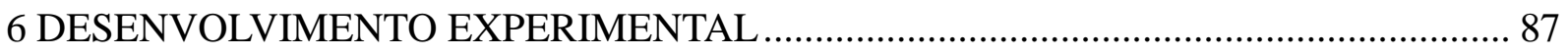

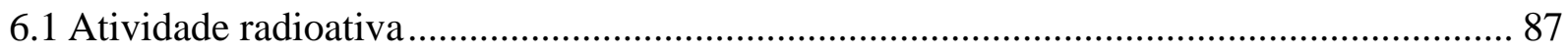

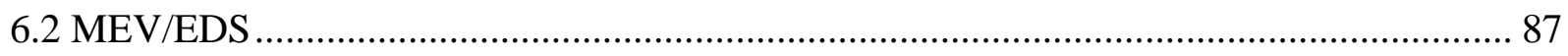

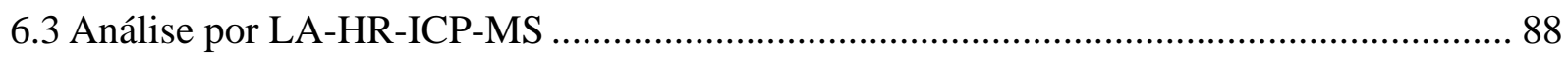

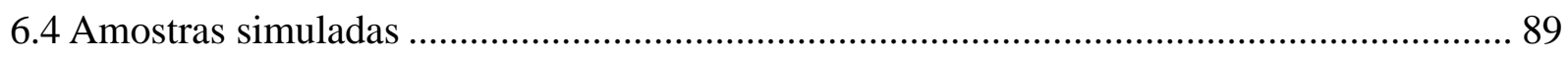

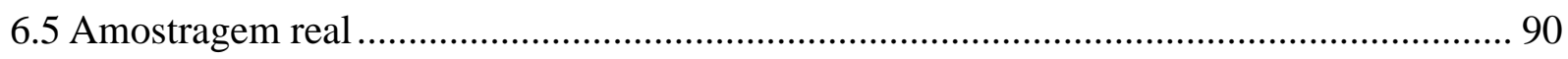

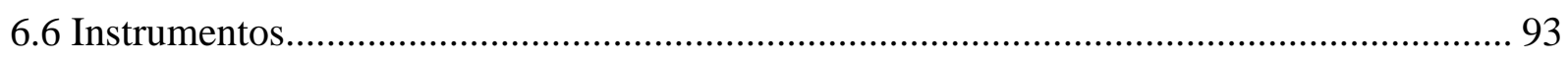

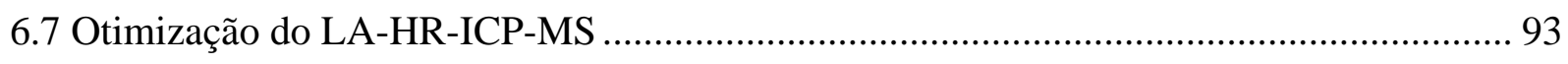

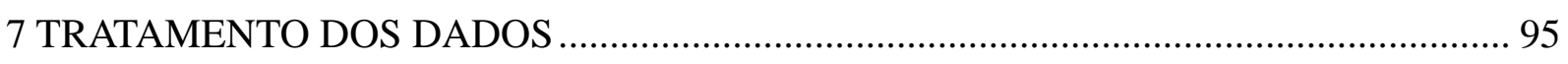




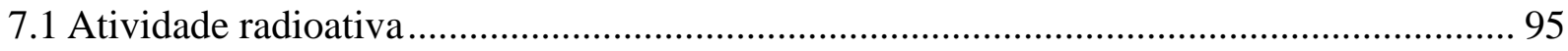

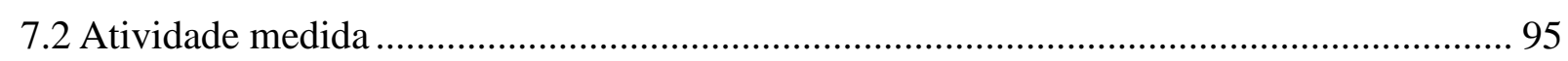

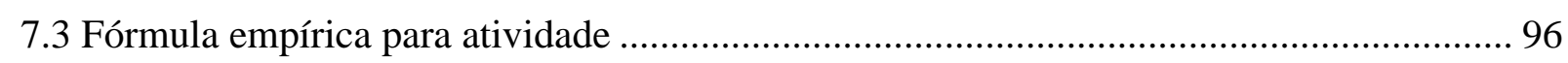

7.4 Fator de discriminação de massa nas medidas de razão isotópica...................................... 96

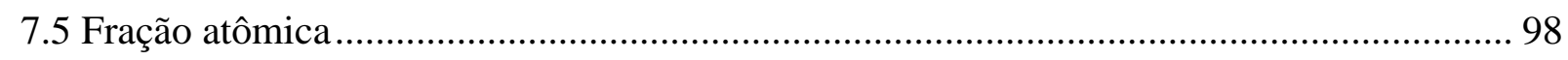

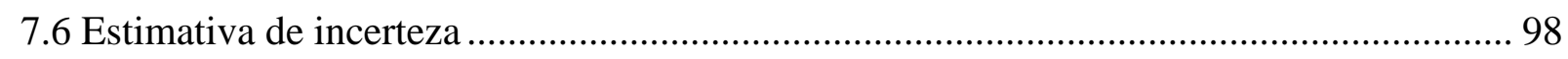

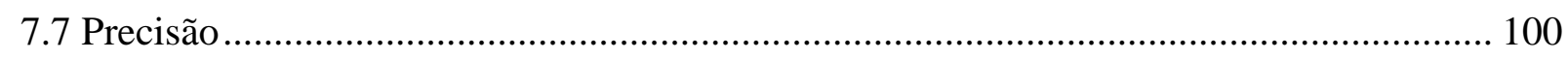

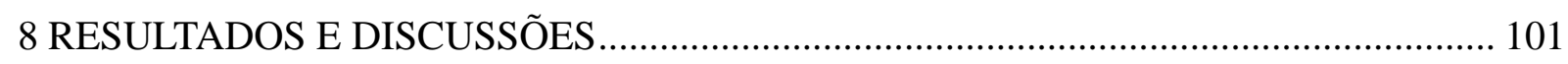

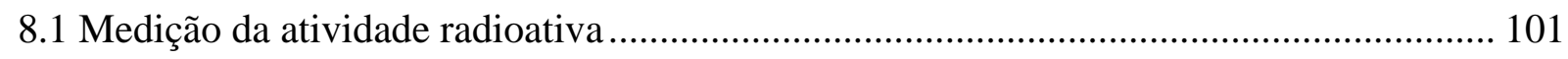

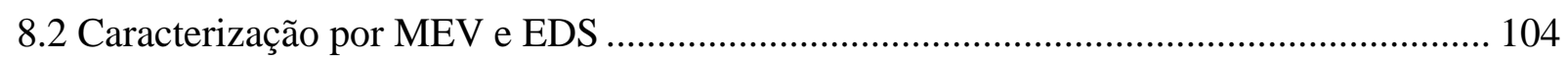

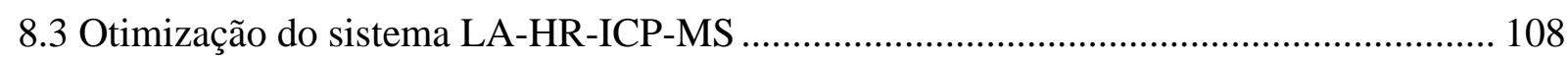

8.4 Composição isotópica medida para a amostra de esfregaço simulada B.............................113

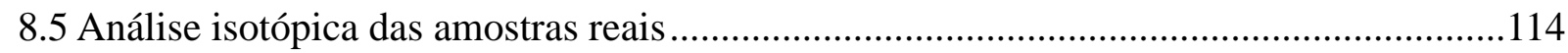

8.6 Comparação entre as incertezas da razão isotópica ${ }^{235} \mathrm{U} /{ }^{238} \mathrm{U}$ da amostra simulada e das

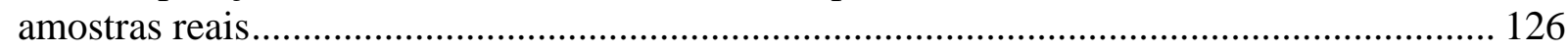

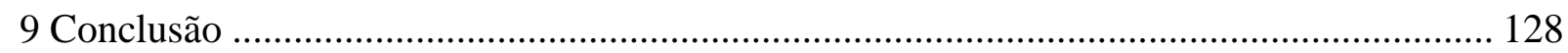

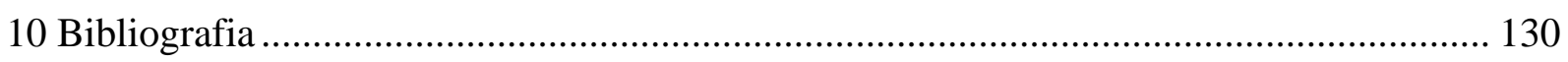




\section{RESUMO}

A amostragem ambiental por esfregaço ou swipe samples é uma metodologia que vem sendo empregada rotineiramente pela Agência Internacional de Energia Atômica (AIEA) para verificar se os Estados signatários do Acordo de Salvaguardas estão realizando atividades nucleares não declaradas. A análise dessas amostras ambientais é complementar aos procedimentos de salvaguardas convencionais para a verificação das informações cedidas pelos Estados.

Neste trabalho, foi descrita uma metodologia que visa a fortalecer os processos de salvaguarda nuclear e da ciência forense nuclear no país. A proposta é estudar e avaliar a técnica de ablação à laser acoplada a um espectrômetro de massa de alta resolução com fonte de plasma indutivamente acoplado (LA-HR-ICP-MS - Laser Ablation High Resolution Inductively Coupled Plasma Mass Spectrometry), como técnica alternativa para a análise das amostras de esfregaço. Adicionalmente, foram empregadas outras técnicas complementares (atividade radioativa, microscopia eletrônica de varredura e espectroscopia de energia dispersiva) com o intuito de garantir maior segurança ao processo de inspeção de salvaguardas e investigações forenses nucleares.

A precisão, medida através do desvio padrão relativo (DPR), dos resultados obtidos para as razões isotópicas ${ }^{234} \mathrm{U} /{ }^{238} \mathrm{U},{ }^{235} \mathrm{U} /{ }^{238} \mathrm{U}$ e ${ }^{236} \mathrm{U} /{ }^{238} \mathrm{U}$ do padrão analisado (CRM - 125A) para a medida do fator de discriminação de massa foram, respectivamente, 1,3\%, 0,2 \% e 7,6 $\%$. Já as incertezas percentuais (u \%), que também contemplam o DPR das medições, variaram de $3,5 \%$ a $29,8 \%$ para as medições da razão isotópica ${ }^{235} \mathrm{U} /{ }^{238} \mathrm{U}$ e de $16,6 \%$ a 42,9 $\%$ para a razão isotópica ${ }^{234} \mathrm{U} /{ }^{238} \mathrm{U}$. Esses valores mostraram-se compatíveis com outros estudos que utilizaram a mesma técnica para análise de amostras reais coletadas em uma instalação nuclear. As amostras coletadas apresentaram nível de enriquecimento que variou de $(2,3 \pm 0,7) \%$ (amostra 3 - corredor de acesso à instalação) a $(17,3 \pm 2,8) \%$ (amostra 18 bancada de recuperação de $\mathrm{UF}_{4}$ ). A partir da coleta de amostras nesses diversos pontos, desde a entrada da instalação até a bancada em que se manuseia o urânio enriquecido, foi possível detectar diversos níveis de enriquecimento no isótopo ${ }^{235} \mathrm{U}$.

Palavras-chave: urânio, salvaguardas, forense nuclear, razão isotópica, espectrometria de massas, LA-ICP-MS, gradiente de enriquecimento. 


\begin{abstract}
Environmental sampling performed by means of swipe samples is a methodology frequently employed by International Atomic Energy Agency (IAEA) to verify if the signatory States of the Safeguards Agreements are conducing unauthorized activities. Swipe samples analysis is complementary to the Safeguards ordinary procedures used to verify the information given by the States.

In this work it was described a methodology intending to strengthen the nuclear safeguards and nuclear forensics procedures. The proposal is to study and evaluate the laser ablation high resolution inductively coupled plasma mass spectrometry (LA-HR-ICP-MS) technique as an alternative to analyze the real-life swipe samples.

The precision achieved through the standard (CRM - 125A) measurements, represented by the relative standard deviation (RSD), was respectively $1.3 \%, 0.2 \%$ e $7.6 \%$ for the ${ }^{234} \mathrm{U} /{ }^{238} \mathrm{U}$, ${ }^{235} \mathrm{U} /{ }^{238} \mathrm{U}$ e ${ }^{236} \mathrm{U} /{ }^{238} \mathrm{U}$ isotopes ratios. The percent uncertainties (u \%), which covers the RSD, ranged from $3.5 \%$ to $29.8 \%$ to the ${ }^{235} \mathrm{U} /{ }^{238} \mathrm{U}$ measurements and from $16.6 \%$ to $42.9 \%$ to the ${ }^{234} \mathrm{U} /{ }^{238} \mathrm{U}$ isotope ratio. These results were compatible with former studies performed by the LA-HR-ICP-MS that analyzed real-life swipe samples collected at a nuclear facility. Swipe samples collected from several points of the nuclear facility presented enrichment level ranging from $(2.3 \pm 0.7) \%$ (sample 3$)$ to $(17.3 \pm 2.8) \%$ (sample 18 ). They also allowed detecting different enrichment levels within the facility.
\end{abstract}

Keywords: uranium, safeguards, nuclear forensic, isotopic ratio, mass spectrometry, LAHR-ICP-MS, enrichment gradient. 


\section{LISTA DE TABELAS}

Tabela 1 - Medidas aprovadas pelo Conselho de Governadores da AIEA para o Programa $93+2(30)$.

Tabela 2 - Técnicas analíticas utilizadas nos processos de forense nuclear (41): densitometria híbrida da borda da camada K (hybrid K-edge densitometry - HKED); espectrometria de mass por diluição isotópica (isotope dilution mass spectrometry - IDMS); espectrometria gama de alta resolução (high-resolution gamma spectrometry-HRGS); espectrometria de massa por ionização térmica (thermal ionization mass spectrometry - TIMS); espectrometria de massa por fonte de plasma indutivamente acoplado (inductively coupled plasma mass spectrometry - ICP-MS); espectrometria de massa por ionização secundária (secondary ion mass spectrometry - SIMS); espectrometria de massa por descarga elétrica (glow discharge mass spectrometry -GDMS); espectrometria alfa (alpha spectrometry - AS); microscopia eletrônica de varredura (scanning electron microscopy - SEM) e microscopia eletrônica de transmissão (transmission electron microscopy - TEM).

Tabela 3 - Valores certificados para a fração atômica da pastilha de $\mathrm{UO}_{2}$. Dados apresentados com suas incertezas expandidas $(U)$ em nível de confiança de $95 \%(k=2)$.

Tabela 4 - Massa de urânio utilizada nas amostras de esfregaço padrão preparadas em laboratório. Dados apresentados com suas incertezas expandidas $(U)$ em nível de confiança de $95 \%(k=2)$.

Tabela 5 - Parâmetros otimizados para o sistema LA-HR-ICP-MS.___ 94

Tabela 6 - Contagens de emissão, em contagens por minuto (cpm,) alfa do branco e das amostras $A, B, C, D, 17$ e 18. Dados apresentados com suas incertezas expandidas $(U)$ em nível de confiança de $95 \%(k=2)$ para as amostras sumuladas.

Tabela 7 - Dados da massa de urânio depositada (m), contagens por minuto (cpm), atividade medida (Am) e atividade total calculada (Aempírica) das amostras de esfregaço simuladas (A, $B, C$ e D) e das amostras de esfregaço reais (17 e 18). Dados apresentados com suas incertezas expandidas $(U)$ em nível de confiança de $95 \%(k=2)$.

Tabela 8 - Composição atômica do padrão $U_{4}$ e da amostra 18. Dados apresentados com suas incertezas expandidas $(U)$ em nível de confiança de $95 \%(k=2)$.

Tabela 9 - Dados das medições de razão isotópica do padrão CRM - 125-A. 111

Tabela 10 - Dados relativos à razão isotópica corrigida (Rt), incerteza expandida $(U)$, incerteza percentual (u\%), graus de liberdade efetivos (veff) e fator de abrangência ( $k$ ) para as medições da amostra simulada $B$ - cujo nível de enriquecimento é próximo do natural.. 113 Tabela 11 - Fator de discriminação de massa obtido pela análise do padrão CRM 125-A pela técnica LA-HR-ICP-MS. Dados apresentados com suas incertezas expandidas em nível de confiança de $95 \%(k=2)$. 115

Tabela 12 - Tabela utilizada para a estimativa das incertezas, contendo os tipos de distribuição e incerteza, incertezas padrão (ui), o divisor, o coeficiente de correlação (ci) e os graus de liberdade (vi). Os dados nela contidos são referentes à amostra 17 116

Tabela 13 - Dados relativos à razão isotópica corrigida (Rt), incerteza expandida $(U)$, incerteza percentual (u\%), graus de liberdade efetivos (veff) e fator de abrangência $(k)$. Tabela 14 - Comparação entre as incertezas expandidas percentuais (u\%) obtidas em três estudos a respeito da análise de amostras de esfregaço pela técnica LA-HR-ICP-MS. 117 Tabela 15 - Dados consolidados dos valores de fração atômica medida $\left(F_{235}\right.$ medida $)$. Dados 
apresentados com suas incertezas expandidas em nível de confiança de 95\% ( $k=2)$.

Tabela 16 - Razões isotópicas corrigidas para as partículas encontradas nas amostras 8 e 11. Dados apresentados com suas incertezas expandidas em nível de confiança de 95\% ( $k=2) .124$ Tabela 17 - Comparação entre as incertezas expandidas percentuais $(u \%)$ da razão isotópica ${ }^{235} U{ }^{238} U$ obtidas para as amostras reais e simuladas. 127 


\section{LISTA DE FIGURAS}

Figura 1- Etapas do ciclo fechado do combustível nuclear ................................................ 14

Figura 2 - A tríade salvaguardas, segurança e proteção. ..................................................... 19

Figura 3 - Casos confirmados envolvendo tráfico ilícito de material nuclear reportados ao Grupo de Trabalho Técnico Internacional contra o Contrabando Nuclear (Nuclear Smuggling International Technical Working Group - ITWG) (43) .................................................... 35

Figura 4 - Fluxograma do processo forense nuclear......................................................... 38

Figura 5 - Cadeia de decaimento do ${ }^{238}$ Pu que é utilizada como cronômetro desse material

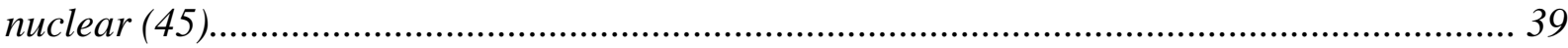

Figura 6 - Terras raras presentes em quinze amostras diferentes provenientes de um produto intermediário de urânio (48). ............................................................................................. 40

Figura 7 - (a) padrão UF4; (b) partícula coletada em uma amostra real. ............................ 42

Figura 8 - Correlação isotópica de Pu para diferentes tipos de reatores (51). ...................... 43

Figura 9-Gráfico 3D da análise de diversos tipos de combustíveis irradiados simulados em diversos tipos de reatores nucleares. Reator de água pressurizada (pressurized water reactor$P W R$ ); Reator de água fervente (boiling water reactor-BWR); reator nuclear canadense (canadian deuterium uranium - CANDU) e reator super-regenerador de nêutrons rápidos refrigerado por metal líquido (liquid metal fast breeder reactor - LMFBR) (52).................. 44 Figura 10-Análise por PCA dos isótopos de plutônio resultantes de combustíveis irradiados em três tipos de reatores nucleares. Reator de água pressurizada (pressurized water reactor$P W R$ ); Reator de água fervente (boiling water reactor $-B W R$ ) e reator avançado resfriado a gás (advanced gás-cooled reactor - AGR) (53)................................................................. 45 Figura 11 - Composição isotópica de chumbo de amostras de yellow cake de minas distintas (54).

Figura 12 - Objetivos das salvaguardas e da ciência forense nuclear.................................. 50

Figura 13 - Tubo de descarga de Goldstein (56)............................................................... 51

Figura 14 - Espectrômetro de massa de Dempster. A - Fonte de íons; B - Eletroimã; $C$ -

Gaiola de Faraday; D - Eletrômetro (56)....................................................................... 53

Figura 15 - Espectrômetro de massa com geometria Nier-Johnson (56)............................... 54

Figura 16 - Interface e tocha de um ICP-MS (56). ............................................................. 58

Figura 17 - Sistema óptico de extração de ions (61)............................................................. 59

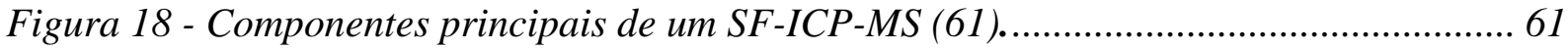

Figura 19 - Analisador eletrostático de um SF-ICP-MS (61).............................................. 62

Figura 20 - Detector do tipo fotomultiplicador ou SEM (56).............................................. 63

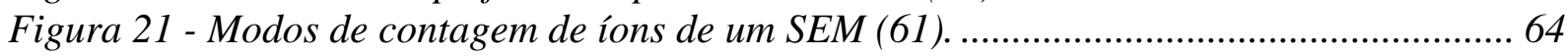

Figura 22 - Processo de absorção de um fóton por um átomo. ............................................. 65

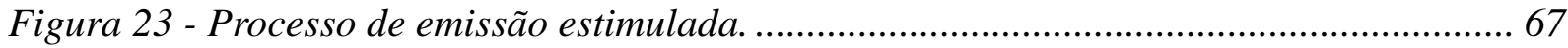

Figura 24 - Cavidade ressonante de um laser (66)............................................................. 68

Figura 25 - Esquema ilustrativo da ablação de um material pelo feixe laser. Podem ocorrer nesse processo a fusão da superfície atingida, a ejeção de partículas, a vaporização, excitação e ionização dos elementos, dependendo da energia do feixe incidente e das propriedades termo-ópticas do material. (71)..................................................................... 71 Figura 26 - Esquema do acoplamento de um sistema de ablação a laser com um ICP-MS (56).

Figura 27 - Esquema do espalhamento elástico de electrons (82)...................................... 79 
Figura 28 - Distribuição dos elétrons secundários (83).

Figura 29 - Esquema de um MEV com fonte de emissão de elétrons de tungstênio (84)........ 81

Figura 30 - Linhas de emissão de raios $X(82)$................................................................... 84

Figura 31 - Particulas coletadas nas amostras de esfregaço em fita adesiva e colocadas em

um suporte (stub) para análise por MEV........................................................................ 88

Figura 32 - Etapas de produção do U3Si2 efetuadas pelo CCN/IPEN................................... 90

Figura 33 - Mapa da área de coleta com a localização do local em que foi realizado o

esfregaço..................................................................................................................... 91

Figura 34 - Kit para a coleta das amostras de esfregaço (29) e uma amostra real................ 92

Figura 35 - Imagens obtidas por MEV: (a) amostra 18 com magnificação de 1200x; (b)

amostra 18 com magnificação de $2500 x$ e (c) padrão de UF ${ }_{4}$ com magnificação de 1500x. 105

Figura 36 - Espectro EDS e mapa de distribuição dos elementos do padrão UF 4 do CEA com

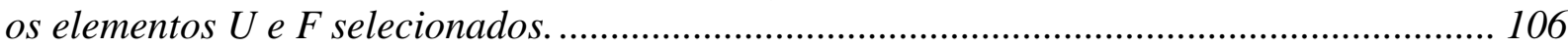

Figura 37 - Espectro EDS amostra 18 com todos os elementos.......................................... 107

Figura 38- Dados do ajuste da potência de RF (rádio freqüência) do LA-HR-ICP-MS. ...... 108

Figura 39 - Dados do ajuste do eixo z do sistema LA-HR-ICP-MS. Este eixo determina o

ponto de foco do feixe de laser sobre a superfície da amostra............................................. 109

Figura 40 - Dados do ajuste do diâmetro do feixe do laser....................................................110

Figura 41 - DPR x razões isotópicas medidas do padrão certificado CRM-125A................112

Figura 42 - Razões ${ }^{235} U /^{238} U$ medidas e suas respectivas incertezas expandidas $(k=2)$ para

as amostras 17 (a) e 18 (b) em comparação com o padrão NIST U200.............................. 120

Figura 43 - Gráfico da razão isotópica ${ }^{234} U{ }^{238} U x^{235} U{ }^{238} U$ para as amostras 17 e $18 \ldots . .121$

Figura 44 - Distribuição da fração atômica para as amostras analisadas. Dados

apresentados com suas incertezas expandidas em nível de confiança de 95\% ( $k=2)$ )........... 123

Figura 45 - Razões isotópicas ${ }^{235} U{ }^{238} U$ das amostras coletadas no CCR/IPEN. Dados

apresentados com suas incertezas expandidas em nível de confiança de 95\% ( $k=2)$. Amostra 3

- Corredor de acesso ao prédio; Amostra 6 - porta de acesso ao prédio; Amostra 8-ponto de troca de sapatos; Amostra 11 - ponto de checagem de radiação; Amostra 16 - capela de $U_{4}$; Amostra 17 - chão em frente à capela de recuperação de UF $F_{4}$; Amostra 18 - capela de recuperação de $U F_{4}$. 


\section{INTRODUÇÃO}

A energia liberada pelas reações de fissão do átomo de urânio vem sendo de grande importância econômica, pois possui um alto rendimento energético. Considerando-se uma reação de fissão completa, a energia gerada por $1 \mathrm{~kg}$ de urânio equivale àquela gerada pela queima de 20 toneladas de carvão ou de 10 toneladas de petróleo (1). Isso torna essa modalidade de geração muito mais atrativa, pois, segundo relatório da Agência Internacional de Energia Atômica (AIEA), é a que apresenta maior potencial para mitigar as emissões de gases geradores do efeito estufa $\left(\mathrm{CO}_{2}\right)(2)$.

A ideia de que a matéria é constituída por partículas elementares vem desde antiguidade, quando os filósofos gregos Leucipo e Demócrito descreveram a teoria atomística. Segundo essa teoria, todo o Universo é composto por partículas indivisíveis, impenetráveis, invisíveis e dotadas de movimento autônomo: o átomo (3). Após de um longo período de latência esta teoria foi trazida à tona em 1803 por John Dalton que possibilitou o primeiro modelo atômico proposto por J. J. Thomson - o Pudim de Ameixas, que consistia de um núcleo positivo incrustado por elétrons.

Anos mais tarde, em 1895, a descoberta dos raios $\mathrm{X}$ por Wilhelm Röentgen impulsionou a comunidade científica a realizar diversos estudos a respeito da radiação eletromagnética. Os trabalhos que mais se destacaram foram de Henri Becquerel (1896) e o de Marie Curie e Pierre Curie (1898). Becquerel estudava materiais fosforescentes e fluorescentes, dentre eles os sais de urânio que não são luminescentes, mas impressionavam chapas fotográficas. Isso o levou a concluir que essa material emitia algum tipo de radiação parecida com os raios X. Ele continuou testando diversos outros compostos de urânio até isolá-lo em sua forma metálica, chegando à mesma conclusão: emissão de um tipo de radiação. Já os Curie estudaram outros materiais diferentes do urânio que emitissem o mesmo tipo de radiação. O primeiro elemento descoberto foi o tório, seguido pelo polônio e por fim o rádio, que tem atividade novecentas vezes maior do que o urânio (4).

Em 1899, Rutherford inspirado pelos trabalhos de Becquerel e dos Curie descobriu que a radiação emitida pelo urânio produzia partículas menos ou mais penetrantes partículas $\alpha$ e $\beta$ respectivamente. Em 1904, através do experimento do espalhamento de partículas $\alpha$ ele notou que elas eram na verdade núcleos de hélio. Essas sucessivas 
descobertas culminaram com a confirmação experimental do átomo e o modelo orbital de Rutherford (4).

O modelo atômico atual é o chamado Átomo de Bohr. Ele representa a aplicação da teoria quântica de Planck e Einstein ao modelo de Rutherford. No modelo proposto por Bohr, o movimento do elétron ao redor do núcleo é regido pelas leis de Newton, podendo ocupar apenas algumas órbitas especiais estacionárias. Essas órbitas só podem ser alteradas com absorção ou emissão de radiação eletromagnética. (5) Anos mais tarde, Enrico Fermi estava trabalhando com a irradiação de diversos elementos com nêutrons, levando-o a descobrir os elementos transurânicos. Tal descoberta garantiu-lhe o Prêmio Nobel de 1938 (6). Em dezembro desse mesmo ano, na Alemanha, Hahn e Strassman anunciaram na revista Naturwissenschaften a descoberta da fissão nuclear ao notar o aparecimento de dois elementos mais leves após o bombardearem um átomo de urânio com nêutrons. Pouco tempo depois o físico Húngaro Leo Szilard notou a liberação de dois nêutrons após um nêutron já emitido no processo colidir com outro átomo de ${ }^{235} \mathrm{U}-\mathrm{o}$ descobrimento da reação em cadeia autossustentada (7).

No entanto, foram os fins militares que levaram os governos da Inglaterra, Alemanha, Estados Unidos e União Soviética a investirem esforços e capital no desenvolvimento da energia nuclear. Tais esforços resultaram numa corrida para determinar qual das potências conseguiria construir a primeira bomba nuclear. Esse cenário envolveu os mais proeminentes cientistas da época, levando Albert Einstein, em 1939, a escrever uma carta endereçada ao presidente Roosevelt afirmando que a Alemanha estava prestes a produzir urânio altamente enriquecido (7) - uma das matérias primas para a bomba atômica. Isso levou Roosevelt a criar o Comitê de Pesquisa de Defesa Nacional (National Defense Research Comittee - NDRC), em 1940, com o objetivo de desenvolver pesquisas associadas à defesa da nação e comandar o Projeto Nuclear. Um ano mais tarde houve o histórico ataque a Pearl Harbor e o Projeto Nuclear ainda não tinha resolvido o problema da reação em cadeia, a produção de ${ }^{235} \mathrm{U}$ ainda era insuficiente e o ${ }^{239} \mathrm{Pu}$ produzido no Ciclotron de Berkley não passava de alguns microgramas, o que levou os cientistas a sugerirem um sistema para a produção de plutônio em larga escala - a ideia do Reator Nuclear.

O primeiro reator nuclear da história foi o Chicago Pile (CP1). Ele foi construído no estádio da Universidade de Chicago, durante o Projeto Manhattan, e gerou a primeira fissão de um átomo no dia 2 de dezembro de 1942 (7).

Este Projeto gerou, além do CP1, mais três frutos - as três primeiras bombas 
nucleares:

i) A primeira em 16 de julho de 1945, chamada Trinity, foi uma bomba de teste detonada no deserto do Novo México;

ii) A segunda em 6 de agosto de 1945, chamada Little Boy, detonada sobre Hiroshima e que dizimou cerca de 140000 pessoas e

iii) A terceira em 9 de agosto de 1945, chamada Fat Man, detonada sobre Nagasaki era de plutônio e dizimou cerca de 70000 pessoas (7).

Após os episódios das bombas atômicas lançadas sobre Hiroshima e Nagasaki, Estados Unidos, Inglaterra e Canadá assinaram um tratado que delegava às Nações Unidas a responsabilidade pela vigilância e controle da energia nuclear, visando sua utilização para fins pacíficos. Pouco tempo depois os Estados Unidos e a Inglaterra propuseram a criação da Comissão de Energia Atômica das Nações Unidas (United Nation Atomic Energy Commission - UNAEC), que foi também aceita pela União Soviética. Durante sua curta existência diversas propostas, muitas delas radicais, foram submetidas à UNAEC. Porém, elas só geravam descontentamento entre as partes. Anos mais tarde houve o fato que culminou com o fim da UNAEC: a União Soviética propôs um acordo em que somente eles e os Estados Unidos estariam sujeitos ao controle das atividades nucleares. Isso só aumentou o atrito entre as duas superpotências da época que estavam prestes a dar início à corrida armamentista - período que ficou conhecido como Guerra Fria (7).

Em outubro de 1952, a Inglaterra anunciou-se detentora da tecnologia da bomba atômica. Este anúncio causou um medo crescente de que mais países detivessem armamentos nucleares. À luz desse cenário foi lançado em dezembro de 1953 pelo presidente Eisenhower o programa Átomos pela Paz. O intuito desse programa era criar um controle global da energia nuclear que aumentasse a cooperação entre os países para pesquisa e desenvolvimento dessa nova tecnologia. Com isso seria permitido que se transferisse qualquer tipo de material nuclear somente para os países que se comprometessem a utilizá-los para fins pacíficos.

A proposta inicial desse programa previa a criação de um banco que seria o proprietário e o controlador de todo material nuclear. Porém essa proposta foi abandonada em detrimento de outro que instituiria uma organização supranacional que controlaria apenas as transações desse material. Isso culminou com a criação, em 1957, da Agência 
Internacional de Energia Atômica (AIEA, cujas principais propostas seriam: i) promover a disseminação global do uso civil da tecnologia nuclear e ii) supervisionar e controlar essa tecnologia com intuito de prevenir a proliferação de armamentos nucleares (7).

Essas duas propostas podem ser divididas em cinco objetivos básicos da AIEA:

- $\quad$ Promover pesquisa, desenvolvimento e aplicação da energia nuclear para fins pacíficos;

- $\quad$ Prover materiais, serviços, equipamentos e instalações para pesquisas;

- $\quad$ Promover a troca de informações técnicas e científicas;

- Criar e aplicar medidas de Salvaguardas para garantir que não haja assistência a qualquer uso militar desses materiais;

- $\quad$ Estabelecer e desenvolver padrões de segurança nuclear.

A AIEA, por meio de seu Conselho de Governadores, passou a instituir acordos e procedimentos de salvaguardas que estabelecem mecanismos de controle e contabilidade de material nuclear, visando sua utilização para fins pacíficos. Isso inclui o controle rigoroso da quantidade e movimentação de todo o plutônio e urânio, bem como de compostos e materiais contendo esses elementos. Uma das primeiras etapas definidas nos procedimentos de salvaguardas é a inspeção realizada pela AIEA. Seus inspetores, além de verificar a contabilização dos materiais nucleares declarados pela instalação a ser monitorada, fazem coletas de amostras ambientais - as amostras de esfregaço (swipe samples). Elas são coletadas em lugares específicos das instalações pertencentes ao ciclo do combustível nuclear. $\mathrm{O}$ objetivo da coleta das amostras de esfregaço é verificar se a instalação em questão está trabalhando conforme o declarado à AIEA. Após as coletas, essas amostras são analisadas por técnicas analíticas como a espectrometria de massa por ionização térmica (thermal ionization mass spectrometry - TIMS), espectrometria de massa por ionização secundária (secondary ion mass spectrometry - SIMS) ou espectrometria de massa por fonte de plasma indutivamente acoplado (inductively coupled plasma mass spectrometry - ICP-MS), dentre outras. 


\section{OBJETIVO}

Este trabalho tem como objetivo desenvolver e avaliar o uso da técnica de ablação a laser conectada a um espectrômetro de massa por fonte de plasma indutivamente acoplado (laser ablation high resolution inductively coupled plasma mass spectrometry - LA-HRICP-MS) e outras técnicas complementares não destrutivas, para a análise das amostras de esfregaço (swipe samples). Essas análises servem como apoio às atividades de salvaguarda de instalações nucleares e investigação forense nuclear. A partir do desenvolvimento dessa metodologia, pretende-se estabelecer procedimentos baseados no Programa 93+2 da AIEA para a análise de amostras de esfregaço, visando à caracterização química de materiais nucleares em instalações do IPEN (Instituto de Pesquisas Energéticas e Nucleares) e o fortalecimento dos processos de salvaguardas nucleares do país. 


\section{RELEVÂNCIA}

A energia nuclear tem uma característica ambígua, podendo ser utilizada para fins militares e pacíficos. Os tratados de salvaguardas, firmados entre a AIEA e os Estados signatários, têm como objetivos principais acelerar e facilitar o uso dessa tecnologia para fins pacíficos; e evitar qualquer diversão ou uso malévolo dos materiais nucleares. Isto promoveu o aumento das atividades nucleares e o acesso a esta tecnologia para diversos países. Portanto, faz-se necessário o desenvolvimento contínuo de metodologias capazes de analisar as amostras coletadas durante as inspeções de salvaguardas em tempo hábil e com confiabilidade. Uma dessas metodologias, que vem sendo estudada por diversos laboratórios do mundo devido ao seu baixo custo e à sua capacidade direta de análise das swipe samples, é baseada na técnica LA-HR-ICP-MS. Por causa dessas qualidades, esta técnica mostra-se ágil e e com a vantagem de não introduzir contaminantes nas amostras, pois não necessita de nenhuma etapa prévia de tratamento.

São poucos os laboratórios que têm capacidade para analisar os materiais nucleares presentes nas amostras de esfregaço (swipe samples). Dentre estes poucos laboratórios pode-se citar aqueles pertencentes à Rede de Laboratórios Analíticos (Network of Analitical Laboratories - NWAL), do qual o Laboratório de Espectrometria de Massas do Instituto de Radioproteção e Dosimetria (IRD) faz parte; e o Laboratório de Caracterização Química e Isotópica do Centro de Química e Meio Ambiente (LCQ/CQMA) do Instituto de Pesquisas Energéticas e Nucleares (IPEN), que também faz parte da Rede Nacional de Laboratórios em Ciência Forense Nuclear (RNLCFN). 


\section{RESUMO TEÓRICO}

\subsection{Ciclo do combustível nuclear}

Combustível nuclear é todo material que contém uma fração fissionável passível de uso em um reator nuclear para a geração de energia elétrica ou em um reator de pesquisa para a obtenção de um fluxo de nêutrons adequado para a produção de radioisótopos ou para estudo de materiais. Para isso é necessário manter uma reação em cadeia, o que pode ser conseguido usando o urânio natural ou enriquecido, ou ainda material físsil obtido em outros reatores, tais como ${ }^{233} \mathrm{U} \mathrm{e}^{239} \mathrm{Pu}(8)$.

O urânio (U) é um elemento cujo número atômico é 92 e cuja massa atômica é $238,02891 \pm 0,00003$. Em 1789, Klaproth encontrou um elemento ainda desconhecido no mineral pitchblenda e tentou isolá-lo, porém esse processo só foi atingido em 1841 por Peligot $(9 ; 10)$.

Os isótopos radioativos mais importantes são o ${ }^{238} \mathrm{U},{ }^{235} \mathrm{U},{ }^{234} \mathrm{U}$ e ${ }^{236} \mathrm{U}$. Sua ocorrência na natureza é de $99,2745 \%$ para o ${ }^{238} \mathrm{U}, 0,72 \%$ para o ${ }^{235} \mathrm{U}$ e $0,0055 \%$ para o ${ }^{234} \mathrm{U}$ (10). O isótopo natural mais importante para a geração de energia nuclear é o ${ }^{235} \mathrm{U}$. Já o ${ }^{236} \mathrm{U}$ não ocorre naturalmente. Ele é obtido através da captura de um nêutron por um átomo de ${ }^{235} \mathrm{U}$ em reatores nucleares. Outro isótopo artificial do urânio também usado como material físsil para reatores regeneradores por nêutrons rápidos (Fast Breeder Reactor - FBR) ou regeneradores por nêutrons térmicos (Thermal Breeder Reactor - TBR) é o ${ }^{233} \mathrm{U}$. Ele pode ser obtido através da irradiação do ${ }^{232} \mathrm{Th}$ com nêutrons, conforme reação abaixo:

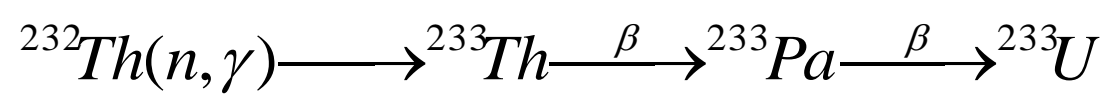

O urânio é encontrado na maioria das rochas sedimentares. Ele está presente em minerais como pechblenda, uraninita, carnotita, autunita, euxenita, torbernite, areia monazítica e lignitita. Dentre estes minerais, o mais importante é a uraninita (mistura de $\mathrm{UO}_{2}$ e $\mathrm{U}_{3} \mathrm{O}_{8}$ ), cuja maior mina encontra-se em Leopoldville, no Congo. As maiores jazidas encontram-se no Brasil, Canadá, EUA, Cazaquistão, Austrália, África do Sul e Namíbia, 
sendo atualmente a Austrália o país com a maior reserva comprovada (11). O Brasil possui atualmente a sétima reserva de U, que é estimada em 310.000 toneladas. Ela está distribuída nos municípios de Itataia (46\%), no Ceará, e Caetité (33\%) na Bahia (9).

O ciclo do combustível nuclear é composto pelas etapas seguintes (Figura 1):

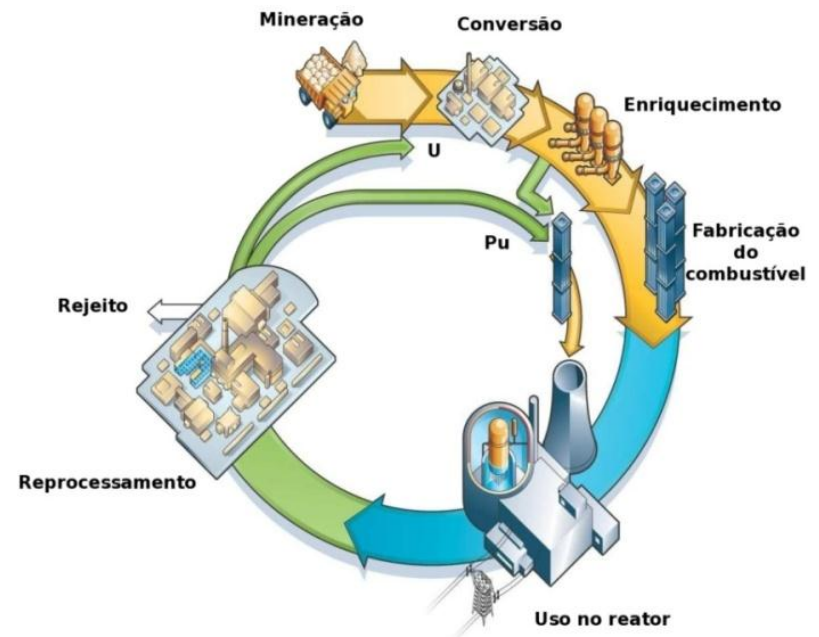

Figura 1- Etapas do ciclo fechado do combustível nuclear

\section{i) Mineração e beneficiamento}

Esta é a primeira etapa do ciclo do combustível nuclear e tem como objetivo prospectar as minas de urânio e posteriormente extrair o minério pelo método de lixiviação. Em seguida, o minério é beneficiado (purificado e concentrado) até chegar sob a forma de um sal de cor amarela, cuja composição química é o diuranato de amônia (DUA) - também conhecido por yellow cake, que no caso das Indústrias Nucleares do Brasil (INB) está na forma do composto $\mathrm{U}_{3} \mathrm{O}_{8}$. No Brasil apenas o complexo de Caetité está em operação para a realização desta etapa do ciclo (9). 


\section{ii) Conversão:}

Nesta etapa, o concentrado de urânio $\left(\mathrm{U}_{3} \mathrm{O}_{8}\right)$ é filtrado, purificado e convertido sob a forma de um gás $\left(\mathrm{UF}_{6}\right)$ para permitir o enriquecimento isotópico, pois é a única forma no estado gasoso do urânio $(9 ; 12)$.

\section{iii) Enriquecimento isotópico:}

O objetivo desta etapa é elevar a concentração do isótopo ${ }^{235} \mathrm{U}$ de aproximadamente $0,72 \%$ (nível natural) para níveis de $2 \%$ a $5 \%$. Estes são os níveis necessários para geração de energia elétrica a partir de centrais termonucleares. O enriquecimento pode ser feito pelos processos de difusão gasosa, ultracentrifugação, jato centrífugo e laser (9). Atualmente o enriquecimento é realizado no exterior, porém uma unidade da Marinha já tem essa capacitação desenvolvida pelo método da ultracentrifugação. Esta instalação é chamada de Unidade Piloto de Hexafluoreto de Urânio (Usexa) e pertence ao Centro Experimental Aramar (CEA) (13).

\section{iv) Conversão em $\mathrm{UO}_{2}$ :}

Após o enriquecimento isotópico, o $\mathrm{UF}_{6}$ é transformado em pó sob a forma do composto $\mathrm{UO}_{2}$. Este processo passa pela vaporização do $\mathrm{UF}_{6}$ em autoclave e posterior precipitação por $\mathrm{CO}_{2} \mathrm{e} \mathrm{NH}_{3}$. Esta etapa produz o tricarbonato de amônio e uranila (TCAU). Em seguida, a $540{ }^{\circ} \mathrm{C}$, o TCAU é quimicamente reduzido por $\mathrm{H}_{2}$ e vapor d'água, resultando em $\mathrm{UO}_{2}$ ainda desestabilizado. Este último composto recebe a adição de $\mathrm{N}_{2}$ e ar para que se estabilize e possa ser manuseado em temperatura ambiente. A última etapa deste processo é a adição de $\mathrm{U}_{3} \mathrm{O}_{8}$ para a fabricação das chamadas "pastilhas verdes" (9).

\section{v) Fabricação do elemento combustível:}

Nesta etapa, as "pastilhas verdes" são sinterizadas a $1750{ }^{\circ} \mathrm{C}$ a fim de adquirirem a resistência mecânica necessária para sua iradiação no reator. Posteriormente, elas são colocados em tubos de zircalloy (varetas combustível), cujo conjunto de varetas forma o elemento combustível (9). 


\section{vi) Uso no reator nuclear;}

O uso mais importante do urânio é como combustível para reatores nucleares, pois o rendimento energético de $0,45 \mathrm{~kg}$ de urânio totalmente fissionado equivale a 1500 toneladas de carvão. Ele pode ser utilizado como combustível nuclear em sua forma natural (238U) em reatores do tipo CANDU (Canadian Deuterium Uranium), com variados níveis de enriquecimento no isótopo 235U: 1,8 \% a $4 \%$ para reatores dos tipos PWR (Pressurized Water Reactor) e BWR (Boiling Water Reactor); e $20 \%$ para reatores de pesquisa. O núcleo do $235 \mathrm{U}$ pode fissionar por diversos processos, respeitando o princípio de conservação de energia. Dentre esses processos, os do tipo $(n, \gamma)$ são os principais. Pode-se citar os seguintes (14):

$$
\begin{aligned}
& { }^{235} \mathrm{U}+n \longrightarrow{ }^{97} \mathrm{Rb}+{ }^{137} \mathrm{Cs}+2 n \\
& { }^{235} \mathrm{U}+n \longrightarrow n \longrightarrow{ }^{27} \mathrm{Zr}+{ }^{137} \mathrm{Te}+2 n \\
& { }^{235} \mathrm{U}+n \longrightarrow{ }^{94} \mathrm{Sr}+{ }^{140} \mathrm{Xe}+2 n \\
& { }^{235} \mathrm{U}+n \longrightarrow{ }^{87} \mathrm{Br}+{ }^{143} \mathrm{La}+6 n \\
& { }^{235} \mathrm{C}+n \longrightarrow+{ }^{92} \mathrm{Ba}+3 n \\
& { }^{23} \mathrm{Ge}+{ }^{148} \mathrm{Nd}+n
\end{aligned}
$$

Também existem os reatores que geram mais materiais físseis do que o utilizado para manter a reação de fissão - são os chamados de reatores regeneradores, que podem utilizar nêutrons rápidos (Fast Breeder Reactor - FBR) ou nêutrons térmicos (Thermal Breeder Reactor - TBR). A reação mais comum de regeneração de materiais físseis é a seguinte:

$$
{ }^{238} U(n, \gamma) \longrightarrow{ }^{239} U \longrightarrow{ }^{\beta}{ }^{239} N p \stackrel{\beta}{\longrightarrow}{ }^{239} P u
$$


A vida útil do combustível nuclear chega ao fim após 3 ou 4 anos no reator. Esse combustível irradiado contém elevadas concentrações de radioisótopos que sofrem transformações exoenergéticas. Por este motivo ele deve ser mantido em piscinas para refrigeração, após ser retirado do núcleo do reator e antes de ser reprocessado $(9 ; 12)$.

\section{vii) Reprocessamento do combustível irradiado:}

O combustível nuclear irradiado passa a não sustentar mais a reação em cadeia ao atingir nível de enriquecimento isotópico de $0,9 \%$ em ${ }^{235} \mathrm{U}$, porém ainda tem maior concentração deste isótopo do que aquele encontrado na natureza. Portanto, pode ser reaproveitado. Além disso, o isótopo ${ }^{238} \mathrm{U}$ produz plutônio ao capturar um nêutron e sofrer decaimentos beta, produzindo o isótopo ${ }^{239} \mathrm{Pu}$. Este isótopo e o ${ }^{241} \mathrm{Pu}$ também podem sustentar reações em cadeia. Consequentemente, podem-se introduzir operações químicas e físicas para separar $\mathrm{U}, \mathrm{Pu}$ e outros elementos radioativos presentes no combustível irradiado. Isto permite a sua reutilização no ciclo combustível nuclear (ciclo fechado), respectivamente na etapa de enriquecimento e de fabricação do elemento combustível de óxidos mistos (mixed oxide - MOX) $(12 ; 15)$. Porém esta é a etapa mais poluente de todo o ciclo, devido ao uso de reagentes químicos.

O outro objetivo da etapa de reprocessamento é converter os rejeitos radioativos em uma forma mais segura para o seu gerenciamento e armazenamento.

\section{viii) Gerenciamento do rejeito radioativo:}

Os resíduos gerados após a etapa de reprocessamento são classificados como sendo de baixa atividade (meia-vida menor do que 30 anos) e de alta atividade (meia-vida maior do que 30 anos). A melhor solução encontrada para o armazenamento desses rejeitos é o isolamento geológico em repositórios profundos. O tempo mínimo de permanência para os rejeitos de baixa atividade são 300 anos, enquanto para os de alta atividade é de aproximadamente 1 milhão de anos $(12 ; 15)$.

Permeando todas essas etapas do ciclo do combustível nuclear têm-se, na área de segurança nuclear, as atividades relacionadas às salvaguardas do material sensível e, mais recentemente, uma preocupação explícita com crimes envolvendo materiais nucleares ou radioativos numa nova área da ciência denominada área forense nuclear. 


\subsection{Salvaguarda de materiais nucleares}

As salvaguardas são medidas destinadas ao controle e proteção do material nuclear e são aplicadas em qualquer planta ou instalação do ciclo do combustível nuclear. Segundo o parágrafo 28 do Acordo de Salvaguardas INFCIRC/153, firmado entre os Estados signatários e a AIEA, o objetivo principal das salvaguardas é a detecção em tempo hábil do desvio de quantidades significativas de materiais nucleares destinados para fins pacíficos $(16 ; 17)$. Essas atividades envolvem procedimentos de contabilização desses materiais, inspeção física das instalações nucleares e uma avaliação independente das informações declaradas pelos operadores das instalações. Além disso, são utilizadas de forma complementar medidas de contenção e vigilância (17).

No entanto, os objetivos das salvaguardas podem ser estendidos a três: a verificação das quantidades significativas de materiais nucleares, a rapidez na detecção de desvios desses materiais e a probabilidade dessa detecção. As quantidades significativas estão relacionadas à massa de material nuclear necessário para aplicações militares. Ela depende do tipo de material e de sua composição isotópica. Para instalações pertencentes ao ciclo do combustível nuclear e sob acordos de salvaguardas, essas quantidades são:

- $\mathrm{Pu}-8 \mathrm{~kg}$;

- ${ }^{233} \mathrm{U}-8 \mathrm{~kg}$;

- urânio altamente enriquecido (high enriched uranium - HEU) - $25 \mathrm{~kg}$;

- urânio com baixo enriquecimento (low enriched uranium - LEU) - $75 \mathrm{~kg}$;

- urânio natural (natural uranium - NU) - 10 toneladas;

- urânio empobrecido(depleted uranium - DU) - 20 toneladas e

- $\mathrm{Th}-20$ toneladas.

A rapidez diz respeito ao tempo necessário para detectar qualquer desvio de quantidades significativas, como por exemplo:

- $\quad$ Pu e HEU - 4 semanas e

- LEU, Th, NU e DU - 1 ano.

Já a probabilidade de detecção está relacionada à probabilidade de se detectar um 
falso alarme $(\leq 5 \%)$ ou a não-detecção $(\leq 5 \%)$ de um possível desvio de material nuclear (18).

As medidas de salvaguardas fazem parte da tríade: Salvaguardas, Segurança Física e Proteção Radiológica. As medidas de salvaguardas são prioritariamente responsáveis pela verificação dos tratados firmados entre os Estados e a AIEA. A segurança física deve garantir a proteção da propriedade intelectual, das informações e dos materiais nucleares. Já a proteção radiológica ocupa-se em proteger os seres humanos e o meio ambiente contra qualquer dano radiológico (19). Essas medidas podem ser representadas em um diagrama de Venn (Figura 2), no qual a intersecção das medidas representa a sinergia entre elas. Portanto, segundo Burrows, B. (19), um incidente em qualquer uma destas esferas representa um incidente nas demais.

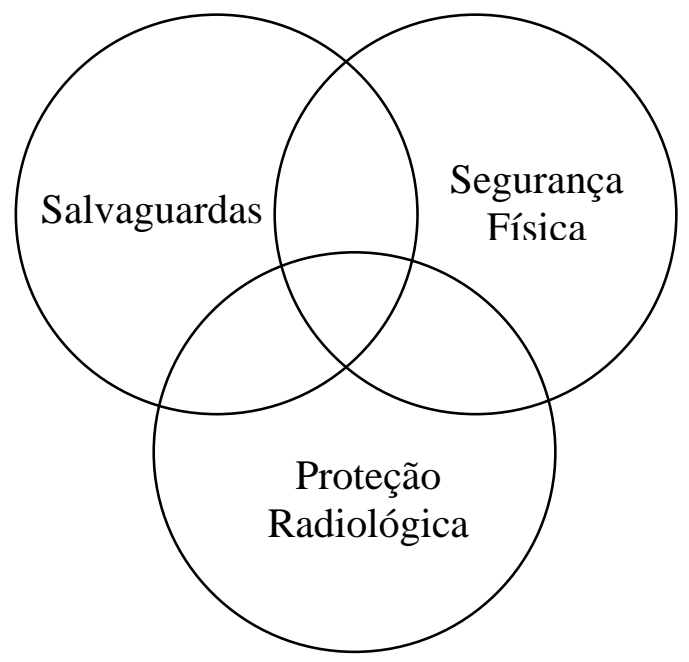

Figura 2 - A tríade salvaguardas, segurança e proteção.

Os seus objetivos comuns são:

i) Impedir e detectar a remoção desautorizada de materiais nucleares, garantindo que todos esses materiais estejam contabilizados;

ii) Prover detecção em tempo hábil de qualquer perda ou desvio de material nuclear;

iii) Determinar a quantidade e localização de qualquer perda e

iv) Prevenir qualquer dano ao meio ambiente (18). 
No Brasil, a responsabilidade pela salvaguarda do material nuclear cabe à CNEN (Comissão Nacional de Energia Nuclear), e é garantida pela Constituição Nacional. No âmbito da CNEN, o departamento responsável é o COSAP (Coordenação de Salvaguardas e Proteção Física), que é composto pela Gerência de Contabilidade e Controle (GCC), pelo Laboratório de Salvaguardas (LASAL) e pela Gerência de Proteção Física (GPF) (20).

Além da AIEA, o país mantém acordo de cooperação na área nuclear com a Argentina, por meio da ABACC (Agência Brasileiro - Argentina de Contabilidade e Controle de Materiais Nucleares). Ela foi criada em 18 de julho de 1991 pelo Acordo Bilateral firmado entre o Brasil e a Argentina, com o intuito de aplicar e administrar o SCCC. Seu processo de criação foi muito longo, pois envolveu diversas negociações entre os dois países. Durante o decorrer das negociações foram assinados dois tratados cruciais para a criação da ABACC: o Comunicado de Buenos Aires e a Declaração de Política Nuclear Comum, ambos em 1990. Esta última declaração firmada foi a responsável pela aprovação do Sistema Comum de Contabilidade e Controle de Materiais Nucleares (SCCC), que precedeu a criação da agência. Com a criação desta agência, foi firmado um acordo entre o Brasil, a Argentina, a AIEA e a ABACC em 13 de dezembro de 1991. Este acordo ficou conhecido com Quadripartite (INFCIRC/435) e está vigorando desde 4 de março de 1994. Seu o objetivo é consolidar o sistema de aplicação das salvaguardas entre esses países e garantir a independência das conclusões de cada organização (21).

\subsubsection{Procedimentos de salvaguardas}

Os procedimentos e acordos de salvaguardas são de responsabilidade do Conselho de Governadores da AIEA. Este conselho é a autoridade que possui poderes executivos para determinar se os países signatários estão agindo de acordo com o compromisso firmado entre eles e a AIEA. Caso o acordo não seja cumprido, o Conselho de Governadores reporta a situação ao Conselho de Segurança e posteriormente para a Assembléia Geral das Nações Unidas. A AIEA é designada para:

- detectar atividades de proliferação que envolvam desvios de materiais do ciclo do combustível nuclear; 
- $\quad$ prover aviso sobre o desvio de quantidades significativas de material nuclear a um fórum internacional em tempo hábil.

O processo tradicional de salvaguarda é composto por três etapas:

- $\quad$ exame das informações fornecidas pelo Estado feito pela AIEA que inclui uma declaração de quais instalações manejam material nuclear;

- $\quad$ coleta de dados e informações independentes feitas pelos inspetores da Agência;

- $\quad$ avaliação da integridade e exatidão das informações cedidas pelos Estados.

Atualmente, a AIEA desempenha um papel central na prevenção da disseminação de armas nucleares devido à necessidade de garantir que os países inspecionados não conduzam atividades nucleares com fins militares em instalações desconhecidas pela agência (22).

$\mathrm{O}$ atual regime de salvaguardas da AIEA pode ser fortalecido, segundo Khater (22), de duas maneiras:

- melhorar a capacidade da AIEA de detectar desvios de materiais nucleares declarados;

- fortalecer a capacidade da AIEA de detectar materiais não declarados e instalações nas quais o Estado esteja tentando conduzir atividades nucleares militares em segredo. 


\subsubsection{Tratados de Salvaguardas}

Os tratados de salvaguardas nucleares são implementados pela AIEA através do Conselho de Governadores e são adaptados conforme as necessidades de segurança de cada país signatário de tratados de não proliferação de armamento nuclear. A implantação do primeiro tratado entrou em vigor no início da década de 1960 e desde então foi sofrendo alterações e melhorias visando a manutenção e o desenvolvimento do uso da tecnologia nuclear para fins pacíficos. A finalidade desses tratados é garantir a operacionalidade do sistema de salvaguardas nucleares vigentes.

\section{i. INFCIRC/26 - 1961}

O INFCIRC/26 foi o primeiro sistema de salvaguardas nucleares aprovado pelo Conselho de Governadores da AIEA. Ele foi concebido com o objetivo de garantir que qualquer informação a respeito de uso de material nuclear físsil, utilização de instalações e equipamentos nucleares estariam disponíveis para a AIEA sempre que fosse requisitado. Esse acordo tratava especificamente de:

- $\quad$ Reatores com potência térmica de até 100 MW;

- Quantidade de U natural ou empobrecido contendo $0,5 \%$ de ${ }^{235} \mathrm{U}$ superior a 10 toneladas métricas;

- $\quad$ Quantidade de U empobrecido contendo menos de $0,5 \%$ de ${ }^{235} \mathrm{U}$ superior a 20 toneladas métricas;

- Quantidade de Th superior a 20 toneladas métricas;

- $\quad$ Quantidade de $\mathrm{Pu},{ }^{233} \mathrm{U}$ ou urânio totalmente enriquecido (100\% de $\left.{ }^{235} \mathrm{U}\right)$ superior a $200 \mathrm{~g}$;

- Quantidade de outros materiais físseis especiais que não ultrapasse $1000 \mathrm{~g}$ e

- Materiais nucleares usados ou reprocessados em instalações sob acordos de salvaguardas com a AIEA (23).

Segundo esse acordo os inspetores da AIEA poderiam realizar inspeções de rotinas nas instalações duas vezes por ano. Essas inspeções deveriam garantir que a instalação 
estivesse em conformidade com seu projeto de construção e que todos os instrumentos de medições estivessem funcionando apropriadamente (23).

\section{ii. INFCIRC/66 - 1965}

O INFCIRC/66 foi a primeira extensão ao sistema de salvaguardas nucleares, tendo como principais medidas adicionais:

- $\quad$ Inclusão de reatores com potência térmica maior do que 100 MW;

- $\quad$ Quantidade de material físsil especial superior a $1000 \mathrm{~g}(\mathrm{Pu}, \mathrm{HEU}$ e U com enriquecimento superior ao natural e inferior ao HEU);

- Reatores que tenham no máximo $3 \mathrm{MW}$ de potência térmica e que produzam menos de $100 \mathrm{~g}$ de $\mathrm{Pu}$ por ano e

- Auditoria sobre relatórios de transportes, processamentos, testes e pesquisas que envolvam materiais nucleares (24).

\section{iii. INFCIRC/140 (Tratado de Não Proliferação Nuclear) - 1970}

Esse tratado começou a ser desenhado em 1968, porém só entrou em vigor em 5 de março de 1970 à luz do temor de uma guerra nuclear. Sua intenção era coibir a disseminação de armas nucleares, promover o desarmamento nuclear e acelerar o uso pacífico dessa tecnologia. Ele também conferiria à AIEA maior capacidade de detectar se um Estado estava em busca de qualquer armamento nuclear, sendo considerado extremamente importante para a prevenção da proliferação do uso militar da tecnologia nuclear. Suas principais medidas foram:

- Nenhum Estado detentor da tecnologia para construção de armamento nuclear (NWS - Nuclear Weapon States) poderia transferir esse conhecimento ou encorajar qualquer Estado que não possuísse esse tipo de armamento (NNWS - Non Nuclear Weapon State); 
- $\quad$ Nenhum NNWS iria receber ou iniciar um programa de armamento nuclear;

- $\quad$ Os NNWS signatários iriam aceitar o sistema de salvaguardas nucleares da AIEA;

- $\quad$ incentivo a pesquisas que tivessem como objetivo o desenvolvimento dos sistemas de salvaguardas e

- $\quad$ O incentivo a medidas que reforçassem o tratado de banimento de testes nucleares no mar, na atmosfera ou no espaço, que foi assinado em 1963 (25).

No entanto, este acordo pode ser considerado altamente discriminatório à medida que polariza o mundo em países detentores de armamento nuclear e aqueles que não o possuem. Desta forma, os detentores continuariam com suas armas e os outros não poderiam prosseguir qualquer programa nuclear que tivesse como objetivo a construção de armas nucleares.

\section{iv. INFCIRC/153(Tratado Abrangente de Salvaguardas) - 1972}

O INFCIRC/153 entrou em vigor em junho de 1972, dando continuidade às melhorias implementadas em tratados anteriores. Segundo esse tratado, o objetivo das salvaguardas nucleares seria detectar, em tempo hábil, que materiais nucleares com utilização autorizada para uso pacífico fossem desviados para produção de armamento nuclear. No entanto, ele também reforçava o papel da AIEA como facilitadora do desenvolvimento pacífico da tecnologia nuclear. Dessa forma as medidas de salvaguardas deveriam ser implementadas de maneira a:

- Evitar que fossem prejudicados a economia e o desenvolvimento tecnológico dos Estados signatários;

- $\quad$ Evitar interferências indevidas por parte da AIEA em atividades nucleares pacíficas;

- Garantir as melhores práticas para a administração das atividades nucleares $\mathrm{e}$

- Proteger segredos comerciais e industriais e outras informações confidenciais. 
Dentre as medidas aprovadas por esse acordo destacam-se:

- $\quad$ A AIEA poderia solicitar informações de áreas fora da instalação;

- $\quad$ A AIEA deveria avisar previamente a realização da inspeção e

- $\quad$ Caso a AIEA detectasse qualquer incoerência com respeito às informações cedidas pelos Estados ela poderia solicitar outra inspeção. Se essa nova inspeção não fosse satisfatória, a agência poderia aumentar o número de pontos estratégicos a serem monitorados (17).

\section{v. INFCIRC/435 (Acordo Quadripartite) - 1994}

- $\quad$ O Acordo Quadripartite foi firmado em 13 de dezembro de 1991 entre o Brasil, Argentina, ABACC e AIEA, tendo entrado em vigor em 4 de março de 1994. Este acordo constitui as bases legais para a aplicação das salvaguardas da AIEA, sendo equivalente às medidas exigidas pelo Acordo Abrangente de Salvaguardas (INFCIR/153). Nele são contemplados (26):

- Estabelecimento do Sistema Comum de Contabilidade e Controle de Material Nuclear (SCCC);

- Desenvolvimento da energia nuclear para fins estritamente pacíficos;

- $\quad$ Estender os frutos da cooperação na área nuclear para outros países que tenham como objetivo o uso da energia nuclear para fins pacíficos;

- Apoio dos respectivos governos à $\mathrm{ABACC}$ na qualidade de agência responsável pelas salvaguardas a que são submetidos os materiais nucleares nos territórios do Brasil e da Argentina;

- $\quad$ A AIEA aplicará suas medidas de salvaguardas de modo que possa verificar os dados do SCCC com o intuito de comprovar que não houve desvio de material nuclear. A verificação poderá incluir medidas e observações independentes por parte da AIEA;

- Evitar que haja impedimento ao desenvolvimento econômico e tecnológico dos Estados signatários do acordo; 
- $\quad$ A AIEA preservará todas as informações confidenciais que cheguem ao seu conhecimento por força do acordo;

- $\quad$ A designação dos inspetores da AIEA deverá ser submetida previamente à ABACC para que esta possa dar seu consentimento e

- $\quad$ As salvaguardas terminarão quando a ABACC e a AIEA determinarem que os materiais nucleares tiverem sido consumido ou diluído de tal forma que não possam ser utilizados para atividades nucleares, ou quando o material nuclear for destinado a atividades não-nucleares.

\section{vi. INFCIRC/540 Corrigido (Protocolo Adicional) - 1997}

O Protocolo Adicional foi aprovado pelo Conselho de Governadores da AIEA em maio de 1997 devendo ser interpretado conjuntamente com os Acordos de Salvaguardas vigentes. A expectativa do Conselho de Governadores era de que os Estados com acordos abrangentes (Conprehensive Safeguards Agreements - CSA) aceitassem as medidas do protocolo sem alterações substanciais e que os países signatários do acordo INFCIRC/66 ratificassem suas medidas a fim de tornar seu sistema de salvaguardas mais efetivo.

As principais medidas aprovadas foram o fornecimento de:

- Informações sobre todas as etapas do ciclo do combustível nuclear, incluindo outras localidades que tenham qualquer tipo material nuclear para uso pacífico;

- $\quad$ Acesso para os inspetores da agência a todas as localidades que utilizem materiais nucleares;

- Informações sobre pesquisa e desenvolvimento referentes ao ciclo do combustível nuclear e os mecanismos de inspeção utilizados;

- Informações sobre todos os prédios do complexo onde a instalação se encontra;

- Informações sobre produção e exportação de tecnologias nucleares;

- O Estado teria o direito de coordenar os inspetores da AIEA de forma a evitar a disseminação de informações sensíveis e de proteger sua propriedade intelectual e 
- $\quad$ Coleta de amostras ambientais, o que inclui as amostras de esfregaço, além das localidades declaradas quando solicitado pela $\operatorname{AIEA}(27 ; 28)$.

Essas medidas, em conjunto com os acordos de salvaguardas vigentes, fornecem um quadro geral da produção e posse de material nuclear dos Estados signatários. A inclusão das coletas ambientais, no INFCIRC/540 Corrigido, forneceu as bases legais para a utilização desta metodologia como um instrumento de monitoração das instalações.

\section{vii. Tratados Regionais}

Além dos tratados propostos e firmados com a AIEA, blocos regionais também firmaram seus próprios tratados com o mesmo objetivo: manter o bloco livre de armas nucleares. Dentre esses tratados destacam-se (16):

- Tratado para Proibição de armas nucleares na América Latina e Caribe Tlateloco (1967);

- Zona Livre Nuclear do Pacífico Sul - Rarotonga (1986);

- Acordo Bilateral entre Brasil e Argentina para o uso exclusivamente pacífico da energia nuclear - Acordo da ABACC (1991);

- $\quad$ Tratado de Zona Livre de Armamento Nuclear do Sudeste Asiático Bangkok (1995) e

- Tratado Africano de Zona Livre de Armamento Nuclear - Tratado de Pelindaba (1996). 
viii. Zonas livres de armas nucleares (NWFZ - Nuclear Weapons Free Zone)

Algumas zonas geográficas específicas também foram declaradas livres de armamentos nucleares por meio de acordos internacionais, tais como:

- $\quad$ Antártica - Tratado da Antártica (1959);

- $\quad$ Leito marinho e subsolo - Tratado de Proibição de Armas Nucleares no leito do mar e subsolo (1972);

- $\quad$ Espaço Sideral (16).

\subsection{Programa 93+2}

A motivação para o desenvolvimento do Programa 93+2 surgiu após incoerências durante inspeções de rotinas no Iraque, realizadas em 1991, e após divergências da declaração inicial de salvaguardas da Coréia do Norte em 1992. Ambos os países eram signatários do Tratado de Não Proliferação (Non-Proliferation Treaty - NPT) de armas nucleares (INFCIRC/140), porém estavam conduzindo um programa clandestino para o desenvolvimento de armas nucleares $(29 ; 30 ; 31)$.

No caso do Iraque os inspetores da AIEA descobriram que aquele país possuía diversos sistemas de separação isotópica de urânio e um laboratório para a separação do plutônio (30).

A Coréia do Norte era signatária do NPT desde 1985, porém o colocou em prática apenas em 1992 com a emissão da declaração inicial de materiais e plantas nucleares. A partir dessa declaração inicial os inspetores da AIEA constataram inconsistências que foram corroboradas por imagens de satélites que indicaram a existência de uma instalação não declarada (30).

À luz desse cenário, o Conselho dos Governadores da AIEA requisitou, em 1993, que o Grupo Consultivo de Salvaguardas (Standing Advisory Group on Safeguards SAGSI) apresentasse propostas para estreitar as medidas do regime de salvaguardas. Essas medidas foram: 
i) Garantir efetivamente que não haja desvio de material nuclear e instalações não declaradas;

ii) Aumentar a cooperação com os Estados e com os Sistemas de Contabilidade e Controle (Systems of Accounting and Control - SSAC);

iii) Aumentar a capacidade dos inspetores da AIEA, do quadro de salvaguardas e dos SSAC;

iv) Ampliar o acesso dos inspetores da AIEA para as instalações além daquelas rotineiramente inspecionadas;

v) Providenciar informações sobre qualquer instalação dentro de uma planta nuclear, inclusive prédios situados fora delas;

vi) Utilização de materiais provenientes de anotações dos inspetores, de análises de terceiros e das amostras ambientas (30).

Essas propostas geraram debates entre os países signatários do acordo até então vigente (INFCIRC/153) e a AIEA em diversas esferas. Isso fez com que o Conselho de Governadores da AIEA dividisse o Programa 93+2 em duas partes (Tabela 1), pois eles concluíram o acordo vigente não contemplava algumas medidas de melhoria propostas.

Tabela 1 - Medidas aprovadas pelo Conselho de Governadores da AIEA para o Programa $93+2(30)$.

\begin{tabular}{|c|c|}
\hline Parte I & Parte II \\
\hline $\begin{array}{c}\text { Entrega da declaração expandida - maiores } \\
\text { informações sobre o SSAC e as atividades } \\
\text { nucleares passadas. }\end{array}$ & $\begin{array}{l}\text { Informações sobre todos os prédios que } \\
\text { compõe o complexo em que se encontram } \\
\text { as instalações nucleares. }\end{array}$ \\
\hline Informações sobre o projeto das instalações. & $\begin{array}{c}\text { Informações além da localidade das } \\
\text { instalações nucleares. }\end{array}$ \\
\hline $\begin{array}{l}\text { Informações sobre qualquer modificação do } \\
\text { projeto das instalações. }\end{array}$ & $\begin{array}{c}\text { Informações sobre as pequenas quantidades } \\
\text { de materiais nucleares que estavam isentas } \\
\text { em acordos anteriores. }\end{array}$ \\
\hline Contabilidade do material nuclear. & Informações sobre minas de U e Th. \\
\hline Programas operacionais & $\begin{array}{c}\text { Informações sobre pesquisa e } \\
\text { desenvolvimento no ciclo do combustível } \\
\text { nuclear. }\end{array}$ \\
\hline $\begin{array}{l}\text { Informações sobre todo o ciclo do } \\
\text { combustível nuclear. }\end{array}$ & $\begin{array}{l}\text { Informações sobre os processos de } \\
\text { enriquecimento e reprocessamento. }\end{array}$ \\
\hline $\begin{array}{l}\text { Informações sobre pesquisas e } \\
\text { desenvolvimento na área nuclear. }\end{array}$ & Aumentar o acesso dos inspetores da AIEA. \\
\hline
\end{tabular}

A implementação do Programa 93+2 iniciou-se em junho de 1995, quando entrou 
em vigor a Parte I que previa a coleta de amostras de esfregaço em locais previamente estabelecidos pelo INFCIRC/153. No entanto, a Parte II do programa, que contemplava as medidas que geraram maiores debates entre os Estados membros e a AIEA, necessitaria de um protocolo adicional.

As medidas apresentadas pelo Programa 93+2 representaram um grande avanço ao processo de salvaguardas nucleares por terem ampliado seu foco, deixando de monitorar apenas o desvio de material nuclear em instalações previamente informadas. $\mathrm{O}$ foco foi ampliado para áreas que demonstrassem maior probabilidade de revelar sinais de atividades clandestinas (30).

Em suma, o programa levou o sistema de salvaguardas nucleares de um patamar de contabilidade e verificação de desvios de quantidades significativas de materiais nucleares, para outro em que evidências podem ser coletadas em diversos pontos do complexo. Ele entrou integralmente em vigor com a aprovação do Protocolo Adicional (INFCIRC/540 (Corr.)) pelo Conselho de Governadores da AIEA em maio de 1997. No entanto, essas medidas só seriam aplicáveis aos signatários dessa ratificação.

\subsubsection{Amostras ambientais e as amostras de esfregaço (swipe samples)}

Nenhuma instalação nuclear é completamente vedada. Por esse motivo pequenas partículas podem escapar durante o processamento de qualquer tipo de material e tornarem-se parte do ambiente. Essas partículas carregam consigo diversas informações químicas, físicas e radiológicas, que auxiliam no estabelecimento de um padrão de composição característica dos materiais coletados nessas instalações. Este padrão é conhecido como assinatura química.

As amostras ambientais abrangem uma vasta gama de vetores, tais como solo, vegetação ar, água, poeira, amostras de esfregaço, etc. Segundo Donohue, D., as amostras de esfregaço apresentam a maior probabilidade de se encontrar vestígios de atividades clandestinas no interior das instalações, além de serem facilmente transportadas e contarem com outro ponto extremamente positivo: são ideais para análise de partículas individuais, que confere a maior quantidade de informações úteis para fins de salvaguardas (29).

A coleta das amostras de esfregaço pode ser executada em qualquer lugar da 
instalação, mas ocorre, preferencialmente, em áreas de trabalho (paredes, pisos, capelas, caixas de luvas) ou em sistemas de exaustão dos laboratórios. Esse tipo de amostragem começou a ser empregado em inspeções da AIEA durante o Programa 93+2. Elas foram efetivamente aplicadas durante inspeções no Iraque e na Coréia do Norte. No primeiro país foram constatadas atividades clandestinas através da análise de elementos traço nas roupas das pessoas. Já no segundo foi constatada a presença de berílio, que é um produto de decaimento radioativo, em uma monitoração de rotina. Nessas inspeções elas comprovaram ser uma metodologia prática e confiável para se detectar (30):

i) Radioatividade;

ii) Assinaturas isotópicas de operações nucleares específicas (reprocessamento, enriquecimento, fabricação de combustível ou operação de reatores) e

iii) Atividades clandestinas (30).

A utilização desse tipo de técnica de amostragem permite que se façam análises tanto da amostra como um todo (bulk analysis) quanto de partículas individuais presentes (particle analysis). As análises desse tipo de material são realizadas em laboratórios limpos (Classe 100), cuja referência é o Laboratório Limpo para Salvaguardas (Clean Laboratory for Safeguards - CLS) em Seibersdorf, Áustria, que é o responsável por fazer o kit de amostragem contendo dez tecidos de algodão, sendo que após a coleta dois ficam em posse do CLS e a terceira fica com o Estado inspecionado como contra prova. Esse laboratório é equipado com um conjunto de técnicas analíticas composto por espectrômetros de fluorescência de raios $X$, gama, beta e alfa, microscopia eletrônica de varredura e espectrômetros de massa por ionização térmica, nos quais as amostras são analisadas como um todo e depois enviadas para outros laboratórios especializados ao redor do mundo (30; $32)$.

O primeiro estudo relevante, que sugeriu metodologias e técnicas analíticas a serem empregadas na determinação da composição isotópica e concentração de urânio em amostras de esfregaço, foi elaborado por Donohue (29). Neste estudo, as amostras coletadas foram triadas inicialmente em um espectrômetro gama para se determinar a atividade da amostra. Em seguida, ela foi analisada por XRF ( $X$ - Ray Fluorescence) para se determinar a concentração de urânio e decidir qual seria a técnica que seria empregada para a determinação da composição isotópica. A técnica de espectrometria de massa por 
ionização térmica (Thermal Ionization Mass Spectrometry - TIMS) foi empregada para que se determinasse a composição isotópica de $\mathrm{U}$ e Pu, pois é uma das técnicas que apresentam a melhor precisão e sensitividade para essas finalidades. As análises foram realizadas tanto na amostra como um todo (bulk), quanto em partículas individuais. Para o TIMS, a amostra foi completamente dissolvida e depositada no filamento de rênio. No caso da análise de partículas individuais é necessário que elas sejam previamente localizadas pela técnica de traço de fissões (fission track - FT), para serem posteriormente removidas e depositadas no filamento do TIMS. Com base neste estudo o autor concluiu que a análise das amostras de esfregaço é uma excelente ferramenta de apoio ao processo de salvaguardas nucleares.

Recentemente a espectrometria de massas com fonte de plasma indutivamente acoplado (Inductively Coupled Plasma Mass Spectrometry - ICP-MS) vem ganhando espaço na análise de amostras de esfregaço para fins de salvaguardas, pois apresenta diversas vantagens analíticas, como alta sensibilidade, precisão, rapidez e possibilidade de análise multi-elementar e isotópica de radionuclídeos $(33 ; 34 ; 35)$.

A maioria dos equipamentos utilizados para a análise isotópica e elementar utiliza espectrômetros de massa quadrupolares com fonte de plasma indutivamente acoplado (inductively coupled plasma quadrupole mass spectrometry - ICP-QMS). Godoy et al. (36), do IRD, publicou um estudo sobre a análise da razão isotópica de plutônio em amostras de sedimento e em amostras sintéticas fornecidas pela AIEA durante um exercício de comparação inter-laboratorial (Round Robin). A técnica analítica utilizada foi o ICP-QMS. Como metodologia de separação e pré-concentração de amostra, utilizou-se a extração cromatográfica. Com essa técnica, foi alcançada uma precisão de até 0,3 \% para o nível de 0,1 ng de plutônio.

Esaka et al. (37) compararam as técnicas ICP-MS e SIMS para análise de amostras de esfregaço. Antes de as amostras serem analisadas por ICP-MS, elas foram levadas a um microscópio eletrônico de varredura para identificação e extração de partículas individuais. Essas partículas foram então dissolvidas em $\mathrm{HNO}_{3}$. Um sistema de dessolvatação foi utilizado para a introdução da amostra com o intuito de se melhorar a sensitividade dessa última técnica. Com respeito aos resultados das medições das razões isotópicas ${ }^{236} \mathrm{U} /{ }^{238} \mathrm{U}$ e ${ }^{234} \mathrm{U} /{ }^{238} \mathrm{U}$ obteve-se um melhor resultado do que em um sistema que não utiliza a dessolvatação; no entanto, para a razão ${ }^{235} \mathrm{U} /{ }^{238} \mathrm{U}$, não foi constatada qualquer melhora. Os autores concluíram que a técnica SIMS apresentou melhor resultado do que a ICP-MS com o método de introdução de amostras sugerido. Entretanto, para partículas de urânio relativamente grandes, os valores obtidos por ambas foram praticamente iguais, o que 
levou os autores a concluírem que o ICP-MS com sistema de dessolvatação é uma boa ferramenta para análise de partículas individuais para fins de salvaguardas nucleares.

Yan Shen et al. (38) estudou a razão isotópica de partículas de urânio pela técnica FT-TIMS (Fission Track Thermal Ionization Mass Spectrometry). Esta técnica consiste em procurar por partículas através da técnica FT e transferíla das swipe samples para um filamento de TIMS. Nesse estudo foi observada uma eficiência de transferência das partículas da amostra de esfregaço para o filamento de rênio de até 90\%, para partículas de $20 \mu \mathrm{m}$. A desvantagem dessa técnica é a utilização de um reator nuclear para irradiar as amostras com nêutrons.

Xiao Zhi Zhang et al. (39) analisaram amostras de esfregaço simuladas com os padrões CRM U050 e U350. Os autores desenvolveram um procedimento que incluiu a transferência de uma única partícula com um manipulador, bem como a dissolução química e análise de razão isotópica da amostra por meio da técnica ICP-MS. Os resultados obtidos para a razão isotópica ${ }^{235} \mathrm{U} /{ }^{238} \mathrm{U}$ apresentou exatidão de $1,8 \%$ com respeito ao material de referência certificado e precisão de 4,2\%. Eles concluíram que essa precisão foi aceitável para fins de salvaguardas nucleares.

Ainda segundo o autor, a técnica FT-TIMS permite que se identifiquem facilmente as partículas de urânio, bem como sua razão isotópica com precisão. No entanto, é necessário que haja um reator nuclear para irradiar a amostra com nêutrons térmicos. Já Degueldre et al. (40) implementou a análise de partículas de urânio por ICP-MS introduzidas por suspensões diluídas. No entanto, essa técnica apresentou dificuldades de aplicação para a análise da razão isotópica, pois somente sinais transientes foram obtidos.

\subsubsection{Laboratórios de Salvaguardas}

Em dezembro de 1995, a AIEA inaugurou o Laboratório Limpo para Salvaguardas (Clean Laboratory for Safeguards - CLS), cujas instalações diminuem os riscos de contaminação, em Seibersdorf, Áustria. Esse laboratório é equipado com um conjunto de técnicas analíticas composto por espectrômetros de fluorescência de raios X, gama, beta e alfa, microscopia eletrônica de varredura e espectrômetros de massa por ionização térmica.

No Brasil, o laboratório oficial é o LASAL (Laboratório de Salvaguardas), localizado no IRD (Instituto de Radioproteção e Dosimetria) (20), cuja responsabilidade é 
monitorar as instalações que participam do ciclo do combustível nuclear, garantindo que as mesmas estejam de acordo com as normas da AIEA e da ABACC (21).

Entretanto, outros laboratórios fazem parte de uma rede de estudos e implantação de novas técnicas analíticas aplicadas à área de salvaguardas, dentre os quais o do grupo de Caracterização Química e Isotópica (LCQ) - IPEN. Com o objetivo de aprimoramento e capacitação de profissionais e laboratórios, essa rede, coordenada pela ABACC e pelo DOE (Departamento de Energia dos Estados Unidos da América), submete-se periodicamente exercícios de inter-comparação, cursos e treinamentos na área. 


\subsection{Forense nuclear}

No começo da década de 1990 os primeiros casos de contrabando é tráfico de material nuclear foram detectados $(41 ; 42)$ (Figura 3). Tais incidentes levaram ao desenvolvimento da ciência forense nuclear e de novas estratégias para caracterizar e interpretar os materiais apreendidos, com o intuito de identificar sua origem.

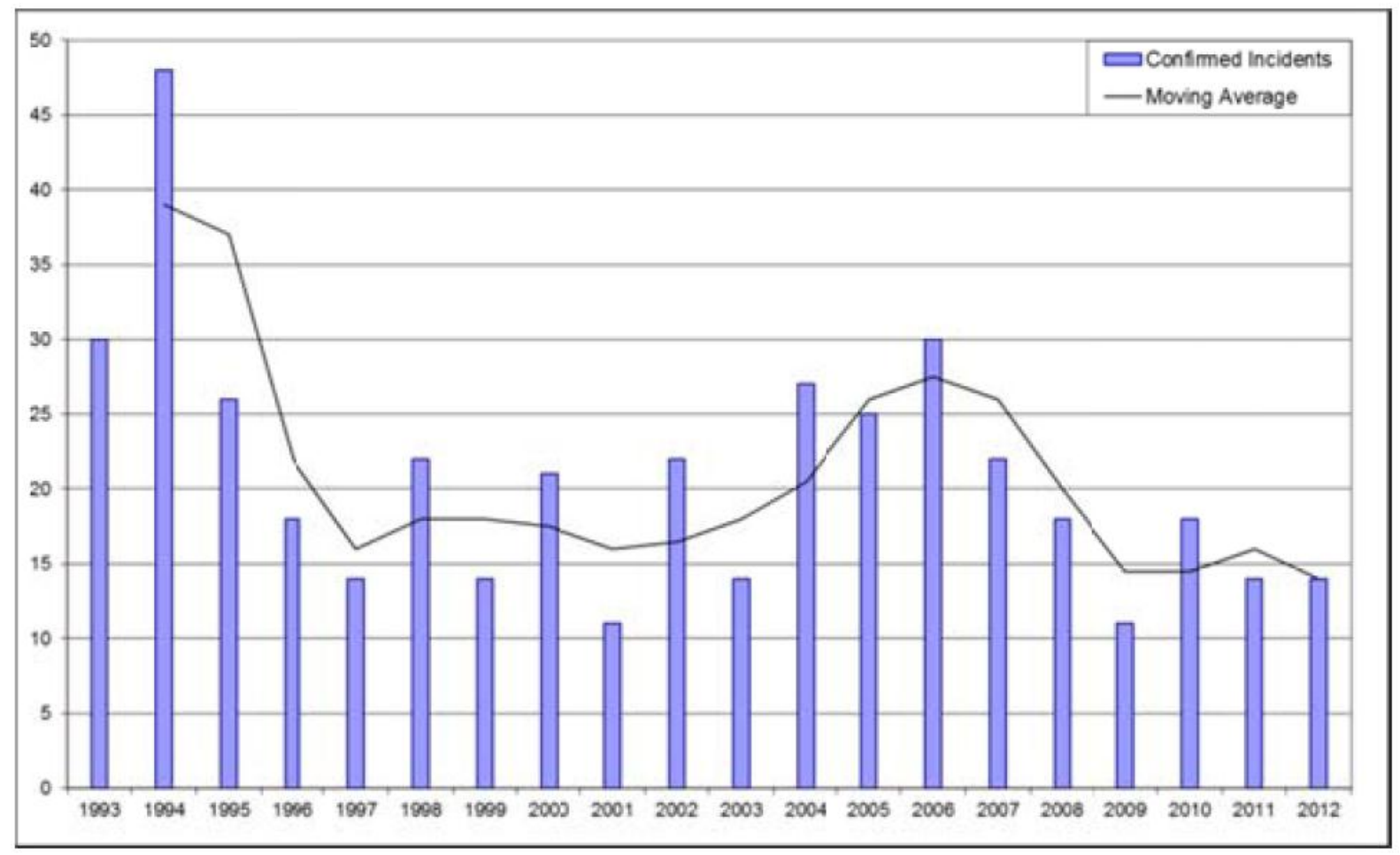

Figura 3 - Casos confirmados envolvendo tráfico ilícito de material nuclear reportados ao Grupo de Trabalho Técnico Internacional contra o Contrabando Nuclear (Nuclear Smuggling International Technical Working Group - ITWG) (43)

Conforme a Figura 3, o número de casos reportados teve um pico em 1994, com uma repentina diminuição em 1995. Desde então, manteve-se praticamente constante até o ano de 2006, quando apresentou um declínio acentuado e vem se mantendo constante até os dias de hoje.

Forense nuclear é a ciência que investiga atos criminosos envolvendo materiais nucleares e radioativos interceptados fora de um regime regulatório e com intenções malévolas de uso. Esses atos podem estar relacionados ao tráfico ilícito desse tipo de material, bombas que espalhem material nuclear, intoxicação de indivíduos, etc. O 
processo de investigação abrange a coleta, análise e avaliação das evidências encontradas na cena do crime. Seu objetivo é fornecer evidências para, em conjunto com a aplicação da legislação, sustentar a hipótese construída a respeito da origem desse material, através do descobrimento de sua rota de tráfico - desde o momento em que foi subtraído até sua apreensão $(44 ; 45)$. Todo esse processo de interpretação requer uma combinação de dados técnicos com uma base de dados relevantes. Essa combinação é o que possibilita a sustentação da hipótese proposta pelos investigadores (46).

A fim de contribuir com os esforços para o desenvolvimento desse novo ramo da ciência, foi criado em 1996 o Grupo de Trabalho Técnico Internacional contra o Contrabando Nuclear (Nuclear Smuggling International Technical Working Group ITWG), com o intuito de prover apoio técnico ao combate do tráfico ilícito de materiais radioativos e nucleares (44). Esse grupo desenvolveu um Modelo de Plano de Ação em resposta aos incidentes envolvendo materiais nucleares.

Um evento envolvendo a apreensão de materiais nucleares ou radioativos requer uma resposta tática e criminal, que é dada através de uma investigação forense nuclear. Esse tipo de investigação é essencial para responder questões específicas levantadas pela autoridade legal de acusação e por sua equipe de investigação. Portanto, é necessário que os responsáveis pela condução da investigação interajam com outras medidas investigativas, como a forense tradicional (44).

A resposta a um incidente que envolva a posse ilícita (fora de controle regulatório) de materiais nucleares inicia-se com a segurança do local, que deve garantir:

i) Minimização dos perigos radiológicos;

ii) Controle dos materiais;

iii) Preservação das evidencias forenses nucleares e tradicionais (44).

A primeira análise dos materiais apreendidos é feita no local do incidente através de dispositivos portáteis de raios X. Este procedimento tem como finalidade indicar se há qualquer ameaça oculta. Isso é característico de qualquer investigação forense tradicional, que ainda recomenda que se faça um diagrama detalhado da cena do incidente. Isso inclui orientação por bússola e coordenadas GPS da localização dos materiais e da extensão da contaminação, bem como a documentação da área por meio de fotografia. Posteriormente são realizadas outras análises não destrutivas, como a detecção de radiação gama, por espectrometria gama, e a detecção de nêutrons. Essas duas últimas análises fornecem a 
categoria do material, que indicam seus constituintes majoritários e são úteis para saber quais leis foram infringidas (44).

Após as coletas das informações e análises realizadas no local da interceptação dos materiais nucleares as evidências são levadas para laboratório. Os especialistas têm a incumbência de realizar a interpretação forense nuclear cruzando os dados obtidos das análises com as informações das bases de dados de métodos de produção e de casos anteriores de apreensão. Essa interpretação subsidia a atribuição nuclear que, além de determinar a origem do material nuclear interceptado pode determinar o seu método de produção, a probabilidade de existência de mais quantidades desse material, sua rota de tráfico e onde que se falhou o controle regulatório.

O processo forense nuclear pode ser dividido nas seguintes etapas:

- $\quad$ apreensão de materiais radioativos ilícitos e investigação preliminar da cena do crime;

- $\quad$ análise e categorização preliminares desses materiais apreendidos;

- caracterização química, física e isotópica desses materiais nucleares em laboratórios especializados. Neles são medidas todas as suas características que possam indicar a intenção de uso, origem e idade (47) e

- $\quad$ Atribuição da origem do material interceptado. O fluxograma da Figura 4 apresenta as etapas do processo forense nuclear. 


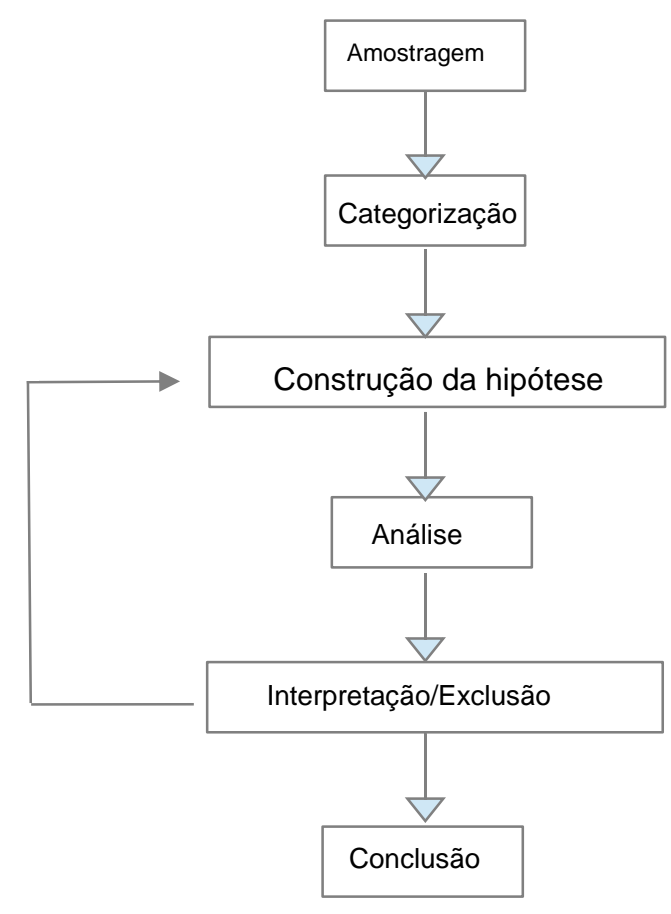

Figura 4 - Fluxograma do processo forense nuclear.

As informações obtidas através das análises de materiais nucleares visam identificar características importantes, tais como: impurezas químicas, composição isotópica, idade e microestrutura. A partir da interpretação dessas características pode-se chegar a uma conclusão que demonstre, ou não, a existência de qualquer atividade ilícita. Essa conclusão é baseada no seguinte processo de avaliação:

- Consistência da informação;

- Coerência entre as amostras e os materiais;

- Conformidade das evidências com o processo declarado e

- Comparação de dados (48).

Dentre os principais parâmetros estudados durante as investigações forenses nucleares, com o intuito de se atribuir a origem dos materiais nucleares interceptados, destacam-se: 


\subsubsection{Determinação da idade}

A idade de um material nuclear pode ser determinada a partir dos isótopos instáveis, assumindo a completa separação dos nuclídeos filhos durante sua produção. Ela é definida como o tempo decorrido desde a última separação química dos isótopos pais de seus isótopos filhos até a data de sua análise. Sua determinação é feita pela quantificação dos nuclídeos pais e filhos durante o processo de decaimento radioativo. Por exemplo, a determinação da idade do plutônio é realizada por espectrometria gama usando principalmente a razão ${ }^{241} \mathrm{Pu} /{ }^{241} \mathrm{Am}$. No caso do urânio a razão mais recomendada é a ${ }^{234} \mathrm{U} /{ }^{230} \mathrm{Th}$ (48). A Figura 5 ilustra uma cadeia de decaimento usada para a determinação da idade de materiais nucleares.

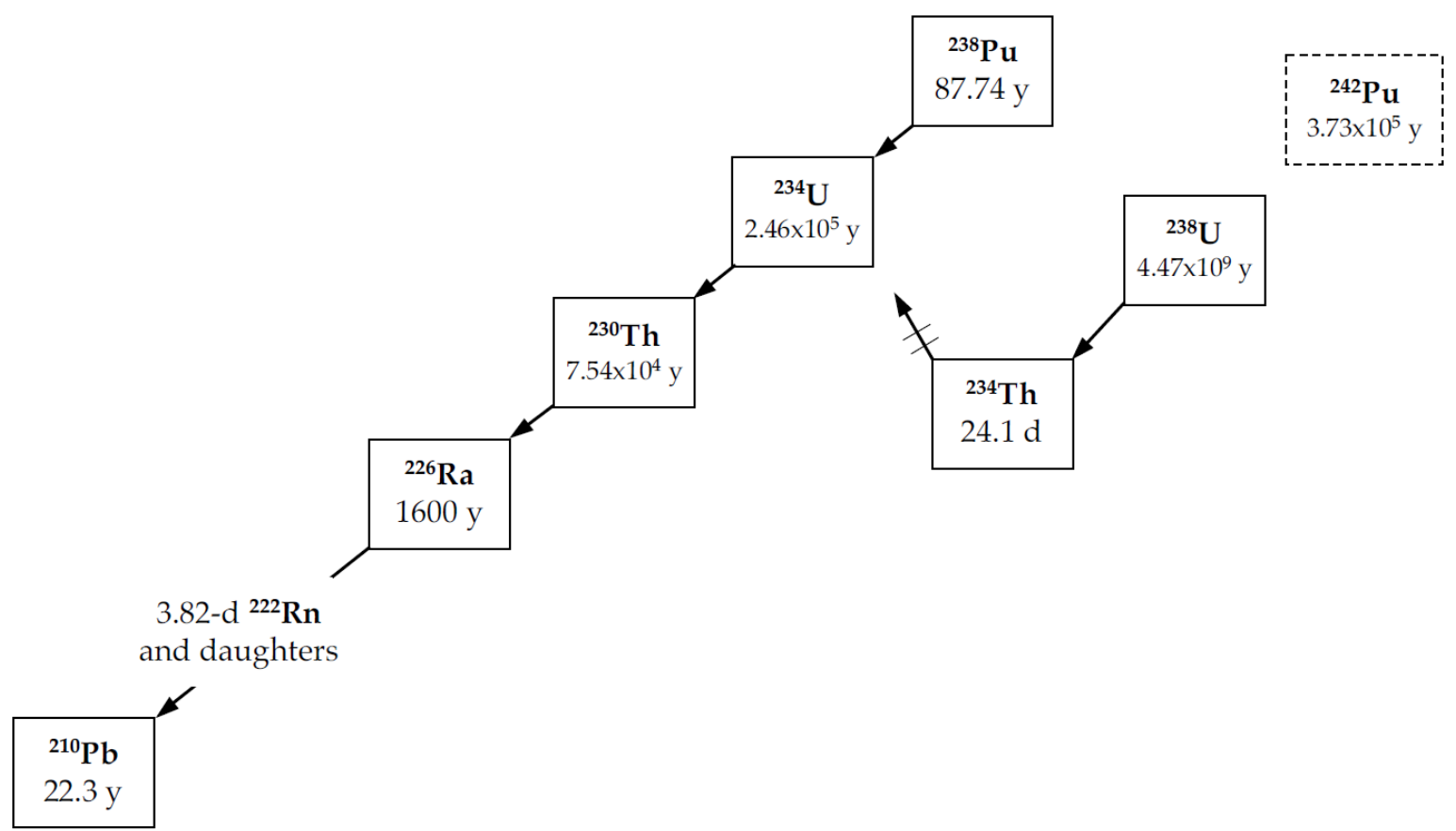

Figura 5 - Cadeia de decaimento do ${ }^{238}$ Pu que é utilizada como cronômetro desse material nuclear (45). 


\subsubsection{Impurezas metálicas}

As impurezas metálicas estão presentes em todo o processo de produção de materiais nucleares. Além disso, essas impurezas também podem ser adicionadas em diferentes etapas do processo. A concentração desses elementos é dependente do processo pelo qual o material passa. Segundo Mayer et al. (48) a concentração das impurezas metálicas durante a análise de algumas amostras pode variar ao acaso. Portanto, sugere-se que se analise a razão entre esses elementos ao invés de sua concentração absoluta. Os especialistas em forense nuclear recomendam a escolha de elementos que possuam um comportamento similar, tal como as terras raras que variam em limites extremamente pequenos (48) e permitem que se identifique a origem do material interceptado. A Figura 6 ilustra a análise de terras raras presentes em amostras interceptadas em um evento forense nuclear. Ela mostra a concentração de terras raras de quinze amostras diferentes. Pode-se notar que as amostras de 1 a 5 são compatíveis entre si.

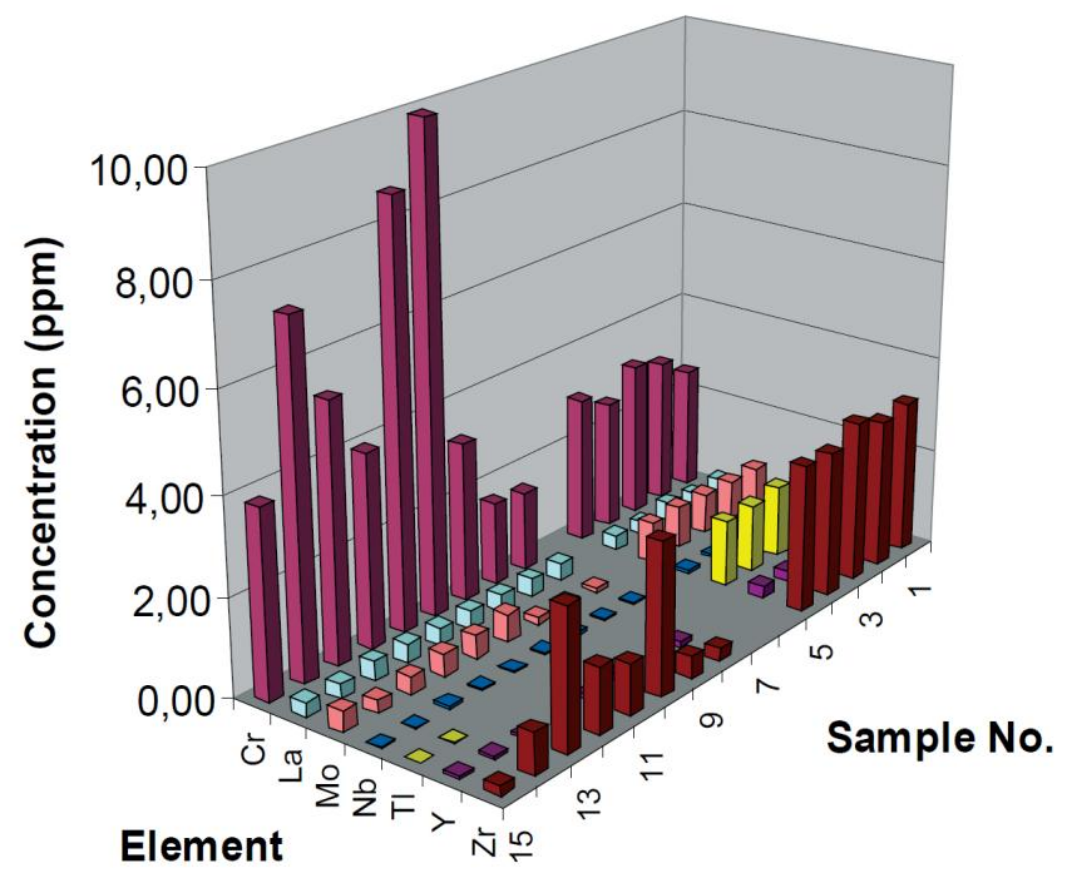

Figura 6 - Terras raras presentes em quinze amostras diferentes provenientes de um 
produto intermediário de urânio (48).

\subsubsection{Impurezas aniônicas}

$\mathrm{Cl}^{-}, \mathrm{F}^{-}, \mathrm{SO}_{4}^{-}$e $\mathrm{NO}_{3}^{-}$são exemplos de impurezas aniônicas que podem ser adicionadas aos materiais nucleares durante o ciclo do combustível nuclear. Elas dependem do tipo de minério e dos reagentes químicos utilizados para extrair o urânio. Portanto, quando se analisa esses materiais pode-se notar diferentes padrões. Mesmo em amostras diferentes que passaram por processos distintos de separação. Essa é uma importante informação adicional, pois também traz informações a respeito da origem do material (48).

\subsubsection{Microestrutura}

A microestrutura de um material reflete diretamente suas propriedades físicas, como resistência, dureza, ductilidade, etc. As informações microestruturais sobre materiais nucleares, principalmente compostos de urânio, refletem o processo de fabricação pelo qual esse material passou. As características que podem ser reveladas são as seguintes: forma, superfície e distribuição do tamanho de partículas e grãos (48). Para exemplificar foram mostradas micrografias de duas partículas de $\mathrm{UF}_{4}$ ( Figura 7 (a) e 7 (b)). A Figura 7 (a) representa a micrografia de um padrão de $\mathrm{UF}_{4}$, enquanto que a Figura 7 (b) representa uma amostra real coletada numa planta de conversão de urânio. Comparando-se essas duas micrografias pode-se notar algumas semelhanças, tais como a granulometria e o formato irregular. 


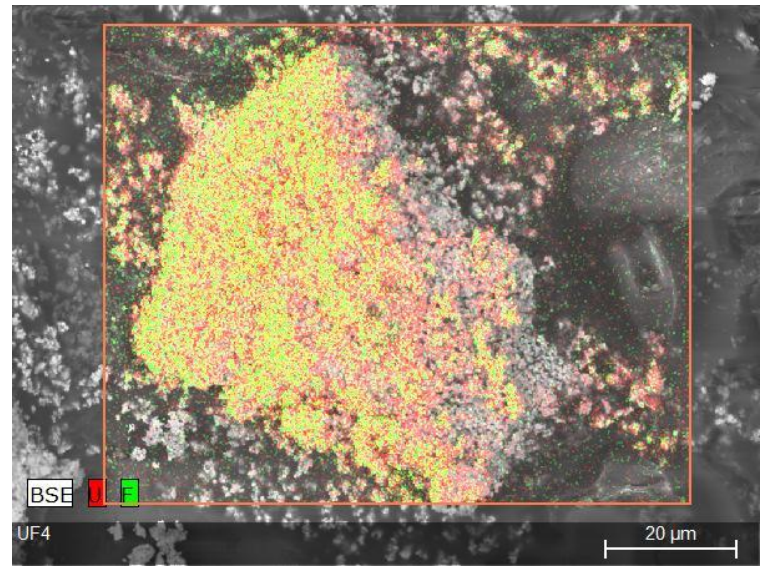

(a)

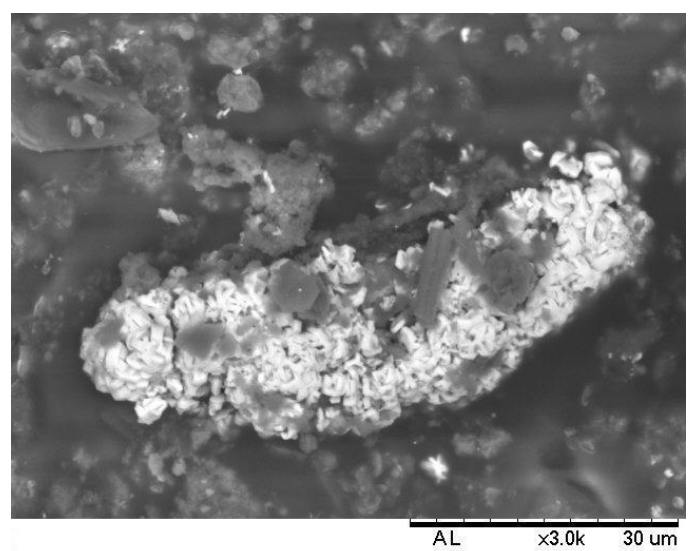

(b)

Figura 7 - (a) padrão UF4; (b) partícula coletada em uma amostra real.

\subsubsection{Composição isotópica}

Dados de composição isotópica trazem importantes informações relacionadas à irradiação de materiais. As razões isotópicas de urânio e plutônio em combustíveis nucleares irradiados são um parâmetro importante para a avaliação do conteúdo desses metais, assim como para o cálculo da quantidade total dos elementos pesados. As informações a respeito dos gases de fissão, como o xenônio, também são amplamente utilizadas para o processo de reprocessamento de combustíveis nucleares.

Com o estabelecimento do processo de fortalecimento das medidas de salvaguardas, os isótopos minoritários de urânio $\left({ }^{234} U\right.$ e $\left.{ }^{236} U\right)$ tornaram-se objetos de grande interesse devido à sua capacidade de indicar o tipo de processo pelo qual os materiais de mesmo enriquecimento isotópico. A razão ${ }^{234} \mathrm{U} /{ }^{238} \mathrm{U}$ quando analisada em conjunto com a razão ${ }^{235} \mathrm{U} /{ }^{238} \mathrm{U}$ pode indicar a origem de materiais nucleares desconhecidos. A presença do isótopo ${ }^{236} \mathrm{U}$ é um forte indicador de urânio reprocessado: a amostra poderia estar contaminada com urânio reciclado ou mesmo ter passado por um processo de reprocessamento $(48 ; 29)$.

Portanto, a avaliação da composição isotópica é de grande importância para as áreas de salvaguardas e forense nuclear, pois possibilita que se tirem conclusões a respeito do tipo de reator no qual o material foi irradiado, da origem do combustível, do seu 
histórico de irradiação e se o material foi reprocessado ou não.

\subsubsection{Correlação Isotópica}

O conjunto de informações extraído dos dados de composição isotópica dos elementos pesados e produtos de fissão presente no combustível nuclear irradiado são dados importantes para o estudo das correlações isotópicas.

Esta técnica foi adotada da área de física de reatores e tem sido utilizada para fins de salvaguardas desde a década de 1970 (48). Sua utilização é baseada no fato de que as leis físicas que governam a irradiação do combustível nuclear são imutáveis. As relações isotópicas são características comuns de cada reator nuclear. Desta forma, baseando-se em uma biblioteca forense nuclear que contenha dados de queima do combustível nuclear, bem como no inventário isotópico de combustíveis irradiados, é possível estabelecer-se diversas correlações matemáticas e usá-las juntamente com os dados obtidos das medições da amostra interceptada $(49 ; 50)$.

A partir dessas correlações pode-se analisar a composição isotópica de $\mathrm{Pu}$ para indicar o tipo de reator, uma vez que a seção de choque para captura de nêutrons é dependente da energia dos nêutrons. A Figura 8 mostra uma correlação isotópica entre ${ }^{242} \mathrm{Pu} /{ }^{240} \mathrm{Pu} \mathrm{e}{ }^{238} \mathrm{Pu} / \mathrm{Pu}$ total de diversos reatores. Ela claramente discrimina o tipo de reator, possibilitando a associação de amostras com seus respectivos reatores.

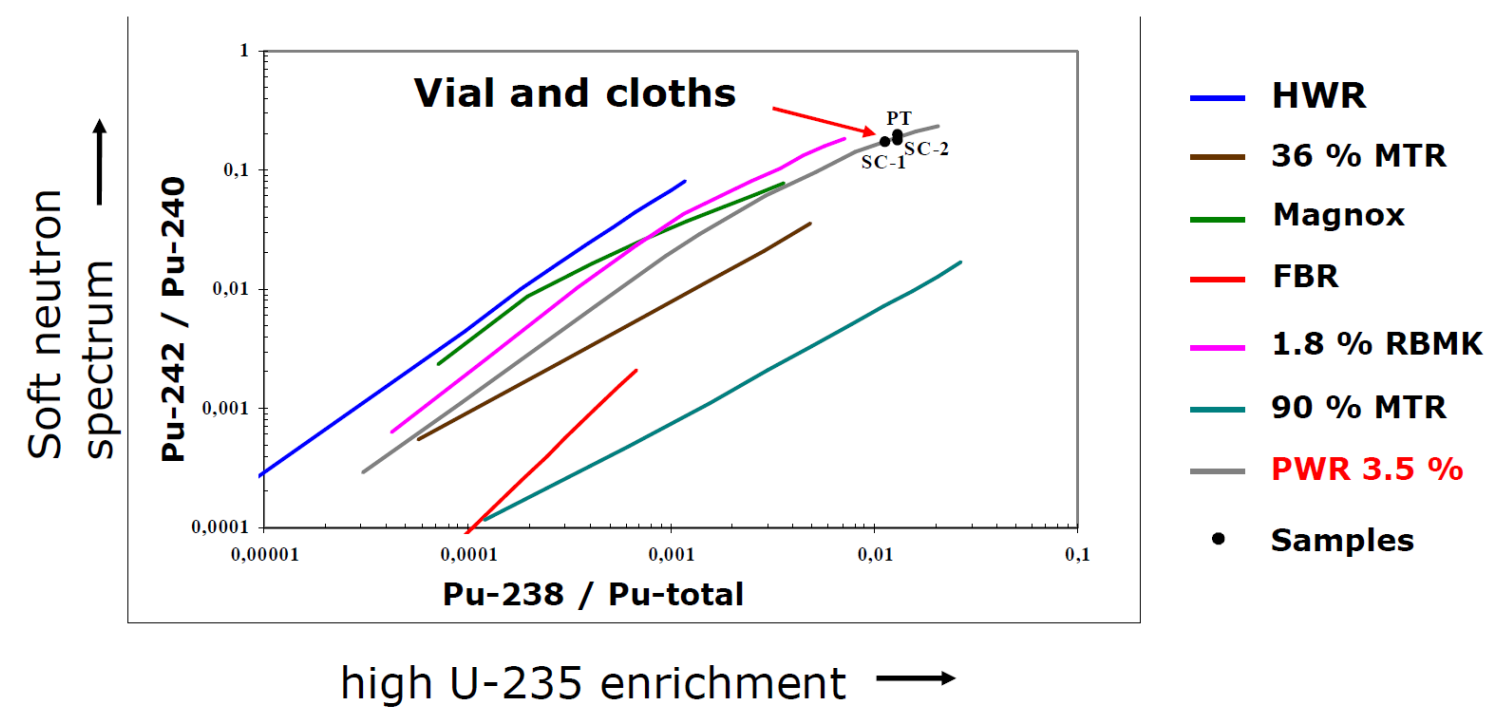

Figura 8 - Correlação isotópica de Pu para diferentes tipos de reatores (51). 
Recentemente, Nicolaou, G. (52) apresentou uma nova abordagem para determinar a origem de materiais nucleares de origem desconhecida. Ela foi baseada em dados de composição isotópica de plutônio $\left({ }^{238} \mathrm{Pu},{ }^{239} \mathrm{Pu},{ }^{240} \mathrm{Pu},{ }^{241} \mathrm{Pu}\right.$ e $\left.{ }^{242} \mathrm{Pu}\right)$. O autor lançou mão de um método estatístico multivariado para discriminar as correlações entre os isótopos e comparar os resultados com bases de dados de combustíveis nucleares. Com base nesse estudo, o autor concluiu que a abordagem empregada é uma ferramenta útil para a ciência forense nuclear, pois permite que se determine o tipo de reator nuclear em que amostras desconhecidas foram irradiadas (Figura 9).

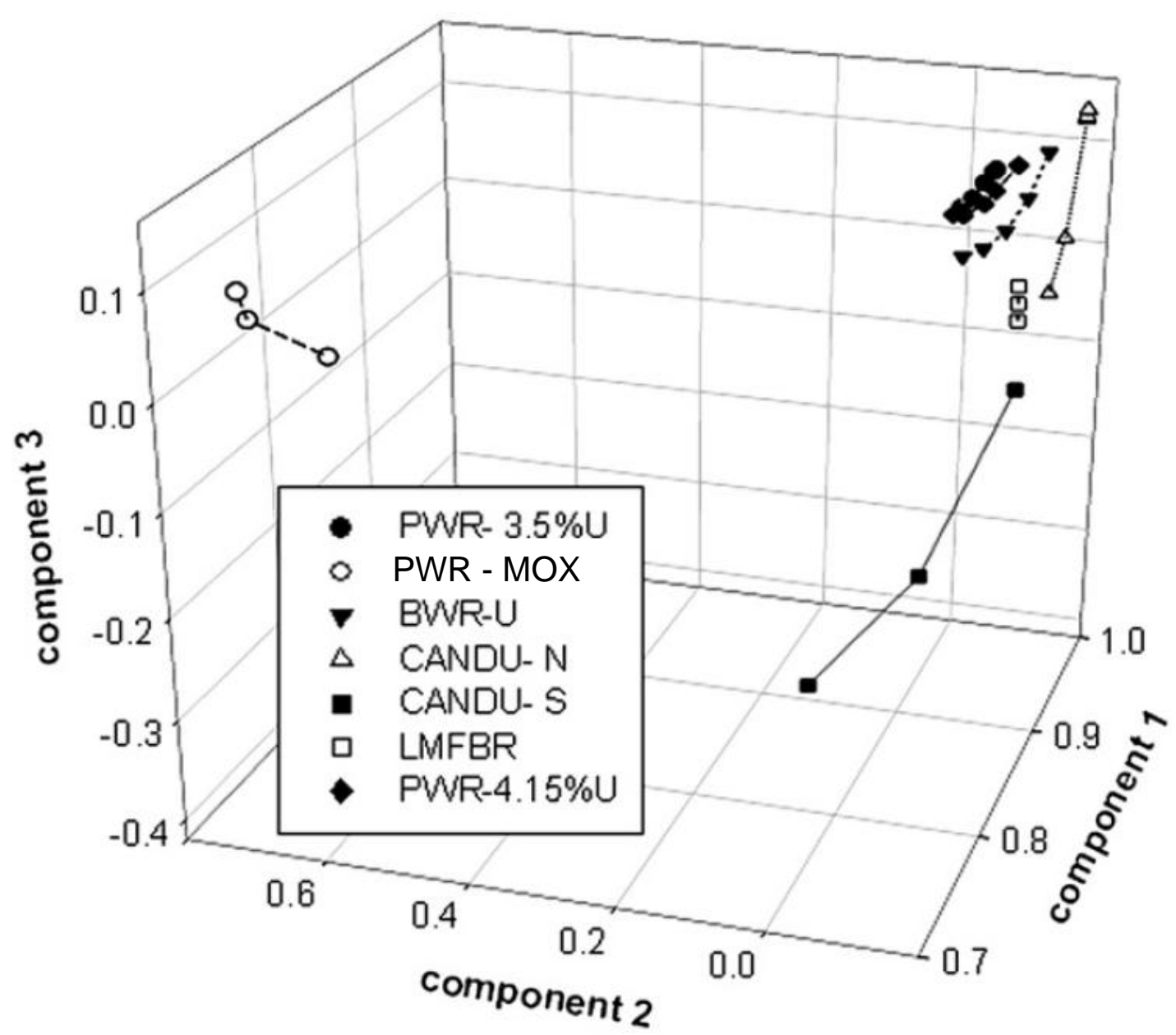

Figura 9 - Gráfico 3D da análise de diversos tipos de combustíveis irradiados simulados em diversos tipos de reatores nucleares. Reator de água pressurizada (pressurized water reactor - PWR); Reator de água fervente (boiling water reactor - BWR); reator nuclear canadense (canadian deuterium uranium - CANDU) e reator super-regenerador de nêutrons rápidos refrigerado por metal líquido (liquid metal fast breeder reactor LMFBR) (52). 
Robel, M. e Kristo, M. J. (53), por sua vez, compararam os métodos de análise de componentes principais (principal components analysis - PCA) e análise discriminante por mínimos quadrados parciais (partial least squares discriminant analysis - PLSDA) para estabelecer correlações entre $\mathrm{U}$ e Pu, em combustiveis nucleares, em função de sua queima (burnup). Segundo os autores, os resultados dessas análises fornecem detalhes sobre a composição inicial do elemento combustível e o tipo de reator em que foi irradiado (Figura 10), pois o grau de geração dos diversos isótopos de Pu é dependente da energia dos nêutrons com os quais o elemento foi irradiado. Com isso pode-se obter um histórico da energia desses nêutrons. Eles concluíram que a PLSDA é uma ferramenta mais efetiva do que a PCA para esse tipo de análise.

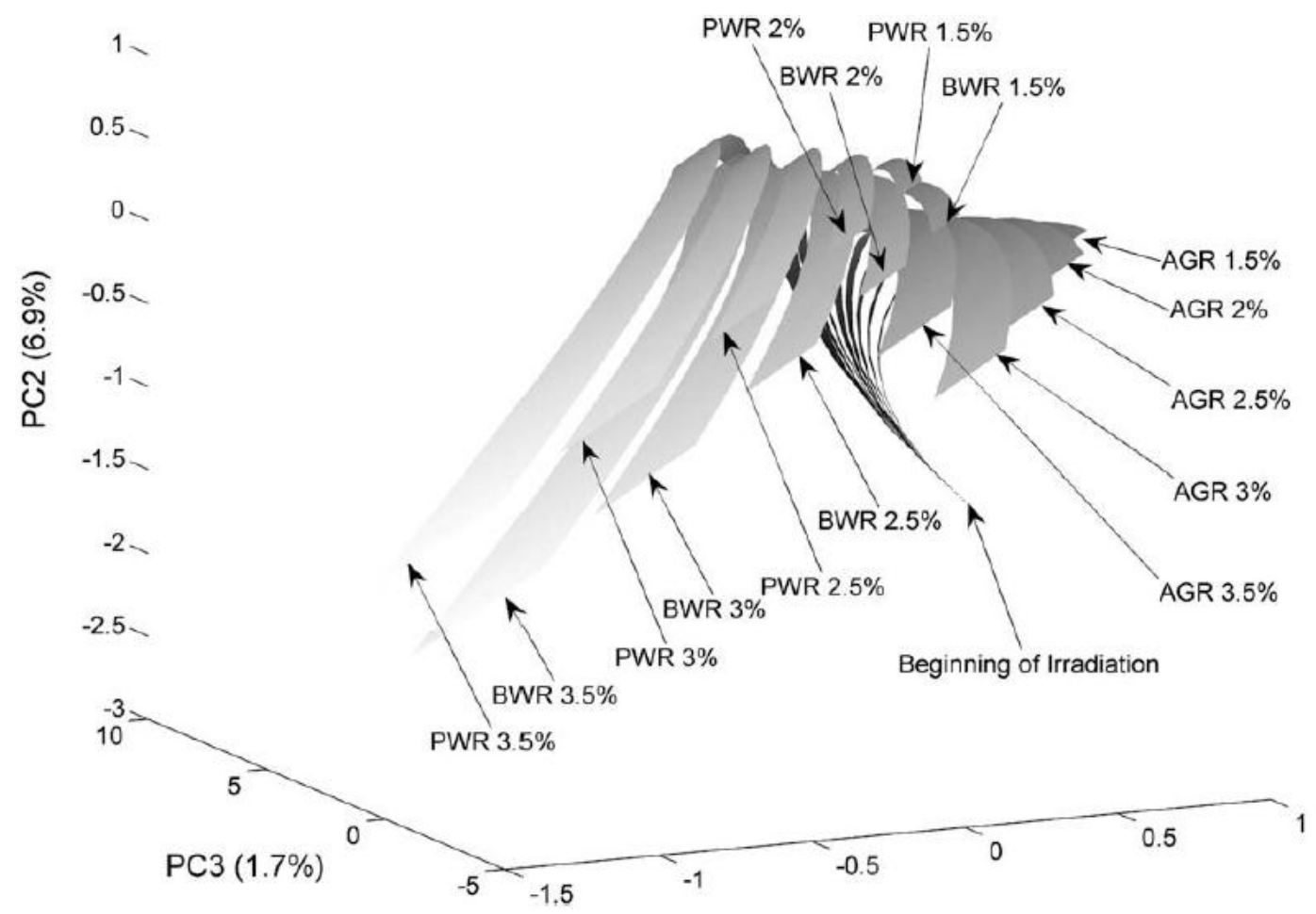

Figura 10 - Análise por PCA dos isótopos de plutônio resultantes de combustíveis irradiados em três tipos de reatores nucleares. Reator de água pressurizada (pressurized water reactor - PWR); Reator de água fervente (boiling water reactor - BWR) e reator avançado resfriado a gás (advanced gás-cooled reactor -AGR) (53). 


\subsubsection{Isótopos estáveis}

Os isótopos estáveis são utilizados para determinar a história e a origem de materiais nucleares, pois materiais de diferentes origens têm composições diferentes de isótopos estáveis. Por exemplo, a determinação da razão $\mathrm{n}\left({ }^{18} \mathrm{O}\right) / \mathrm{n}\left({ }^{16} \mathrm{O}\right)$, em $\mathrm{UO}_{2}$, foi demonstrado por Pajo L. et al. (46) como uma excelente ferramenta para a ciência forense nuclear, pois é um parâmetro que auxilia na determinação da origem desses materiais.

A ciência forense nuclear também incorporou a análise da composição isotópica de chumbo. Tal parâmetro pode indicar se o chumbo presente na amostra é proveniente do decaimento de isótopos de urânio ou é de origem natural (primordial). Por exemplo, quando se analisa a composição isotópica de chumbo em amostras de yellow cake pode-se distinguir os materiais que são de localidades distintas (48). A Figura 11 apresenta a composição isotópica de chumbo de diferentes amostras de yellow cake provenientes de minas distintas.

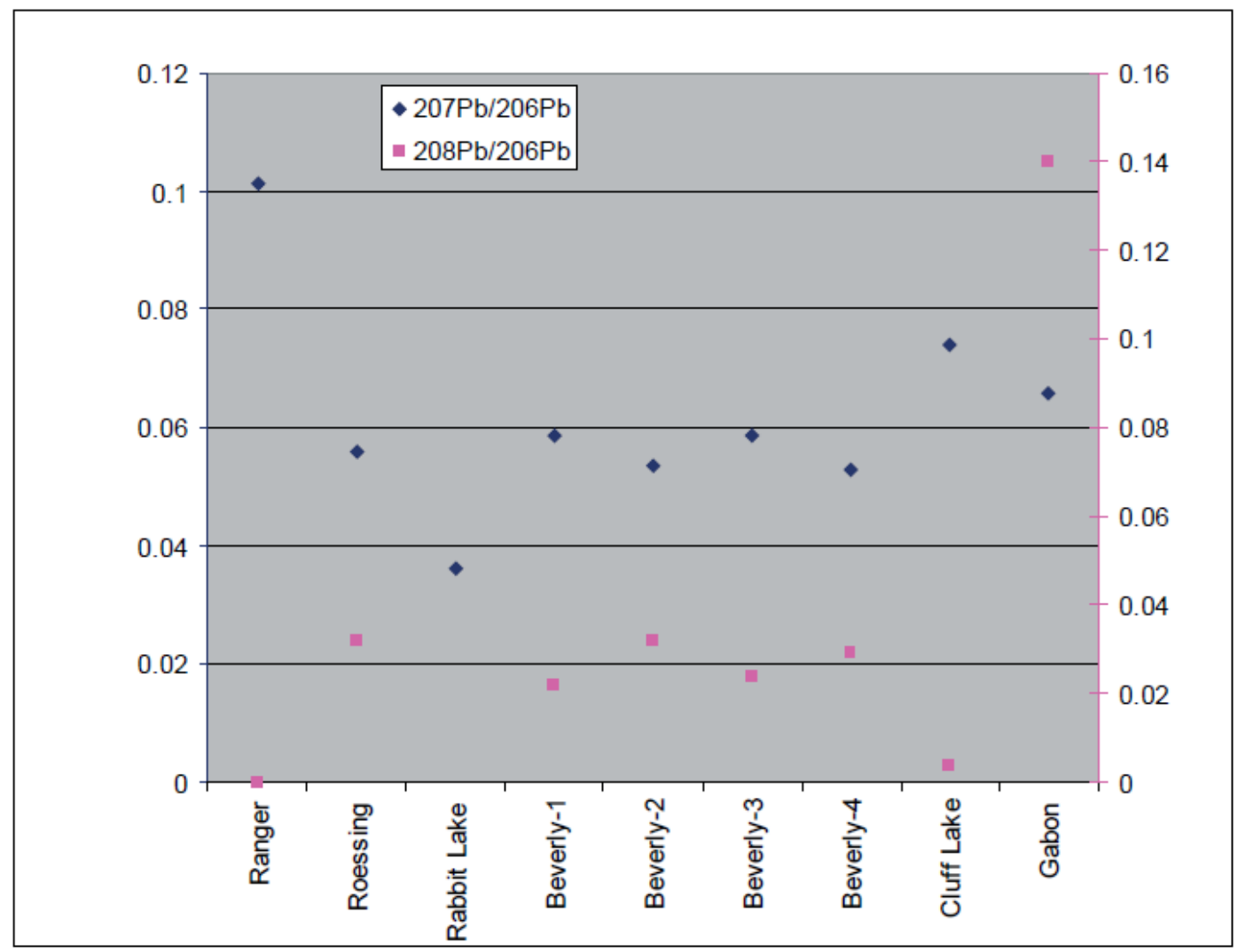

Figura 11 - Composição isotópica de chumbo de amostras de yellow cake de minas distintas (54). 


\subsubsection{Casos reais de investigações forense nuclear}

O processo investigativo da ciência forense nuclear pode envolver uma rede criminosa, na qual existem os indivíduos que praticam os furtos e os receptadores. Além disso, podem envolver Estados, empresas e outras instituições; o que faz com que essas investigações corram em sigilo e assim permaneçam após sua conclusão. Neste processo, o papel do cientista forense nuclear não se restringe apenas em identificar os responsáveis pelo crime e a origem desses materiais. Ele deve estabelecer uma relação entre eles e a cadeia de responsabilidades (55).

Existem diversos e estudos que envolvem investigações de cunho forense nuclear. Muitas delas foram compiladas por Sarkis, J.E.S. et al. (55) .No entanto, para ilustrar uma investigação foram apresentados dois estudos que demonstraram os resultados de análises de materiais nucleares, interceptados enquanto eram transportados de maneira ilegal.

Wallenius, M. et al. (41) apresentaram dois casos clássicos de eventos forense nuclear. Ambos os casos ocorreram em 2003. O primeiro foi referente a quatro pastilhas de combustível nuclear $\left(\mathrm{UO}_{2}\right)$ apreendidas na Lituânia. Já o segundo ocorreu na Republica Tcheca, com a apreensão de quatro amostras de pó de urânio. As duas evidências foram analisadas por diversas técnicas (Tabela 2), a fim de se atribuir suas origens. Para o caso das pastilhas, foi descoberto que suas idades eram de aproximadamente 13 anos (12,6 \pm 0,8) anos, indicando que sua fabricação foi no final de 1990. Esta informação, juntamente com os dados referentes às impurezas presentes e à composição isotópica em ${ }^{235} \mathrm{U}-(1,986$ $\pm 0,012) \%$ em massa atômica, foi comparada com uma base de dados existente. Com isso, foi possível determinar que o material era proveniente de um fabricante de combustível nuclear da extinta União Soviética. Já para o urânio em pó, foi encontrado um enriquecimento isotópico em ${ }^{235} \mathrm{U}$ compatível com o que é necessário para produzir armamento nuclear - $(89,59 \pm 0,43) \%$ em massa atômica. Sua idade aproximada foi de 27 \pm 3 anos. No entanto, os autores não puderam inferir com certeza absoluta a origem do material, pois não havia muitas informações em bases de dados a respeito de pó de urânio, que é um produto intermediário. Mesmo assim, por exclusão de hipóteses, foi possível estimar que a origem fosse também a União Soviética. 
Tabela 2 - Técnicas analíticas utilizadas nos processos de forense nuclear (41): densitometria híbrida da borda da camada $K$ (hybrid K-edge densitometry - HKED); espectrometria de mass por diluição isotópica (isotope dilution mass spectrometry IDMS); espectrometria gama de alta resolução (high-resolution gamma spectrometry $H R G S$ ); espectrometria de massa por ionização térmica (thermal ionization mass spectrometry - TIMS); espectrometria de massa por fonte de plasma indutivamente acoplado (inductively coupled plasma mass spectrometry - ICP-MS); espectrometria de massa por ionização secundária (secondary ion mass spectrometry - SIMS); espectrometria de massa por descarga elétrica (glow discharge mass spectrometry GDMS); espectrometria alfa (alpha spectrometry - AS); microscopia eletrônica de varredura (scanning electron microscopy - SEM) e microscopia eletrônica de transmissão (transmission electron microscopy - TEM).

\begin{tabular}{|ccc|}
\hline Parâmetro & Informação & Técnica \\
Aparência & Tipo do Material & Microscopia Óptica \\
Dimensão & Tipo de reator & Base de dados \\
U, Pu & Composição química & HKED, IDMS \\
Composição isotópica & Enriquecimento & HGRS, TIMS, ICP- \\
& & MS, SIMS \\
Impurezas & Processo de produção & ICP-MS, GDMS \\
& e geolocalização & \\
Idade & Data de produção & AS, TIMS, ICP-MS \\
${ }^{18} \mathrm{O} /{ }^{16} \mathrm{O}$ & Geolocalização & TIMS, SIMS \\
Rugosidade & Planta de produção & Perfilometria \\
Microestrutura & Processo de produção & SEM, TEM \\
\hline
\end{tabular}

G. Capannesi et al. (47) caracterizou uma vareta de combustível nuclear apreendida na Itália. Ele utilizou como técnicas analíticas a espectrometria gama e a gamografia para comparar a vareta apreendida com uma utilizada em um reator nuclear do tipo TRIGA (Training, Research, Isotope, General Atomic). Com isso os autores puderam deduzir:

i) o tempo de irradiação, a quantidade de ${ }^{239} \mathrm{Pu}$ produzida e a quantidade de ${ }^{235} \mathrm{U}$ consumido;

ii) que o enriquecimento isotópico em ${ }^{235} \mathrm{U}$ era de $20 \%$, que é compatível com 
os elementos combustíveis não irradiados de reatores TRIGA;

iii) que a vareta em questão havia sido irradiada por um curto período de tempo por um fluxo de nêutrons térmicos, devido à presença de ${ }^{137} \mathrm{Cs}$;

iv) que a última irradiação ocorreu há mais de vinte anos, pois a presença de ${ }^{54} \mathrm{Mn}$ e ${ }^{134} \mathrm{Cs}$ era insignificante;

v) e o mais importante: a vareta foi subtraída de uma reator TRIGA de Kinshasa, no Zaire.

Todas essas constatações feitas pelos autores representam um clássico exemplo do processo forense nuclear que compreendeu a análise de uma amostra apreendida, a interpretação dos dados e atribuição da origem do material em questão. 


\subsection{Salvaguarda de materiais nucleares e a área forense nuclear}

As atividades de salvaguardas e forense nuclear são conceitualmente diferentes; entretanto, possuem alguns objetivos (Figura 12), técnicas e metodologias em comum, que dependem do material a ser investigado (material nuclear, material radioativo, enriquecido, natural, irradiado, não irradiado etc.), da sua forma química ou física (líquido, gasoso, sólido, pós, pastilhas etc.), da motivação (controle, contabilidade, determinação da idade, origem etc.), da situação (investigação, inspeção) e do local (laboratórios, fábricas, cenas de crime externas, internas etc.).

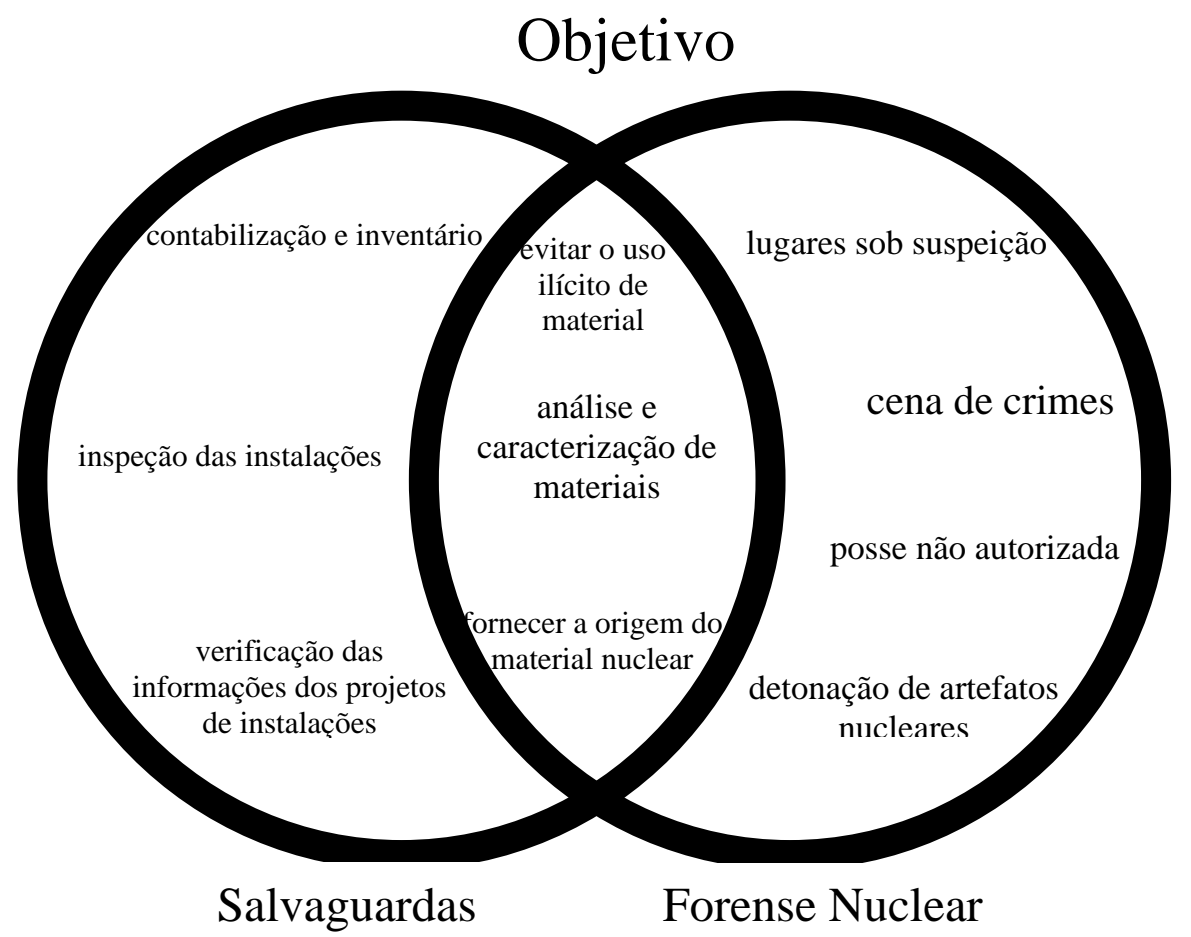

Figura 12 - Objetivos das salvaguardas e da ciência forense nuclear. 


\section{Técnicas Analíticas}

\subsection{Espectrometria de massas}

\subsubsection{História da espectrometria de massas}

A técnica de espectrometria de massas tem uma história relativamente recente pouco mais de 100 anos. Ela representou uma grande contribuição para o desenvolvimento da física nuclear - a comprovação experimental da estrutura do núcleo dos átomos devese à espectrometria de massa.

Diversos prêmios Nobel foram conferidos a cientistas que se utilizaram dela para a comprovação de suas hipóteses. Dentre eles pode-se citar Thomson, que recebeu um Nobel pelo descobrimento do elétron e determinação de sua razão massa-carga (m/z) em 1906 $(56 ; 57)$.

Os sistemas de espectrometria de massa existentes são frutos de uma grande descoberta de Goldstein em 1886 - os raios anódicos, que consistem de íons gasosos carregados positivamente. O tubo de descarga luminosa (Figura 13) era o tipo de fonte de íons mais simples possível e gerava íons carregados positivamente. Esse método foi utilizado em 1898 por Wien para analisar os raios anódicos através da deflexão por um campo magnético. Esse experimento possibilitou que ele chegasse à conclusão de que essa deflexão em um campo magnético é compensada por uma deflexão no campo elétrico (58).

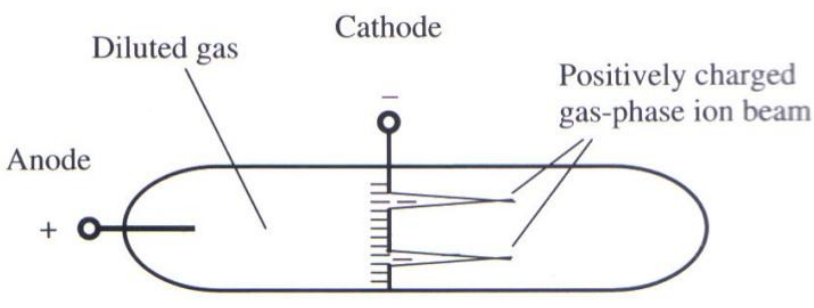

Figura 13 - Tubo de descarga de Goldstein (56). 
O início do desenvolvimento da espectrometria de massas deu-se efetivamente em 1907, quando Thomson desenvolveu um espectrógrafo de massa parabólico. Nesse aparato, os íons carregados positivamente eram formados em um tubo de descarga, colimados por duas aberturas e então defletidos pela sobreposição de campos elétricos e magnéticos com orientação paralela ao feixe de íons. Esses íons sofriam alteração de sua trajetória e eram detectados em um filme fotossensível. Em 1910, ele aperfeiçoou seu aparato instrumental anterior e descobriu que o neon consistia de dois diferentes isótopos com massas 20 u e $22 \mathrm{u}$, conectando a história dos isótopos com a espectrometria de massas. Poucos anos mais tarde Aston descobriu que o neon tinha mais um isótopo, cujo número de massa era $21 \mathrm{u}(56 ; 58)$.

Em 1918, Dempster construiu o primeiro espectrômetro de massa com setor magnético em ângulo de $180^{\circ}$ (Figura 14). Esse instrumento contava com focalização direcional de íons para análise isotópica e com uma fonte de íons mono energética. Os íons eram acelerados através de uma fenda e selecionados no setor magnético com curvatura de $180^{\circ}$ na direção de uma fenda de saída. Os íons separados eram coletados em uma gaiola de Faraday e medidos em um eletrômetro. Tal tecnologia possibilitou o descobrimento dos isótopos do lítio, magnésio, zinco e potássio (56). 


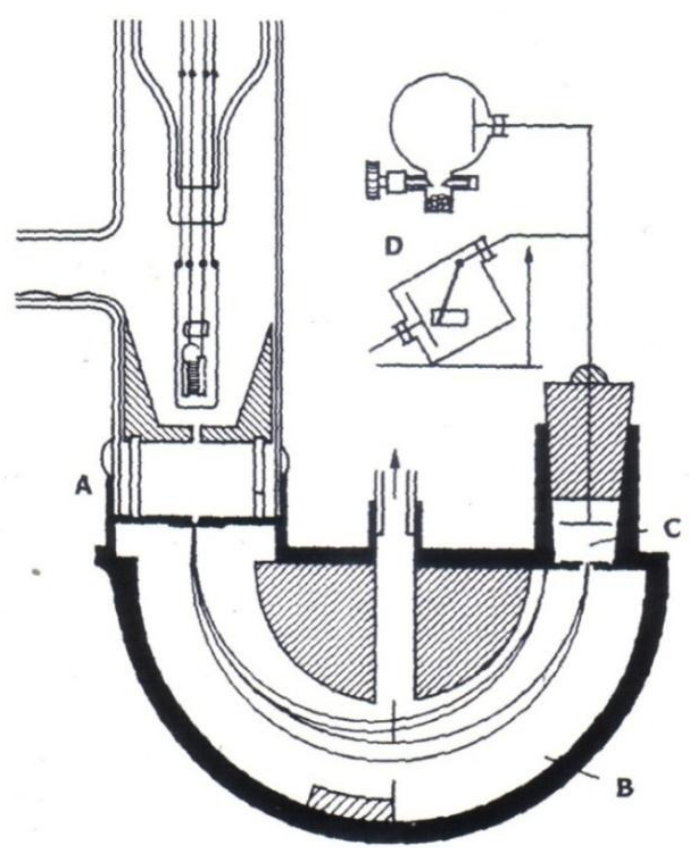

Figura 14 - Espectrômetro de massa de Dempster. A - Fonte de íons; B - Eletroimã; $C$ Gaiola de Faraday; D - Eletrômetro (56).

Aston, em 1919, desenvolveu um instrumento capaz de medir massas de isótopos com precisão de $0,1 \%$, porém ele não era ideal para medições de abundância relativa de isótopos. Esse espectrômetro contava com a separação dos campos elétricos e magnéticos e usavam como sistemas de detecção placas fotossensíveis. Os íons eram formados em um tubo de descargas e direcionados, usando dois diafragmas, para uma região de campo elétrico e subsequentemente para outra região sob a ação de um campo magnético (58). Nesse percurso os íons eram separados de acordo com suas diferenças de massa e focalizados no mesmo ponto da placa fotossensível. Seu segundo espectrômetro de massas foi concebido em 1921 e contava com uma placa fotossensível curvada para produzir seu próprio campo elétrico. Esse desenho fazia com que as partículas defletidas ficassem entre as placas. Seu setor magnético era composto por um imã que gerava um campo de até 1,6 Teslas. O terceiro instrumento foi desenvolvido em 1937 e contava com um setor magnético melhorado; um sistema de fendas para focalização que podia ser ajustado externamente e, também, uma placa fotográfica mais sensível. A resolução para medição de massa nesse instrumento era 20 vezes maior e tinha uma exatidão 100 vezes melhor 
para determinação de massa de íons separados, em comparação com o seu primeiro espectrômetro. O poder de resolução desse equipamento chegou à ordem de 2000 , frente à resolução em massa de 130 que atingia o seu primeiro espectrômetro (56).

No ano de 1940 Nier concebeu um espectrômetro de massa de setor magnético com curvatura de $60^{\circ}$, que era mais simples e barato do que aqueles com dupla focalização. Esse instrumento foi largamente utilizado para separação isotópica de urânio durante o projeto Manhattan na década de 1940. Nier, em parceria com Johnson, desenvolveu, em 1952, um sistema muito importante e que ainda é utilizado por espectrômetros comerciais (Figura 15). Ele empregava um analisador eletrostático simétrico e um analisador magnético assimétrico, que permitiam uma grande divergência angular enquanto mantinham a focalização $(56 ; 58)$.

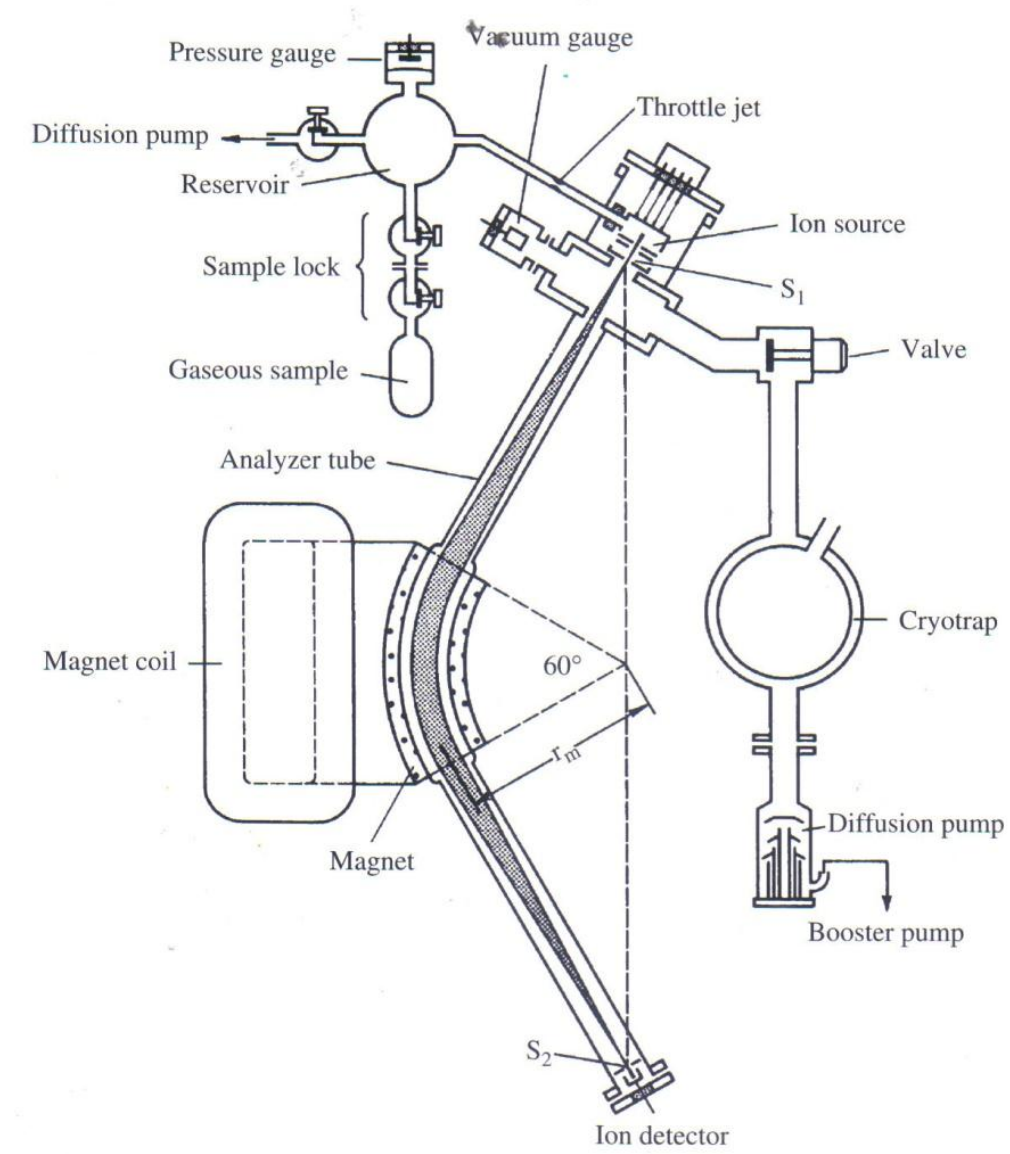

Figura 15 - Espectrômetro de massa com geometria Nier-Johnson (56). 
A evolução dos espectrômetros de massa de setor de campo deu-se com a substituição do magneto por um analisador quadrupolar. Isso possibilitou uma grande diminuição de seu custo e do tempo de análise. O primeiro sistema quadrupolo foi comercializado pela Finnigan em 1968 (56).

\subsubsection{Espectrometria de massas com fonte de plasma indutivamente acoplado (Inductively Coupled Plasma Mass Spectrometry - ICP-MS)}

A utilização do plasma indutivamente acoplado (ICP), como fonte de íons para espectrômetros de massa, teve início em 1971. Neste ano, cientistas da Universidade de Surray, no Reino Unido, estavam buscando um instrumento capaz de mediar massas atômicas na faixa de 6 u a 238 u. Este instrumento também deveria ter limite de detecção da ordem de centenas de $\mathrm{ngg}^{-1}$. No entanto, eles tinham disponíveis apenas os espectrômetros de emissão óptica com fonte de plasma indutivamente acoplado (inductively coupled plasma optical emission spectrometry - ICP-OES), que tinham baixa precisão ( $25 \%$ DPR). Além disso, essa técnica não era capaz de fornecer informações sobre a composição isotópica dos elementos. Essas foram as principais motivações que motivaram alguns cientistas a buscar o desenvolvimento do ICP-MS.

Dando continuidade ao processo, Alan Gray, em 1974, concluiu os estudos que culminaram com o desenvolvimento do espectrômetro de massa com fonte de plasma por corrente contínua (direct current plasma mass spectrometry - DCP-MS). Este tipo de fonte de excitação atingia temperaturas que variavam de $3000 \mathrm{~K}$ a $6000 \mathrm{~K}$, que ionizava os elementos cujo potencial de ionização fosse inferior a 8,5 eV.

No entanto, o DCP não era capaz de ionizar tantos elementos quanto os cientistas queriam. Em 1980, um grupo de pesquisadores trabalhou, paralelamente, em prol do desenvolvimento do ICP, pois este tipo de fonte produzia um plasma de maior energia. Dentre esses grupos destacaram-se o de Alan Gray (Universidade de Surrey - Reino Unido), o de Sam Houk (Universidade do Estado de Iowa - Estados Unidos) e o de Dan Douglas (Universidade de Toronto - Canadá), culminado com a obtenção do primeiro espectro em 1981 (59).

A viabilidade comercial do ICP-MS foi possível apenas em 1983. Isto se deu a partir da associação entre os grupos de Alan Gray e Dan Douglas com empresas como VG, 
Thermo e Sciex. $(57 ; 59)$. Desde então esta técnica analítica vem sendo a mais empregada para análise inorgânica devido às suas qualidades, tais como análise multielementar, alta taxa de amostragem, baixo limite de detecção, ampla faixa dinâmica que varia de $\operatorname{pgg}^{-1}$ a

$\mu \mathrm{gg}^{-1}$ e facilidade de introdução de amostras entre outras. Essas características permitem a especiação de átomos e moléculas. No entanto, essa técnica apresenta algumas desvantagens, como a interferência isobárica por íons poliatômicos, íons de carga única ou íons dupla carga. Para superar essas desvantagens foi introduzido, ainda na década de 1980, o sistema ICP-MS com setor magnético e dupla focalização (double focusing sector field inductively coupled mass spectrometer - SF-ICP-MS). Mais tarde, já na década de 1990, foi introduzido o sistema de ICP-MS com célula de colisão ou reação (60).

\subsubsection{Formação do plasma}

O plasma é um gás de íons quimicamente inerte. Os elementos mais comumente utilizados para a sua formação são o $\mathrm{Ar}, \mathrm{He}, \mathrm{N}_{2}$ e $\mathrm{O}_{2}$. $\mathrm{O}$ argônio (Ar) é o gás mais utilizado devido ao seu elevado potencial de ionização $(15,8 \mathrm{eV})$. Dessa forma ele consegue ionizar a maioria dos elementos da tabela periódica, além de representar um custo menor frente aos demais gases. Com esse potencial de ionização todos os elementos cujo potencial seja menor do que $8 \mathrm{eV}$ são ionizados; e os elementos cujos potenciais estão entre 8 e 11 eV tem rendimento de ionização variando de $91 \%$ a $12 \%(56 ; 57)$.

Os componentes necessários para a ignição do plasma são:

- $\quad$ Tocha de quartzo que consiste de três tubos concêntricos com diâmetros diferentes por onde fluem os gases e a amostra;

- $\quad$ Bobina de indução de rádio frequência e

- Gerador de rádio frequência, que fornece potência variando de $1000 \mathrm{~W}$ a $2200 \mathrm{~W}$ a frequências fixas de $27 \mathrm{MHz}$ ou $40 \mathrm{MHz}$.

A formação do plasma se dá quando o argônio passa pela tocha e a potência 
fornecida pelo gerador à bobina induz um campo magnético que promove a aceleração de elétrons. Esses elétrons colidem com outros átomos, liberando mais elétrons e iniciando uma reação em cadeia. Nesse memento uma grande quantidade de energia é fornecida por uma faísca que causa a ignição do plasma. A temperatura do plasma pode variar de $5000 \mathrm{~K}$ a $8000 \mathrm{~K}$, dependendo da posição da tocha em relação à bobina de radio frequência. O processo de ionização do Ar se dá pela seguinte reação (56):

$$
A r+\text { é } \rightarrow A r^{+}+2 \text { é }
$$

Com o plasma aceso as amostras são introduzidas através do sistema de introdução de amostras, que é composto pelo nebulizador e pela câmara de nebulização. Em seguida, ela é transportada por um fluxo de argônio para o interior da tocha, que possui diversas zonas de diferentes temperaturas. Nesse trajeto até a interface do analisador, a amostra é dessolvatada transformando-se em um sólido, vaporizada. Quando a amostra atinge a zona analítica do plasma ( 7000 K) ela é atomizada, formando um átomo neutro e, então, ionizada - nesse processo a amostra passa de aerossol a íons (57).

No seu caminho para o analisador de massas esses íons passam de uma região com pressão atmosférica para uma região sob alto vácuo. A interface entre essas regiões é composta por dois cones (sample cone e skimmer cone) espaçados e despressurizados por uma bomba mecânica diferencial. A função da interface é transportar os íons positivamente carregados eficientemente para o analisador de massa que está a uma pressão de aproximadamente $10^{-6}$ Torr $\left(10^{-4} \mathrm{~Pa}\right)$. A Figura 16 representa a interface e a tocha de um ICP-MS (56; 57): 


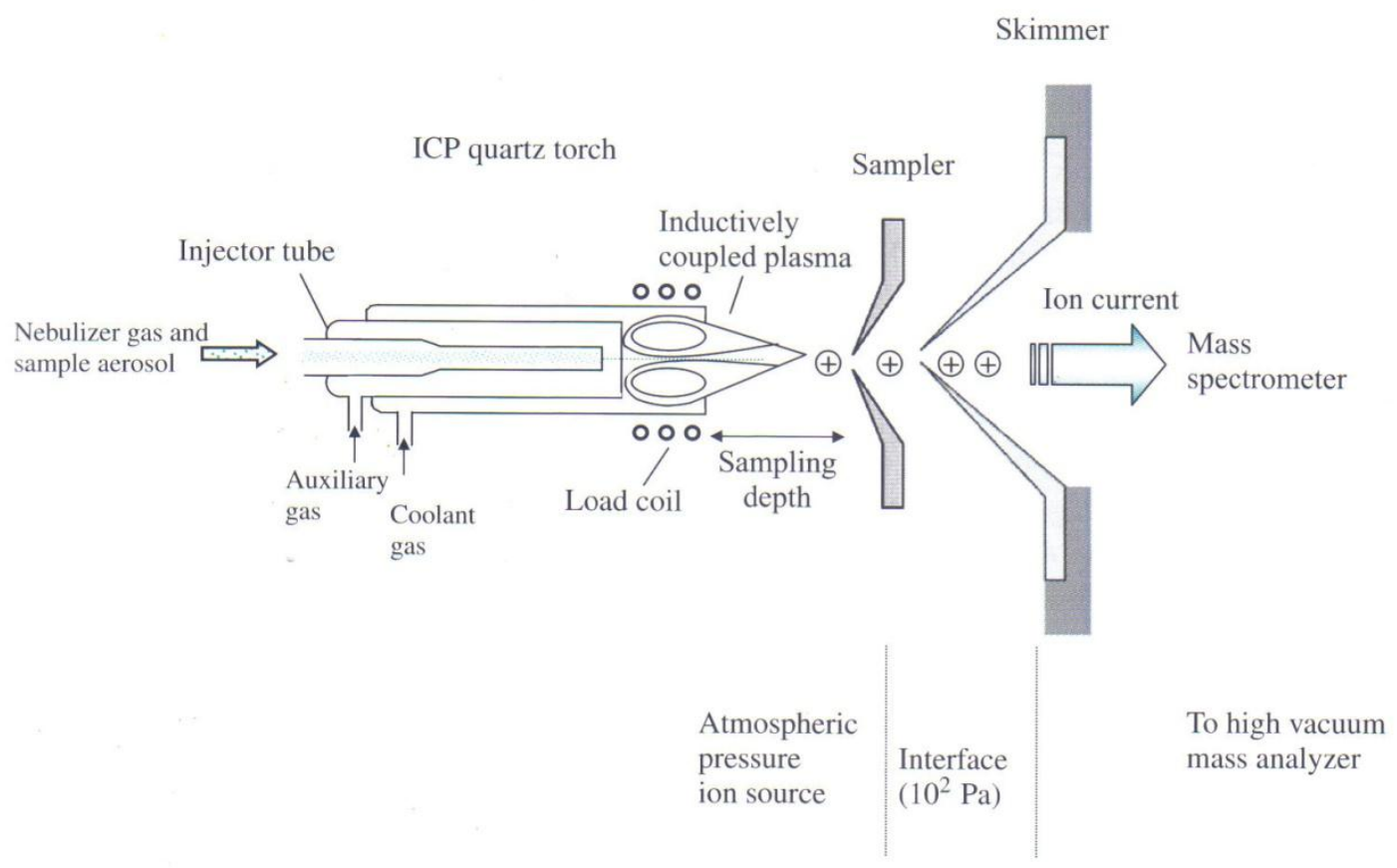

Figura 16 - Interface e tocha de um ICP-MS (56).

Os processos que ocorrem na interface são muito complexos e podem introduzir algumas interferências durante a análise, como os íons duplamente carregados causados pela descarga secundária, espalhamento de energia cinética e formação de íons do material do cone de amostragem. Esses efeitos são causados pelo acoplamento capacitivo entre a tensão na bobina de RF e a descarga de plasma, que pode ser parcialmente solucionado com o aterramento da bobina (60).

Os íons que saem do skimmer cone vão em direção ao sistema óptico (Figura 17) que faz a separação por massa. Ele consiste de lentes eletrostáticas mantidas em alto vácuo. Ao saírem do skimmer cone o gás de íons sofre uma grande expansão devido à abrupta redução de pressão. Esse processo é controlado pela dinâmica dos gases, uma vez que o comprimento de Debye (máxima distância que um íon pode influenciar os seus vizinhos) é pequeno em comparação com o diâmetro do skimmer cone. Os elétrons, então, se difundem do feixe resultando em um feixe de íons positivamente carregados. A expansão do gás pode causar os efeitos de cargas espaciais, que causam maior deflexão dos íons com menor massa do que naqueles com maior massa, gerando a discriminação de 
massas.

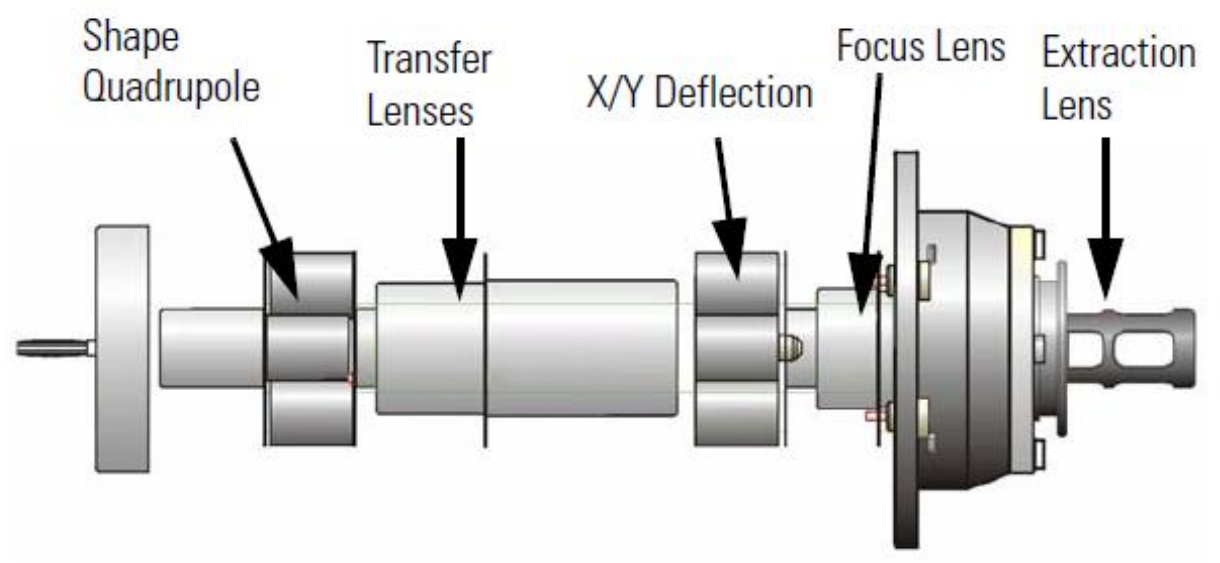

Figura 17 - Sistema óptico de extração de ions (61).

5.1.4 Espectrômetros de massa com fonte de plasma indutivamente acoplado de setor de campo (Sector Field Inductively Coupled Mass Spectrometry - SFICP-MS)

Os espectrômetros de massa de setor magnético têm sido usados desde o começo do século 20 para investigações de abundâncias isotópicas e de pesos atômicos, pois eram aqueles que apresentavam a melhor resolução para a separação de massas (57). Em 1946, Ewald demonstrou que um espectrômetro de dupla focalização construído a partir da geometria Mattauch-Herzog atingia resolução em massa de 30.000 a 50.000 (56). Esta característica consolidou os espectrômetros de setor magnético como sinônimo de alta resolução.

Nessa época, as fontes de íons tinham características microanalíticas, tais como a espectrometria de massas por íons secundários (secondary ion mass spectrometry - SIMS), espectrometria de massas por micropontas de íons (íon microprobe mass spectrometry) e a espectrometria de massas por indução a laser (laser induced mass spectrometry) (57). Dessa forma, elas vaporizavam apenas uma pequena quantidade da superfície da amostra. 
Isto obrigava que a amostra estudada fosse o mais homogênea possível, para garantir que os dados obtidos a representassem como um todo. Portanto, elas eram inapropriadas para se analisar as amostras como um todo.

Uma das primeiras soluções para obter dados representativos de uma amostra como um todo foi pela utilização da técnica de glow discharge como fonte de íons para o espectrômetro, em 1974. A revolução aconteceria em 1980 quando Houk et al. Utilizou uma fonte de plasma indutivamente acoplado a um analisador de massas do tipo quadrupolo (ICP-QMS) (56). No entanto, esse último sistema tem uma grande limitação causada pelas interferências espectrais poliatômicas. Isso levou os pesquisadores a procurarem uma alternativa para atingirem a alta resolução, que os fez investir no desenvolvimento de uma técnica que utilizasse o plasma indutivamente acoplado como fonte de íons para espectrômetro de massas de setor magnético. Após quase uma década de trabalho, o sistema estava sendo comercializado sob a geometria Nier-Johnson reversa (Figura 18). Esse tipo de construção separa os componentes de alta tensão da interface e consiste de dois analisadores: um eletromagnético e outro eletrostático, que permitia que se atingisse um poder de resolução de até 10000 (57), que permite resolver a maioria das interferências espectrais. Esse poder de resolução é dado pela seguinte equação:

$$
R=\frac{m}{\Delta_{m}}
$$




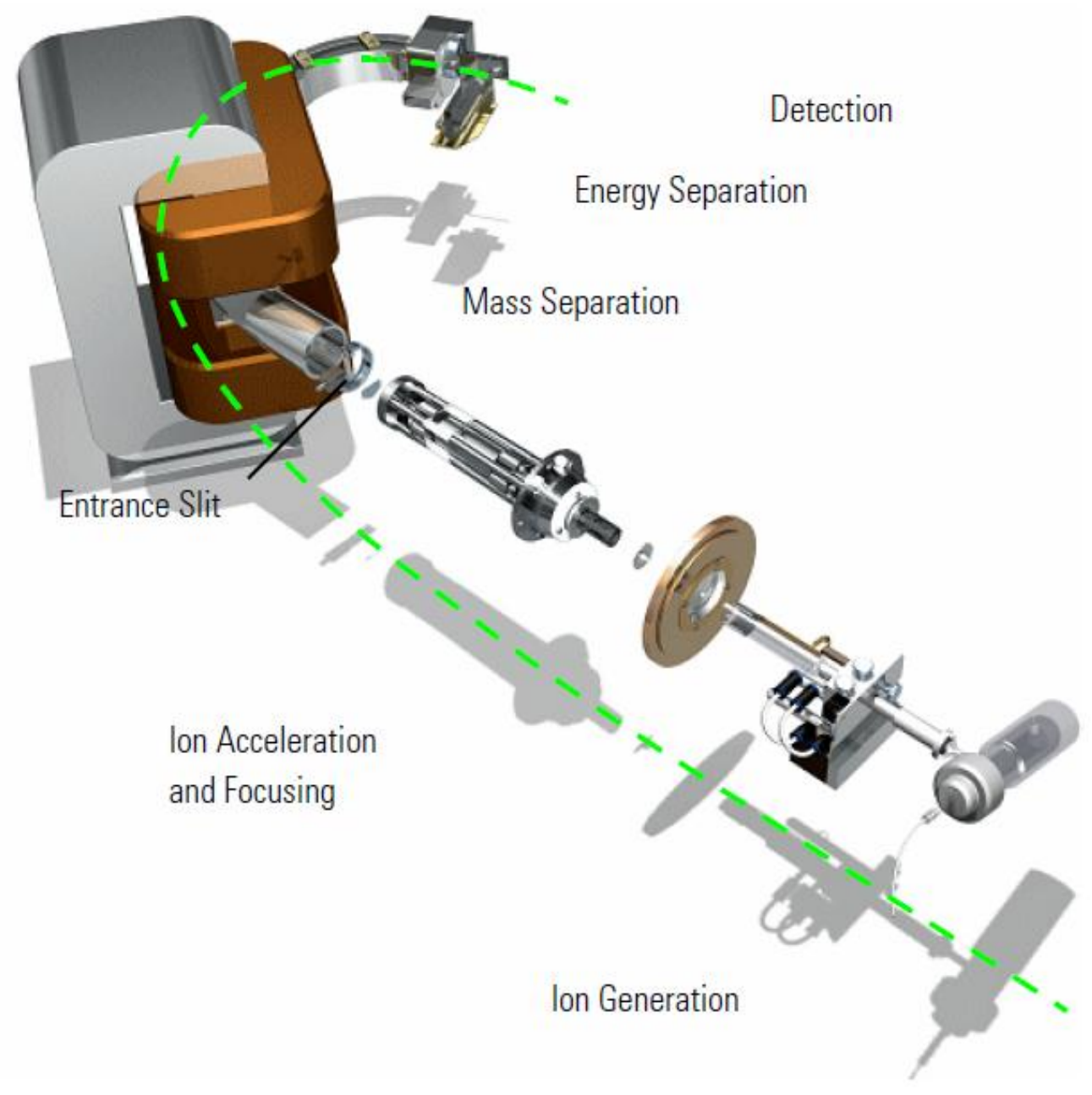

Figura 18 - Componentes principais de um SF-ICP-MS (61).

Esse tipo de instrumento conta com uma alta transmissão de íons quando em baixa resolução, alta sensitividade, baixo ruído de fundo e desvio padrão relativo (DPR) variando de $0.01 \%$ a $0,05 \%$ em baixa resolução e menor do que $0,1 \%$ em alta resolução (56). 


\subsubsection{Princípio de funcionamento}

O princípio fundamental de funcionamento de um espectrômetro de massa de setor magnético consiste em fazer uma varredura ao longo de todo o espectro de massa variando o campo magnético e mantendo o campo elétrico constante. Essa varredura é realizada em massas individuais. Consecutivamente, o sistema deve estabelecer o campo magnético, parar, adquirir as medições e, então, examinar a próxima massa. Esses passos, no entanto, tornavam as análises demoradas. A solução veio com a implementação do SF-ICP-MS, que é um sistema de dupla focalização. Nesse sistema, os íons provenientes do plasma são acelerados em direção do sistema óptico e passam por uma fenda de entrada e outra de saída. Ao passarem pela fenda de entrada eles saem espalhados em diversos ângulos. Nesse estágio é que o campo magnético entra em ação para focalizá-los em direção ao analisador eletrostático (eletrostatic analyzer - ESA) (Figura 19), que, por sua vez, direciona esses íons para o detector através da fenda de saída (57).

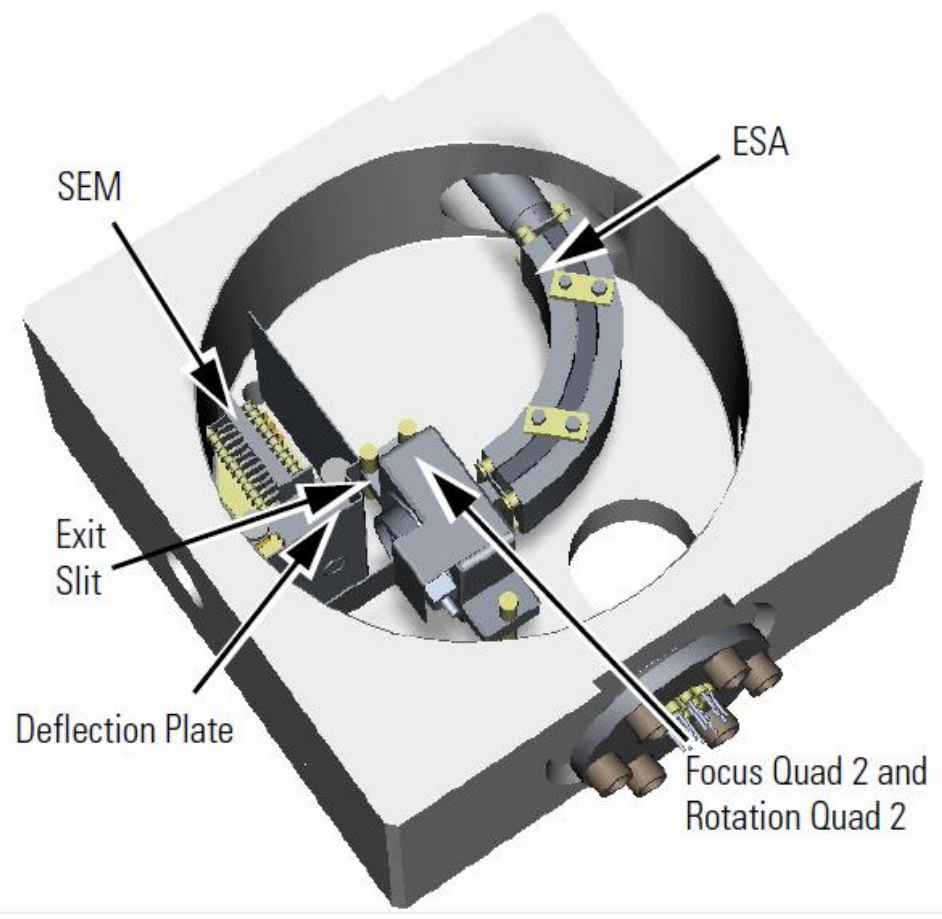

Figura 19 - Analisador eletrostático de um SF-ICP-MS (61). 
O detector (Figura 20) é posicionado fora do eixo do feixe de íons para minimizar o ruído de fundo (background) e as espécies neutras. Quando o feixe de íons atinge o primeiro dinodo ele causa a liberação de elétrons secundários do material de cobre. Esses elétrons secundários são acelerados em direção ao próximo dinodo produzindo ainda mais elétrons. Esse processo é repetido conforme a quantidade de dinodos presentes no multiplicador de elétrons secundários (Scondary Electrons Multiplier - SEM) até gerar uma corrente elétrica que é capturada no anodo do SEM.

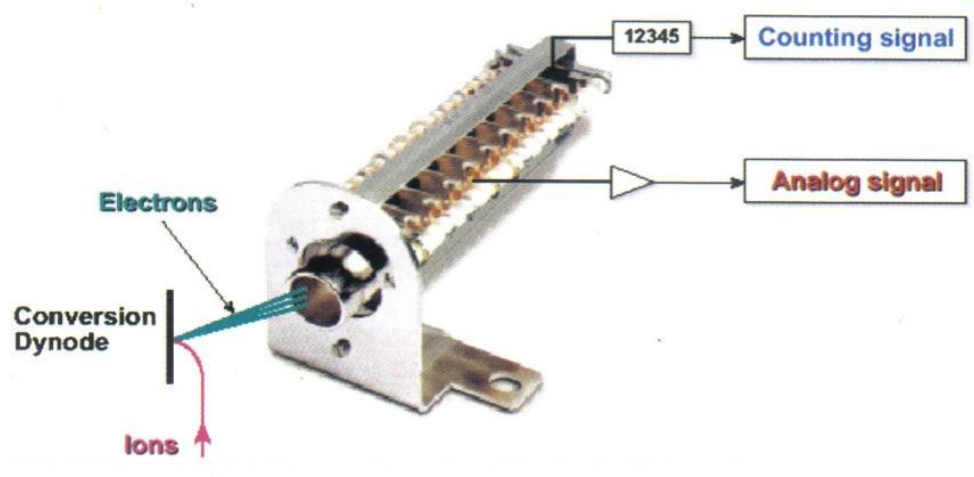

Figura 20 - Detector do tipo fotomultiplicador ou SEM(56).

Os primeiros SEM tinham cerca de cinco ordens de grandeza de faixa dinâmica linear (da ordem de $\mu \mathrm{gg}^{-1}$ até $\mathrm{ngg}^{-1}$ ), possibilitando a análise de até centenas de $\mathrm{ngg}^{-1}$. Essa linearidade pode ser aumentada utilizando-se detectores que operem nos modos analógicos e digitais. O modo analógico possui menor sensibilidade do que o modo digital, pois o número de dinodos utilizados é menor. No modo digital é possível detectar elementos presentes em níveis extremamente baixos, atingindo-se a ordem de $\mathrm{fgg}^{-1}$. Esse último tipo de detector também pode ser operado em ambos os modos (Figura 21), estendendo sua faixa dinâmica em até $10^{9}$ vezes. Isso permite que se meçam concentrações da ordem de $\mu \mathrm{gg}^{-1}$ até $\mathrm{fgg}^{-1}(57)$. 


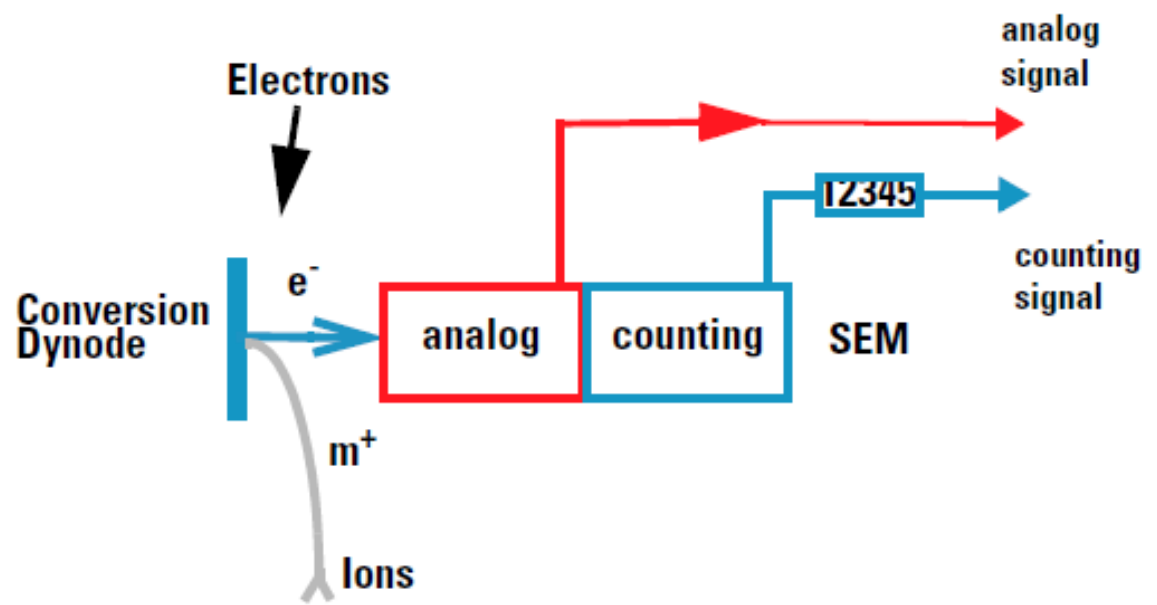

Figura 21 - Modos de contagem de íons de um SEM(61).

\subsection{Laser}

\subsubsection{Introdução}

O termo laser é um acrônimo para "light amplification by stimulated emission of radiation", que significa amplificação de luz por emissão estimulada de radiação. Seu princípio foi descrito teoricamente por Einstein em 1917 (62; 63), porém sua aplicação prática deu-se somente no ano de 1957 quando C. H. Townes usou o maser ("Microwave Amplification by Stimulated Emission of Radiation”), que é um feixe de ondas ultracurtas.

O primeiro laser foi possível apenas em 1960, quando T. H. Maiman apresentou o laser de rubi, utilizando a técnica de bombeamento óptico desenvolvida em 1950 por A. Kastler e J. Brossel (64).

O funcionamento de um laser é dependente das seguintes condições fundamentais: um meio ativo, que é composto por uma coleção de átomos, moléculas ou íons que emitem radiação na faixa visível do espectro; inversão de população, que é gerada por um processo de excitação chamado de bombeamento óptico e faz com que o meio ativo seja um amplificador de radiação; e por final uma cavidade óptica para sediar uma oscilação laser $(65 ; 64)$. 


\subsubsection{Absorção}

Os elétrons que orbitam ao redor do núcleo de um átomo podem ocupar qualquer camada com posições bem conhecidas. Quando um elétron sofre uma transição para uma camada mais afastada desse núcleo há um aumento da energia interna do átomo. Portanto, para que esse elétron tenha sido promovido para uma camada superior ocorreu absorção de energia. Essa energia pode ter origem cinética (choques de outras partículas) ou eletromagnética (fóton). Nesse último caso a radiação incidente pode ser parcialmente ou totalmente absorvida e é dada pela relação h $v$, em que h é a constante de Planck $\left(6,62 \times 10^{-34}\right.$ $\mathrm{Js}^{-1}$ ) e $v$ é a freqüência da radiação eletromagnética do fóton. Portanto, é obedecida a seguinte relação (64):

$$
E_{2}-E_{1}=h v
$$

em que $\mathrm{E}_{1}$ é o nível de energia inicial do átomo e $\mathrm{E}_{2}$ é o seu nível de energia final. A Figura 22 representa o processo de absorção de energia por um átomo:

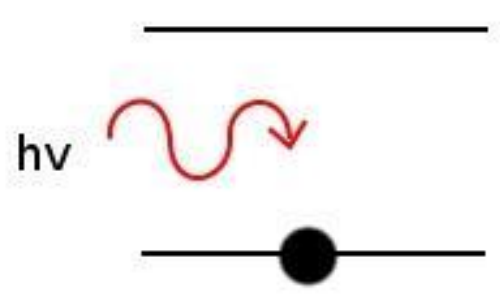

(a)

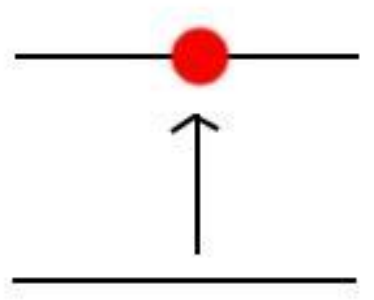

(b)

Figura 22 - Processo de absorção de um fóton por um átomo. 


\subsubsection{Emissão espontânea}

Após o processo de absorção de energia pelo átomo poderá ocorrer a emissão espontânea dessa energia adquirida. Ela ocorre pela transição de um elétron no estado excitado para um estado de menor energia e pode ser na forma de energia cinética ou radiação eletromagnética (fluorescência). Essa transição não ocorre de maneira ordenada para todos os elétrons excitados, sendo o número de elétrons que permanecem excitados no final de um tempo t proporcionais a (64):

$$
e \alpha \frac{t}{\tau}
$$

em que $\tau$ é a vida média do estado excitado, ou seja, o tempo que os elétrons permanecem nele.

Nesse tipo de emissão não existe relação de fase, direção ou polarização entre a radiação emitida. Portanto, trata-se de um fenômeno incoerente, pois cada átomo emite radiação independente dos outros (64).

\subsubsection{Emissão estimulada}

A emissão estimulada é correspondente à emissão espontânea, no que diz respeito à liberação de um fóton após a transição de um átomo no estado excitado para um nível de menor energia. No entanto, essa emissão deixa de ser espontânea à medida que ela é desencadeada por um fóton incidente de energia igual àquela que pode ser liberada pelo átomo que retorna a um nível inferior de energia, ou seja, o fóton indutor deve ter a mesma frequência daquele que ele irá induzir. Isso faz com que eles tenham a mesma fase, direção e polarização (64).

Para haver emissão estimulada é necessário que a população de átomos no estado excitado seja maior que a população dos átomos em um estado de energia inferior. Essa condição somente é satisfeita fora do equilíbrio térmico através de uma excitação exterior denominada bombeamento. A relação entre as populações é dada por (64): 


$$
\frac{N_{2}}{N_{1}}=e^{\left(\frac{E_{2}-E_{1}}{K T}\right)}
$$

Em que K é a constante de Boltzmann $\left(1,38 \times 10^{-23} \mathrm{~J} / \mathrm{K}\right)$ e T é a temperatura absoluta do meio (K).

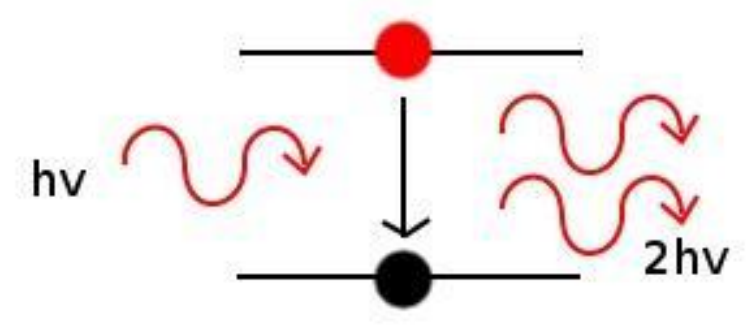

Figura 23 - Processo de emissão estimulada.

O processo descrito na Figura 23 representa o bombeamento, que produz uma inversão de população entre o nível fundamental (0) e o nível 2. Em seguida a população do nível 2 migra para o nível 1, através de uma transição térmica e a transição final da população do nível 1 para o estado fundamental é que sofrerá emissão espontânea ou estimulada (64).

\subsubsection{Cavidade ressonante}

Como descrito anteriormente o laser é uma fonte de radiação eletromagnética e não promove a amplificação dessa radiação por si só. A amplificação é promovida pela cavidade ressonante que é iluminada pela radiação emitida pelo laser. Essa cavidade é composta por dois espelhos planos, sendo um deles semi-transparente para permitir a saída da radiação gerada no interior desse oscilador. A condição de ressonância dessa cavidade é dada por (64): 


$$
n \frac{\lambda}{2}=l
$$

Em que 1 é o comprimento da cavidade, $\lambda$ é o comprimento de onda da ressonância e $\mathrm{n}$ é um número inteiro.

Essa cavidade pode ressoar em um número muito grande de comprimentos de onda que é limitado pela raia de fluorescência, porém ainda é capaz de gerar uma radiação monocromática e está esquematizada na Figura 24.

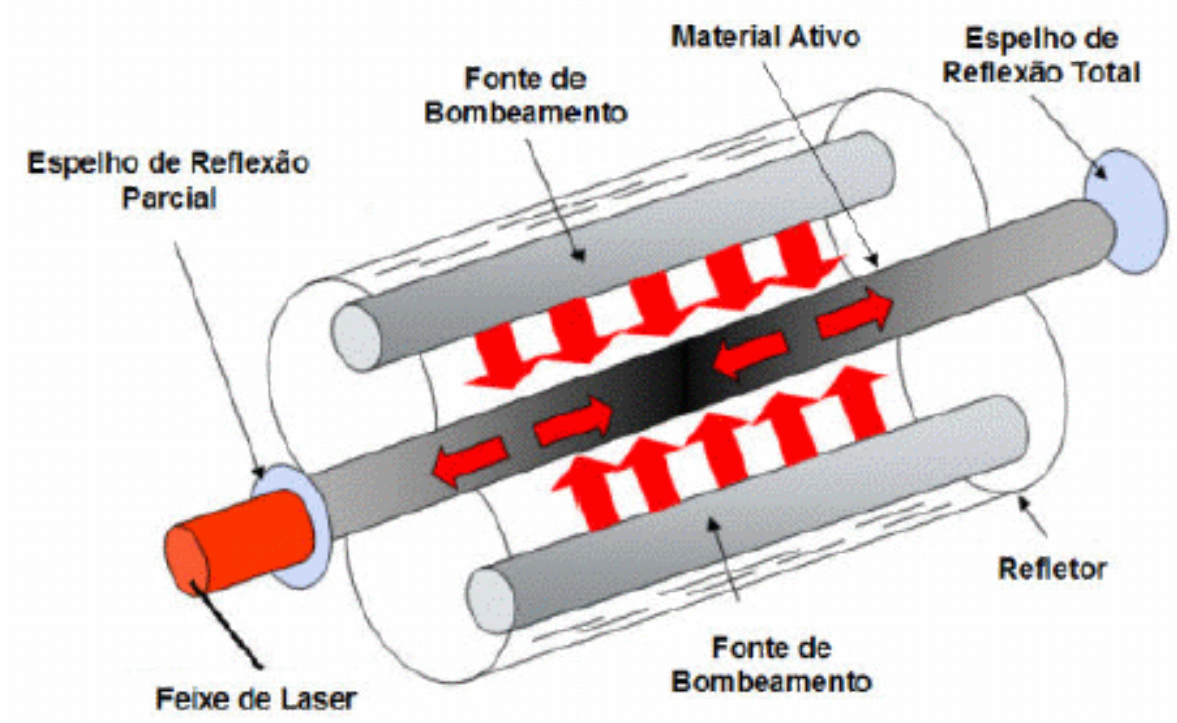

Figura 24 - Cavidade ressonante de um laser (66).

\subsubsection{A fonte laser}

Uma fonte laser contém os seguintes componentes:

i) o meio ativo: pode ser um material em fase sólida, líquida ou gasosa. Os lasers de estado sólido mais comuns empregam o rubi, que é um cristal de alumina dopado com íons $\mathrm{Cr}^{3+}$. Outro material a ser empregado é o vidro dopado com neodímio. E para fechar esse 
conjunto de materiais existem os lasers de granada de ítrio e alumínio dopada com neodímio (Nd:YAG - Yttrium Aluminium Garnet). Os lasers a gás são compostos geralmente de uma mistura de hélio e neônio, argônio ionizado e o anidrido carbono. Já os que tem o líquido como material ativo são muito raros, sendo restritos apenas aos laboratórios de pesquisa

ii) a cavidade ressonante: sua construção varia de acordo com o material do meio ativo. Para um laser de estado sólido, os espelhos podem ser as faces terminais do cilindro do meio ativo. Já para os lasers a gás, ela pode ser a parede que reveste o recipiente do gás.

iii) o dispositivo de bombeamento: No caso do bombeamento óptico, o dispositivo que bombeia os fótons é um flash, que pode ser linear ou helicoidal. Outras formas de bombeamento podem ser realizadas empregando arcos de xenônio, descargas elétricas, feixes de elérons, expansão hidrodinâmica, feixe de íons ou fontes de raios X (64).

\subsubsection{Coerência temporal e espacial}

As propriedades de coerência temporal e espacial são conferidas pela emissão estimulada e pela cavidade ressonante. Tais propriedades são exclusivas das fontes lasers, pois mesmo outras fontes monocromáticas emitem radiação incoerente.

A coerência temporal é a medida da correlação da fase da onda luminosa, que varia de forma senoidal, em diferentes pontos ao longo da direção de propagação. A coerência espacial é a medida da correlação da fase da onda luminosa em diferentes pontos no sentido perpendicular ao de propagação dessa onda. Como conseqüência da coerência temporal tem-se a diretividade da radiação laser. No entanto, as propriedades de coerência não são possíveis de serem atingidas na prática e as divergências da maioria dos lasers comerciais estão na ordem de $10^{-3}$ radianos (64). 


\subsubsection{Modos de funcionamento}

Os modos de funcionamento dos lasers variam de acordo com seu sistema de bombeamento, podendo ser por:

i) emissão contínua: o meio ativo é bombeado continuamente gerando uma emissão laser permanente;

ii) emissão pulsada: o material ativo é bombeado progressivamente para chegar a um nível de excitação limiar que permita a emissão de radiação laser, despovoando parcialmente os níveis excitados. Isto acaba gerando uma sucessão de pulsos muito próximos até o final do bombeamento.

iv) emissão desencadeada ou Q-switched: nesse modo o meio ativo é bombeado para além de seu limiar de funcionamento para posterior liberação da radiação laser. Com esse sistema produzem-se pulsos de energia muito maior do que na emissão pulsada, de curta duração (da ordem de ns) e com potência de pico elevada (64).

\subsection{Ablação a laser (Laser Ablation)}

Segundo o dicionário, ablation significa perda de parte de um material por vaporização ou derretimento. Logo, é necessário que haja absorção de energia pela matéria e para isso é necessária uma fonte de energia, que no caso da ablação a laser é a utilização da radiação laser. Essa radiação retira porções da matéria por fusão, vaporização, sublimação, ionização, erosão ou explosão $(67 ; 68 ; 65)$. Esse processo gera formação de vapor, plasma e material particulado.

O sistema de ablação a laser consiste de um conjunto de lentes incorporadas a um CCD, câmara de ablação, uma plataforma ajustável e um meio ativo. Dentre os diversos tipos possíveis de meios ativos utilizados deste sistema (Figura 25), o Nd:YAG é o mais utilizado devido ao seu baixo custo de produção e de manutenção $(63 ; 69 ; 70)$. 


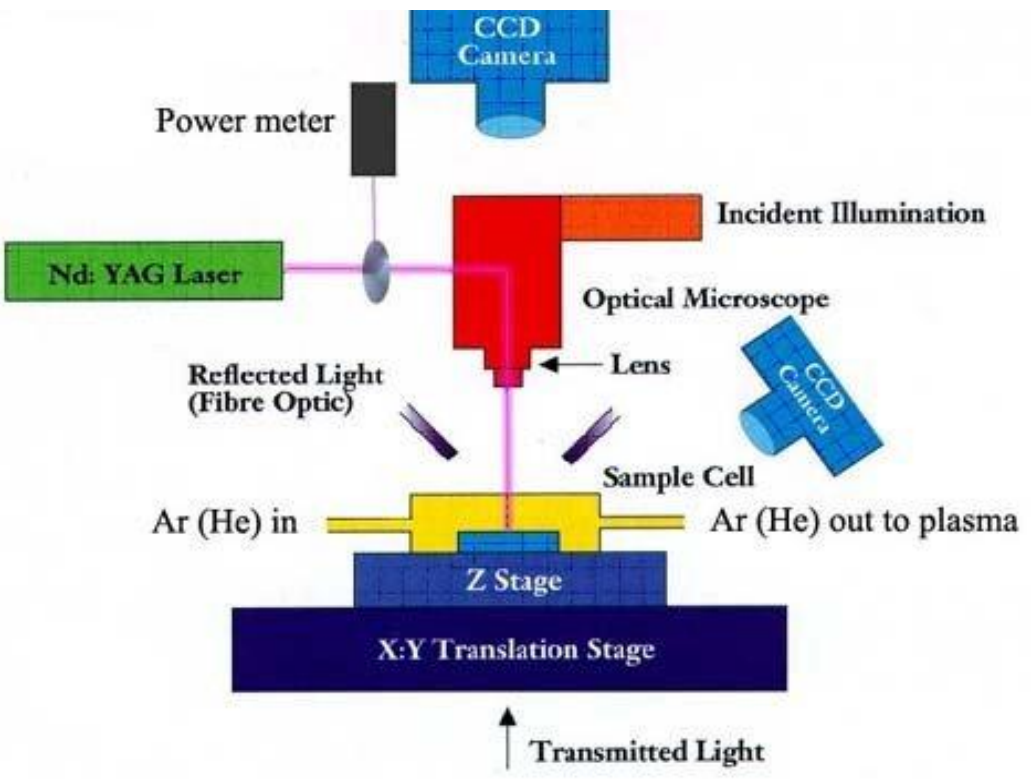

Figura 25 - Esquema ilustrativo da ablação de um material pelo feixe laser. Podem ocorrer nesse processo a fusão da superfície atingida, a ejeção de partículas, a vaporização, excitação e ionização dos elementos, dependendo da energia do feixe incidente e das propriedades termo-ópticas do material. (71)

As características do processo de ablação fornecem uma gama de informações extremamente importantes para a química analítica, em especial para aplicações microanalíticas, como o seu acoplamento a um ICP-MS para análise direta de sólidos. Essa técnica minimizou o tempo de análise das amostras, pois eliminou os demorados processos de preparação e digestão. Em suma, essa técnica tem se demonstrando muito poderosa e promissora, pois traz vantagens como rapidez, análise local, análise multielementar e possibilidade de análise direta sem preparação da amostra $(67 ; 69 ; 70 ; 72)$.

\subsubsection{Processos de ablação}

A ablação é caracterizada por diversos processos não lineares, que se iniciam no momento em que o feixe do laser atinge a superfície da amostra. Dentre eles pode-se citar a liberação de elétrons, íons, moléculas, átomos, aglomerados e partículas. 
O primeiro processo da ablação é a ignição do plasma que é governado pela irradiância do laser e pela duração de seu pulso. A expansão do plasma é o processo seguinte. Ele está relacionado com o ambiente gasoso e com a massa e energia iniciais da pluma. Essa expansão será adiabática até aproximadamente $1 \mathrm{~ms}$ após o pulso do laser iniciar. Decorrido esse tempo começa a ocorrer grande perde de energia por radiação, causando a queda da temperatura $(73 ; 68)$.

Esses dois processos citados anteriormente são os que promovem a formação das partículas, que se inicia quando a pluma de vapor atinge a temperatura de ebulição do material ( 3000 K). Na fase líquida, as partículas são ejetadas devido a um elevado gradiente de alta pressão no interior da pluma de vapor. Já na fase sólida, as partículas são formadas por um processo de esfoliação causado pelo rápido processo de aquecimento que quebra a amostra em pedaços irregulares (65).

\subsubsection{Ablação com pulsos de nanosegundos}

A irradiância para pulsos com duração de ns é da ordem de $10^{7}$ a $10^{11} \mathrm{Wcm}^{-2}$, que provoca mecanismos de derretimento, fusão, sublimação, vaporização e ionização. Quando a irradiância é menor do que $10^{8} \mathrm{Wcm}^{-2}$, o processo térmico é dominante e leva ao aumento da temperatura da superfície do material até seu ponto de vaporização. A distribuição de temperatura nesse material será dada por:

$$
\frac{\partial T}{\partial t}(x, t)=\frac{\partial}{\partial x}\left[\left(\frac{k}{c_{p} \rho_{s}}\right) \frac{\partial T}{\partial x}(x, t)\right]+\frac{\alpha}{C_{p} \rho_{s}} I(x, t)
$$

em que $\mathrm{T}$ é a temperatura dentro do material, x é posição na superfície, $\mathrm{k}$ é a condutividade térmica, $\mathrm{C}_{\mathrm{p}}$ é a capacidade térmica, $\rho_{s}$ é densidade e $\alpha$ é o coeficiente de absorção (65).

A massa vaporizada pode ser ionizada ao absorver os fótons provenientes do feixe de laser, gerando o plasma. Quando esse plasma atinge a densidade crítica, a última parte do feixe incidente pode ser absorvida antes de atingir a matéria, devido a um fenômeno inverso ao Bremsstrahlung (65). 


\subsubsection{Comprimento de onda no processo de ablação}

O comprimento de onda do feixe de laser está diretamente relacionado com a interação laser-matéria. Comprimentos de onda curtos geram fótons de alta energia. A maioria dos elementos têm energia de ligação de poucos $\mathrm{eV}$, portanto esses fótons altamente energéticos são muito importantes no processo de ablação, pois geram mecanismos não-térmicos que induzem diretamente os processos de atomização e ionização sem aquecer a superfície e trazendo uma melhor qualidade analítica.

Um estudo realizado por Russo et. al. (73) investigou a influência do comprimento de onda no fracionamento gerado pelo laser utilizando feixes das seguintes energias: 4,7 $\mathrm{eV}, 5,8 \mathrm{eV}$ e 7,9 eV. Ele chegou à conclusão que quanto menor o comprimento de onda, maior será o controle e reprodutibilidade na taxa de ablação.

A taxa de ablação é caracterizada pela quantidade de material retirado por pulso de laser e por unidade de área. Sua função é servir como indicador da eficiência da interação da energia do feixe de laser com o material alvo, que é dependente da absorbância óptica. Um exemplo da dependência da interação laser-alvo com o comprimento de onda é o elemento Al que tem uma taxa de ablação de 1,04 mm/pulso para um feixe laser com comprimento de onda de $266 \mathrm{~nm}$ e 0,7 para um feixe de $193 \mathrm{~nm}$, segundo estudos feitos por Gunther et. al. (74).

Outro fenômeno que tem uma pequena influência do comprimento de onda do feixe laser é o fracionamento elementar. Esse fenômeno é originado durante a interação dos pulsos de nanosegundos com materiais que dificultam a propagação das ondas térmicas no material, criando uma enorme camada derretida que é evaporada.

\subsubsection{Energia do feixe laser no processo de ablação}

A fluência $\left(\mathrm{Jcm}^{-2}\right)$ e a irradiância $\left(\mathrm{Wcm}^{-2}\right)$ do feixe laser são os principais parâmetros que influenciam a interação laser-matéria. A energia e a duração do pulso definem as características do plasma induzido, da taxa de ablação e da massa ablacionada, que aumenta conforme a energia do feixe laser se eleva, ou seja, quanto maior a energia 
maior é a eficiência da ionização (65).

\subsubsection{Laser Ablation Inductively Coupled Mass Spectrometry (LA-ICP-MS)}

A técnica LA-ICP-MS consiste na associação de um sistema de ablação a laser com um espectrômetro de massa com fonte de plasma indutivamente acoplado (ICP-MS). Ela tem se tornado um método consagrado para análise isotópica e de elementos traço em sólidos, devido a sua capacidade multielementar, baixo limite de detecção, rapidez analítica, mínima necessidade de preparação de amostra, alta sensitividade, capacidade de análise micrométrica e excelente resolução espacial. Tais características são extremamente úteis para as áreas forenses, geológicas, bioquímicas, biomédicas, nuclear e de materiais $(56 ; 72)$.

Sua primeira utilização se deu em 1985 quando Gray, A. L. (75) montou um dispositivo que transportava material sólido evaporado através de um fluxo de argônio à pressão atmosférica. A evaporação do material sólido era feita pela incidência de um feixe de laser em sua superfície, que gerava o seu aquecimento e desencadeava o processo de ablação. O primeiro sistema comercial de ablação a laser era de estado sólido com meio ativo de Nd:YAG e operava na frequência fundamental com comprimento de onda de 1064 $\mathrm{nm}$, que compreende a região do infravermelho. No entanto, lasers desse comprimento de onda geravam muita instabilidade no sinal quando se analisavam materiais com baixa absorção na região do infravermelho ou materiais com concentração da ordem de $u g^{-1}$. A solução encontrada para esse problema foi a utilização das outras harmônicas dessa frequência, ou seja, multiplicado-se a frequência fundamental obtiam-se os seguintes comprimentos de onda: $532 \mathrm{~nm}, 266 \mathrm{~nm}$ e $216 \mathrm{~nm}$ (56).

Outro tipo de laser são os excimer lasers que têm um gás como meio ativo e operam com comprimento de onda de até $126 \mathrm{~nm}$, sendo mais comercial o de $193 \mathrm{~nm}$. Esse menor comprimento de onda gera fótons de maior energia, que atingem densidades de até $35 \mathrm{Jcm}^{-2}$. Eles são majoritariamente empregados em análises de vidros de alta pureza, diamantes e materiais altamente transparentes (56).

Os sistemas de ablação a laser são usualmente acoplados a espectrômetros de massa do tipo quadrupolo (inductively coupled plasma quadrupole mass spectrometry - 
ICP-QMS), com setor de campo duplamente focalizado (sector field inductively coupled plasma mass spectrometry - SF-ICP-MS), com tubo de voo (inductively coupled plasma time of flight mass spectrometry - ICP-ToF-MS) e com multicoletores (multi colector inductively coupled plasma mass spectrometry - MC-ICP-MS). Os sistemas que utilizam pulsos de femtossegundos são os que oferecem melhor sensitividade e maior reprodutibilidade para análise direta de sólidos. Isso se deve ao fato da condução térmica sobre a superfície do material ser praticamente desprezível, fazendo com que a transição seja diretamente da fase sólida para o vapor (ou plasma) (72).

O arranjo experimental de um sistema LA-SF-ICP-MS está representado na Figura 26:

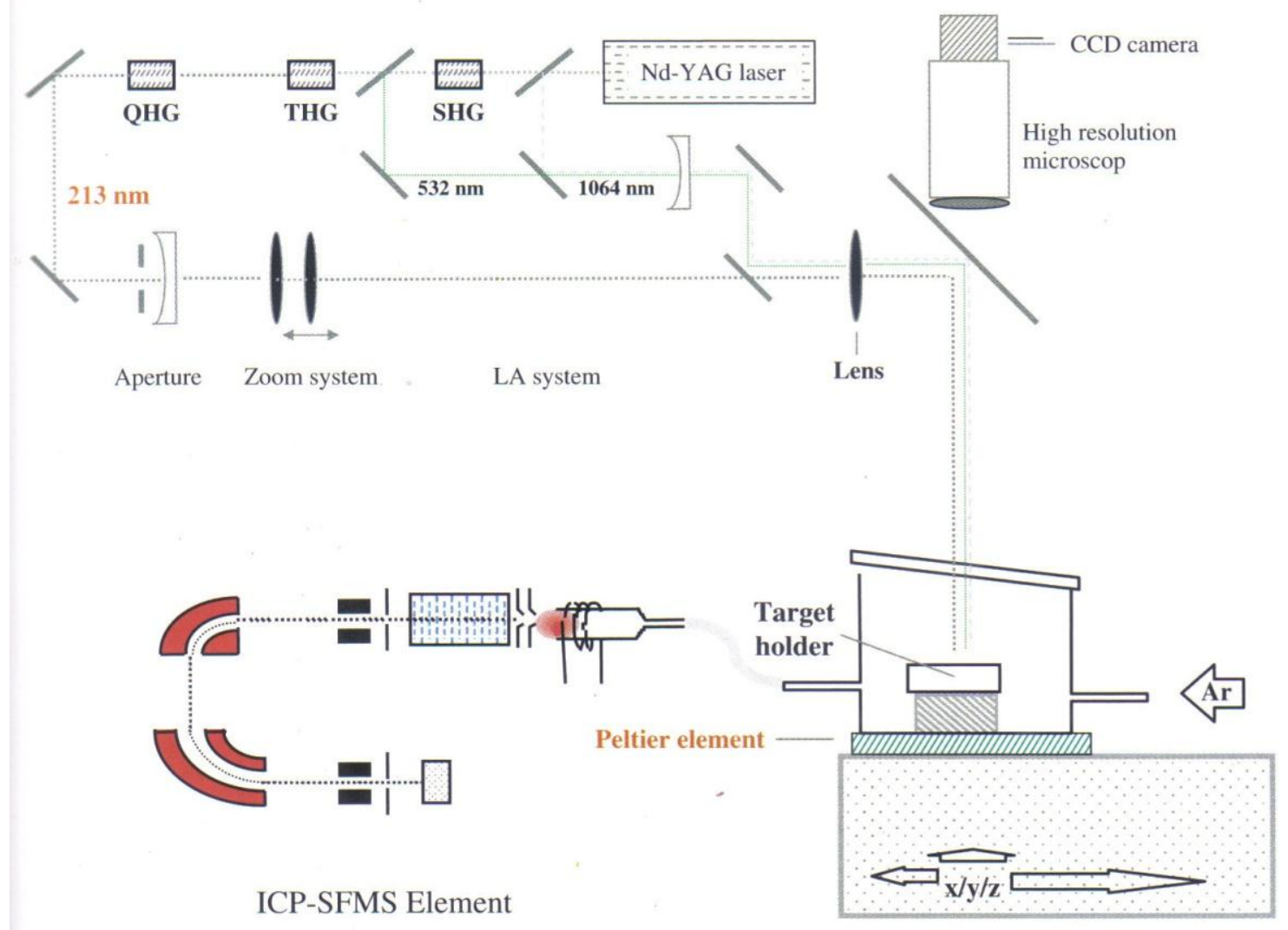

Figura 26 - Esquema do acoplamento de um sistema de ablação a laser com um ICP-MS (56). 


\subsubsection{Utilização da técnica LA-ICP-MS como metodologia de análise de materiais nucleares}

A utilização da técnica LA-ICP-MS possibilita a medição de actinídeos em nível traço em amostras ambientais e, principalmente, a análise direta de sólidos sem a necessidade de qualquer diluição ou outro tratamento químico. Segundo Széles, et al., ela também se mostra uma técnica quase não destrutiva e de pequeno tempo de análise. Todas as características anteriores fazem essa técnica adequada para propostas de salvaguardas e forense nuclear, no que tange a determinação da idade de amostras que contenham urânio (71).

Um dos grandes problemas da técnica ICP-MS são as interferências isobáricas e a precisão das medidas da razão isotópica, que vêm sendo estudadas por diversos autores (56; 72; 60; 76). Z. Varga (77) descreve a aplicação da técnica LA-ICP-MS para a análise da razão isotópica de partículas de urânio utilizando um processo suave de ablação. Ele encontrou medidas precisas para o ${ }^{234} \mathrm{U} /{ }^{238} \mathrm{U},{ }^{235} \mathrm{U} /{ }^{238} \mathrm{U}$ e ${ }^{236} \mathrm{U} /{ }^{238} \mathrm{U}$, com DPR variando de $0,9 \%$ a $5,1 \%$ para partículas de até $10 \mu \mathrm{m}$.

Já S. Bürger et al. (78) utilizou a técnica de ablação a laser como metodologia de introdução de amostras em um espectrômetro de massa por tempo de voo com fonte de plasma indutivo (LA-ToF-ICP-MS). Com esse trabalho foi possível o estabelecimento de um procedimento rápido e eficaz para a análise de materiais nucleares sólidos, alcançando precisão de $4 \%$.

Outras aplicações da técnica LA-ICP-MS na área nuclear têm se mostrado satisfatórias, como a análise de amostras do grafite de reatores nucleares e sedimentos (69), bem como de materiais particulados coletados em 1992 nas vizinhanças de Chernobyl (79).

Devanathan Alamelu et al. utilizaram a técnica LA-ICP-MS para determinar impurezas em $\mathrm{ThO}_{2}$, tendo o elemento $\mathrm{Mg}$ como padrão interno de quantificação. Nesse trabalho concluiu-se que a técnica adotada é eficiente uma vez que não envolve dissolução ou separação do Th, bem como provê dados multi-elementares com boa precisão e acurácia, sem muito esforço adicional. Também foi ressaltada a quantidade irrelevante de rejeitos, fato que é muito relevante quando se trata de material nuclear (80).

S.F. Boulyga et al. analisaram $\mathrm{Pu}$ e Am em amostras de musgos pela técnica LAICP-MS para determinação de elementos em nível de ultratraço. Os resultados apresentados se mostraram de acordo com aqueles encontrados pela técnica de 
espectrometria alfa. Esse trabalho permitiu medidas isotópicas de $\mathrm{Pu}$ em patamares de concentração de $5 \times 10^{-14}$ a $2,5 \times 10^{-13} \mathrm{gg}^{-1}(81)$.

\subsection{Técnicas complementares utilizadas na estratégia analítica}

A fim de se complementar a análise das amostras de esfregaço por LA-HR-ICP-MS foram utilizadas as técnicas de MEV e EDS para a identificação e caracterização de partículas de urânio presentes nas amostras.

\subsubsection{Microscopia Eletrônica de Varredura (MEV)}

A técnica de microscopia eletrônica de varredura (MEV) pode adquirir imagens de espécimes inteiros ou particulados. Essas imagens são obtidas pela aceleração de elétrons gerados em canhões dos tipos termiônicos, Schottky ou por emissão de campo - através de uma diferença de potencial entre um anodo e um catodo, variando de $0,1 \mathrm{keV}$ até $50 \mathrm{keV}$. O diâmetro do feixe de elétrons produzido pela sua fonte não permite que sejam adquiridas imagens nítidas com alta magnificação, sendo necessário o uso de lentes magnéticas para colimar e, assim, focalizar o feixe. Esse feixe tem geralmente menos de 100 Å de diâmetro e possui corrente suficiente para gerar imagens claras, que são formadas pela interação entre o feixe e o espécime que é penetrado em aproximadamente $1 \mu \mathrm{m}$ (82).

O sistema de deflexão é o responsável pela formação da imagem. Esse sistema faz com que o feixe de elétrons percorra a superfície da amostra ponto a ponto formando uma varredura retangular. Ele controla a magnificação da imagem, que é a razão entre o tamanho linear da tela e o tamanho da varredura.

A partir da interação do feixe com a superfície do espécime são gerados muitos sinais devido ao espalhamento elástico e inelástico dos elétrons gerados pelo feixe, dentre os quais se destacam os elétrons retroespalhados e os secundários (82). 


\subsubsection{Espalhamento de elétrons}

O espalhamento de elétrons é o fenômeno físico principal por trás da técnica de microscopia eletrônica. Esses elétrons podem sofrer espalhamento elástico e inelástico durante sua interação com o espécime e são tratados como um feixe devido à quantidade de elétrons presentes. $\mathrm{O}$ termo espalhamento elástico está relacionado à conservação de energia do feixe espalhado em relação ao feixe incidente. Quando esse tipo de espalhamento ocorre em ângulos maiores do que $90^{\circ}$, o feixe é chamado de retroespalhado e contém elétrons remanecentes do feixe original. Já o espalhamento inelástico relacionase com uma quantidade mensurável de energia que o feixe incidente perde após a interação com o espécime. Ela é distribuída através de diversos processos secundários:

i) Elétrons secundários, que são os elétrons liberados pela amostra e tem distribuição contínua de energia;

ii) Elétrons Auger com energias características;

iii) Raios X de freamento (bremsstrahlung);

iv) Raios $\mathrm{x}$ característicos e

v) Catodoluminiescência.

\subsubsection{Elétrons retroespalhados}

O retroespalhamento ocorre quando o feixe de elétrons penetra na nuvem eletrônica do átomo e sofre atração Coulombiana pelo núcleo. Esse fenômeno resultao em um espalhamento de ângulos maiores do que $90^{\circ}$. Esse efeito aumenta conforme se eleva o número atômico $(\mathrm{Z})$ dos átomos presentes no espécime, ou seja, o número de $\mathrm{Z}$ controla a interação elástica com o núcleo (Figura 27).

Os elétrons retroespalhados trazem informações extremamente úteis a respeito da composição química do espécime, topografia, forma, cristalografia e campos magnéticos internos. O conhecimento dessas propriedades é fundamental para a interpretação das 
micrografias e compreensão dos procedimentos de correção para análises de raios X.

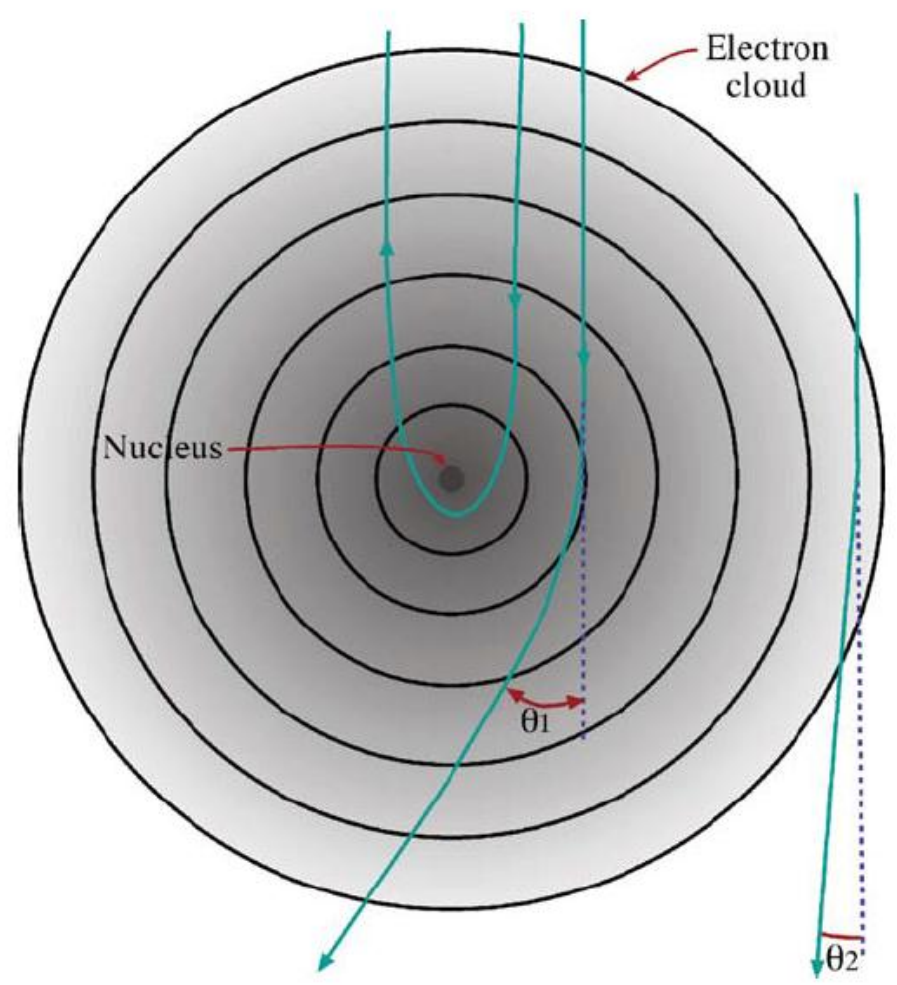

Figura 27 - Esquema do espalhamento elástico de electrons (82).

\subsubsection{Elétrons secundários}

Ao se medir a distribuição de energia de todos os elétrons entre a energia do feixe e $0 \mathrm{keV}$ nota-se que essa distribuição é dominada pelos elétrons retroespalhados. Nas regiões com energia abaixo de $50 \mathrm{eV}$ há um aumento expressivo do número de elétrons emitidos do espécime, que supera a contribuição devida aos elétrons retroespalhados. A Figura 28 representa a distribuição dos elétrons secundários em função de sua energia. 


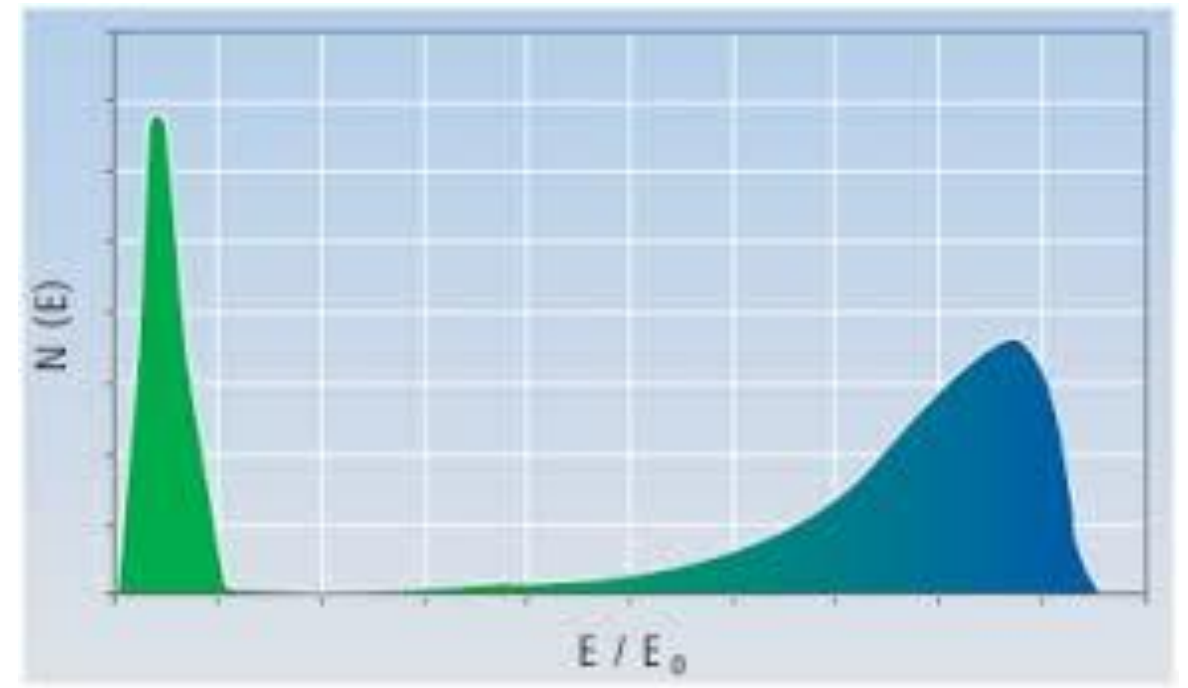

Figura 28 - Distribuição dos elétrons secundários (83).

Os elétrons secundários são produzidos principalmente como resultado da interação entre o feixe e à fraca ligação da banda de condução dos elétrons nos metais. Como a diferença de energia entre o feixe de elétrons e os elétrons do espécime é muito acentuada, apenas uma pequena quantidade de energia cinética é transferida aos elétrons secundários (82).

\subsubsection{Fontes de elétrons}

As fontes de elétrons fornecem uma quantidade grande e estável de corrente em um pequeno feixe de elétrons. Elas variam na capacidade de fornecer elétrons, no seu tamanho, estabilidade de corrente e no tempo de vida. 


\subsubsection{Fonte de tungstênio}

O tipo de fonte mais utilizada nos MEV de mesa é a de tungstênio. Ela é uma fonte confiável, barata e suas propriedades são bem conhecidas. Sua aplicação se dá geralmente quando não se necessita de alto brilho. Sua vida útil está altamente ligada à temperatura $\mathrm{e}$ ao brilho demandado para a análise, sendo inversamente proporcional a esses dois parâmetros.

Um catodo típico de tungstênio (Figura 29) consiste em um filamento de aproximadamente $100 \mu \mathrm{m}$ em forma de V. A emissão termiônica ocorre quando o catodo é aquecido até o ponto em que os elétrons começam a ser ejetados e posteriormente acelerados em direção do anodo por uma fonte de alta tensão (82).

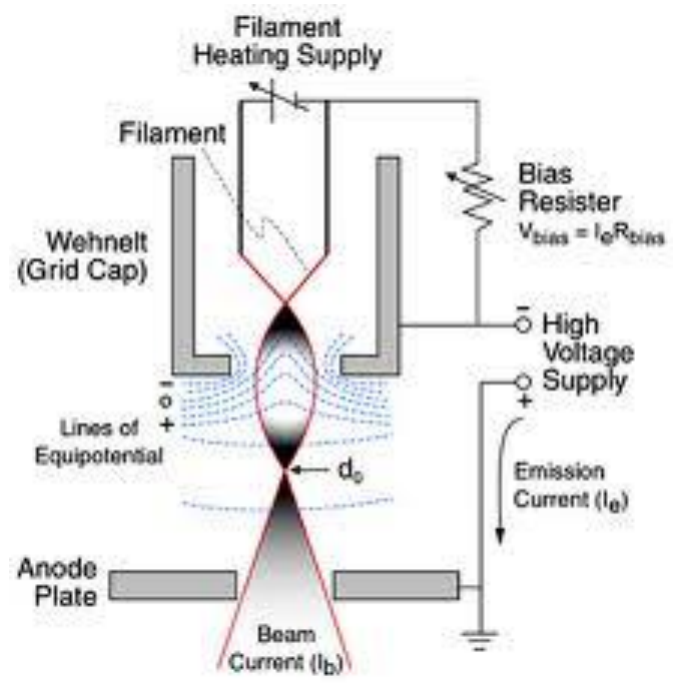

Figura 29 - Esquema de um MEV com fonte de emissão de elétrons de tungstênio (84). 


\subsubsection{XEDS - Espectroscopia de Energia Dispersiva de Raios X}

A técnica de espectroscopia de energia dispersiva de raios $\mathrm{X}$ (X-Ray energy dispersive spectroscopy - XEDS) foi desenvolvida no final da década de 1960 e colocada em operação em meados da década de 1970. Esse rápido crescimento foi conseqüência de seu tamanho compacto, robustez, facilidade de operação e interpretação de dados.

O sistema XEDS é controlado por um computador que, idealmente, deveria processar um único raio $\mathrm{X}$ por vez. Portanto, o detector é desligado sempre que um fóton de raio $\mathrm{X}$ é detectado e ligado novamente após o processamento do sinal gerado por esse fóton. Após essa etapa, o computador associa o sinal captado com o seu respectivo canal de energia no sistema de armazenamento de dados e calibra o espectro obtido.

Os principais componentes do XEDS são o detector, a eletrônica de processamento e o computador. $\mathrm{O}$ detector gera um pulso proporcional às energias dos raios $\mathrm{X}$, que é convertido em um sinal elétrico (voltagem). Essa voltagem é amplificada através de transistores de efeito de campo (FET - Field Effect Transistors), isolada dos outros pulsos, e então identificada eletronicamente como resultado de um raio $\mathrm{X}$ de energia específica. Finalmente, o sinal é digitalizado e armazenado no canal associado àquela energia.

\subsubsection{Detectores}

A detecção de raios $X$ é realizada quando sua energia é depositada em um semicondutor. Assim, os elétrons são transferidos da banda de valência para a de condução, criando pares elétrons-lacunas. A energia necessária para essa finalidade é de aproximadamente $3,8 \mathrm{eV}$ à temperatura de $-196{ }^{\circ} \mathrm{C}$ para o silício. Como os raios $\mathrm{X}$ característicos têm energia de aproximadamente $1 \mathrm{keV}$, milhares de pares elétrons-lacunas são criados proporcionalmente à energia dedo fóton de raio X. Mesmo assim, nem toda essa energia é convertida em pares elétrons-lacunas, porém o número desses pares é suficiente para garantir uma boa precisão estatística.

$\mathrm{O}$ resfriamento dos detectores de semicondutor à temperatura de $-196{ }^{\circ} \mathrm{C}$ é necessário para que se evite: a ativação dos pares elétrons-lacunas devido à energia 
térmica; danos à suas características intrínsecas e mascaramento do sinal de raios $\mathrm{X}$ de baixa energia devido ao ruído do FET.

Comercialmente existem três tipos de detectores: silício-lítio (silicon-lithium $(\mathrm{Si}(\mathrm{Li}))$; detector de deriva de silício (silicon drift detector - (SDD)) e o de germânio intrínseco (IG). O detector que é largamente utilizado é o Si(Li).

O detector do tipo $\mathrm{Si}(\mathrm{Li})$ é construído pelo preenchimento dos lugares de recombinação de $\mathrm{Si}$ com $\mathrm{Li}$, criando-se uma região de $\mathrm{Si}$ intrínseco na qual elétrons e lacunas podem ser separados. Esse procedimento se faz necessário, pois mesmo o Si com maior índice de pureza comercializado contém impurezas que fazem com que ele apresente um comportamento de semicondutores do tipo $\mathrm{P}$, auxiliando a recombinação dos pares elétrons-lacunas. Assim, o pulso eletrônico é medido quando se aplica um sinal reverso que faz com que os pares elétrons-lacunas sejam separados.

$\mathrm{O}$ detector SDD consiste basicamente de um dispositivo de carga acoplada (Charge Coupled Device - CCD) formado por anéis concêntricos de Si dopado tipo P implantado em um cristal de Si do tipo N através do qual uma tensão elevada é aplicada para capturar os elétrons gerados. Aplicando-se essa tensão do interior para o exterior do detector permite-se a coleta de elétrons no Si do tipo $\mathrm{N}$ utilizando-se quatro vezes menos voltagem. Outra grande vantagem é que esse tipo de detector necessita de uma mínima refrigeração termoelétrica (utilização de célula peltier) ou até mesmo nenhuma refrigeração (82).

\subsubsection{As linhas de raios $X$}

O sistema XEDS pode aquisitar o espectro na faixa de $0,1 \mathrm{keV}$ a $20 \mathrm{keV}$ em um período curto de tempo (10 a $100 \mathrm{~s}$ ), permitindo que se avalie a amostra rapidamente. A eficiência de seu detector é de aproximadamente $100 \%$ na faixa de $3 \mathrm{keV}$ a $10 \mathrm{keV}$ e a altura relativa observada para os picos de intensidades são muito próximos aos valores esperados. No entanto, sua resolução em energia é muito pobre, ocasionando interferências espectrais frequentes, bem como a dificuldade de separar os membros de famílias cuja energia seja muito baixa $(<3 \mathrm{keV})$. Existem picos característicos a todos os detectores semicondutores utilizados em XEDS, que são conhecidos como picos de escape. No caso de detectores $\mathrm{Si}(\mathrm{Li})$ ele ocorre em $1,74 \mathrm{keV}$. Esses picos aumentam a complexidade do 
espectro, particularmente quando picos de baixa intensidade relativa são considerados.

A presença das famílias K, L e M (Figura 30) em um espectro XEDS na faixa de energia de $0,7 \mathrm{keV}$ a $10 \mathrm{keV}$ é muito importante para se detectar elementos desconhecidos. A família $K$ consiste em duas linhas $\left(\mathrm{K}_{\alpha}\right.$ e $\left.\mathrm{K}_{\beta}\right)$, cuja razão entre suas intensidades é de 10:1. Qualquer desvio significante desse valor deve ser averiguado cautelosamente para evitar equívocos de identificação dos compostos ou a presença de um segundo elemento (82).

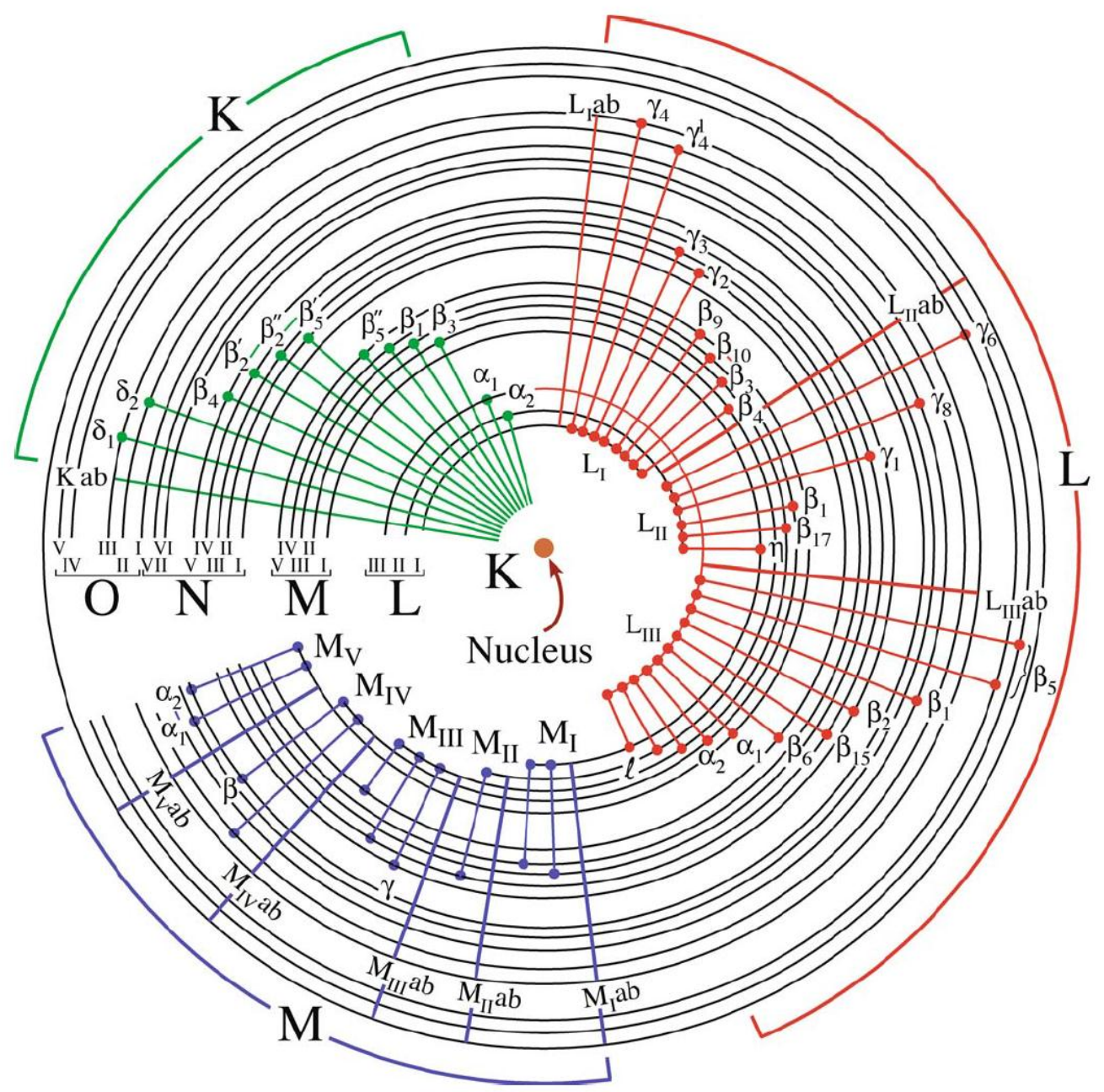

Figura 30 - Linhas de emissão de raios X (82). 


\subsubsection{Análise qualitativa de raios $X$}

O primeiro passo para a análise de uma amostra de material desconhecido é a identificação dos elementos que a compõe. Para descobrir quais elementos são esses podese realizar análises qualitativas de raios $\mathrm{X}$, que indicam os constituintes majoritários com um alto grau de confiança. Já os elementos minoritários sofrem interferências espectrais devido às baixas contagens estatísticas. Portanto, deve-se garantir que a estatística de contagem seja a maior possível. Em suma, os passos para se realizarem análises qualitativas por XEDS são os seguintes:

i) Considerar somente picos estatisticamente significantes, ou seja, três vezes maiores do que o desvio padrão do ruído de fundo;

ii) Adquirir os dados com a maior taxa de contagem possível;

iii) Manter o compromisso entre alta voltagem e a necessidade de minimizar a absorção;

iv) Garantir que todas as linhas de raios $\mathrm{X}$ nas famílias possíveis estejam marcadas para o elemento desejado (82).

A informação mais importante para que se realizem análises qualitativas é a energia específica dos picos de raios X característicos. Essa informação é tabelada e disponível em gráficos ou base de dados do computador do analisador de espectros de raios $\mathrm{X}$.

\subsubsection{Análise quantitativa de raios $X$}

A análise quantitativa de amostras como um todo foi descrita primeiramente na tese de doutorado de Castaing em 1951. Ele assumiu que uma dada concentração $C_{i}$ de um elemento i no espécime gera certa intensidade de raios $\mathrm{X}$ característicos. Caso essa 
concentração fosse utilizada para medir a composição de um padrão conhecido ou certificado $\mathrm{C}_{\text {is }}$ se poderia estimar a concentração de qualquer elemento comparando-se as razões $\mathrm{C}_{\mathrm{i}} / \mathrm{C}_{\mathrm{is}}$ com os números de contagens $\left(\mathrm{I}_{\mathrm{i}} / \mathrm{I}_{\mathrm{is}}\right)$, conforme a expressão:

$$
\frac{C_{i}}{C_{i s}}=k \frac{I_{i}}{I_{i s}}
$$

$\mathrm{Na}$ qual k é o fator de sensitividade que considera a diferença entre os raios $\mathrm{X}$ gerados e medidos. Suas contribuições são devidas ao número atômico $(Z)$, à absorção de raios $\mathrm{X}$ no interior do espécime e à fluorescência de raios $\mathrm{X}$ no interior do espécime.

Considerando um espécime fino o suficiente a ponto de se desconsiderar sua espessura e fluorescência, Cliff e Lorimer (1975) demonstraram que a quantificação por XEDS poderia ser realizada através de uma simplificação da equação de Castaing. Com isso se poderia desconsiderar a intensidade dos raios $\mathrm{X}$ provenientes do padrão e considerar apenas as intensidades adquiridas simultâneamente. A equação de Cliff-Lorimer é dada por:

$$
\frac{C_{A}}{C_{B}}=k_{A B} \frac{I_{A}}{I_{B}}
$$

$\mathrm{Na}$ qual $\mathrm{k}_{\mathrm{AB}}$ é o fator de Cliff-Lorimer.

Para se determinar o valor absoluto de $\mathrm{C}_{\mathrm{A}}$ e $\mathrm{C}_{\mathrm{B}}$ é necessária uma outra equação:

$$
C_{A}+C_{B}=1
$$




\section{DESENVOLVIMENTO EXPERIMENTAL}

Este trabalho foi desenvolvido no Laboratório de Caracterização Química e Isotópica do IPEN, que pertence à RNLCFN. A metodologia utilizada para a análise das amostras de esfregaço seguiu o padrão do Programa 93+2 adotado pela AIEA. Decidiu-se também incluir a caracterização morfológica das amostras de esfregaço com o intuito de se extrair informações complementares à caracterização isotópica. A caracterização morfológica foi realizada com o auxílio das técnicas de MEV e EDS; enquanto que a caracterização isotópica foi realizada por meio do LA-HR-ICP-MS.

\subsection{Atividade radioativa}

As amostras foram analisadas com respeito às suas emissões alfa, em um contador Ludlum 2929, com a finalidade de se constatar a presença de material radiativo, selecionar os melhores testemunhos e estimar a massa de urânio presente em cada uma delas. A partir da contagem dessas emissões pôde-se obter as atividades radioativas das amostras.

\subsection{MEV/EDS}

As amostras coletadas nas dependências do CCR/IPEN e aquelas simuladas com o composto $\mathrm{UF}_{4}$ padrão passaram por um processo de captura de partículas com fita adesiva para fixação no suporte (stub) do MEV/EDS (Figura 31). O intuito deste procedimento foi localizar possíveis partículas de urânio presentes no esfregaço e caracterizá-las quanto a sua forma (MEV), pois os diferentes processos de fabricação formam partículas distintas. Tais formatos de partículas constituem uma das impressões digitais do processo e contribuem para a determinação da origem do material. Além disso, foi realizada a caracterização da composição atômica por EDS, com o objetivo de se determinar por qual composto de urânio a partícula foi formada. Estas análises foram realizadas em quatro medições replicadas, com tempo de aquisição em 120 s, magnificação de 1500x e selecionando-se apenas os elementos químicos que compunham essa partícula (U e F). 


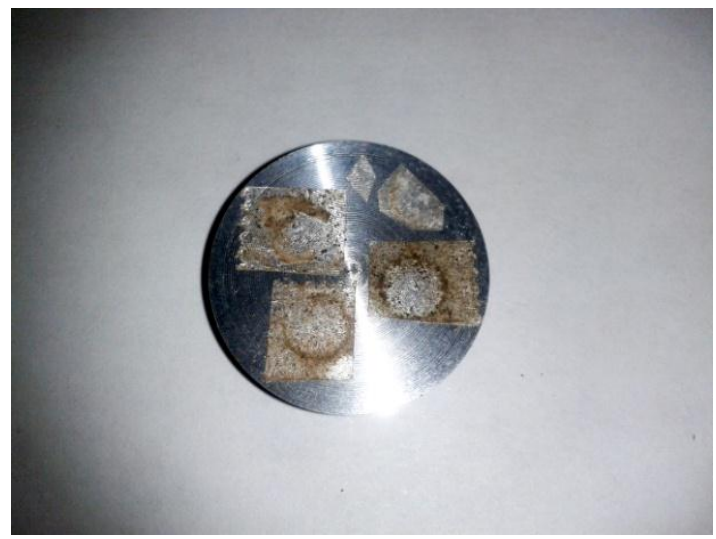

Figura 31 - Particulas coletadas nas amostras de esfregaço em fita adesiva e colocadas em um suporte (stub) para análise por $M E V$.

\subsection{Análise por LA-HR-ICP-MS}

No contexto deste trabalho, o objetivo da análise das amostras de esfregaço por LA-HR-ICP-MS é determinar a composição isotópica das partículas de urânio presentes nessas amostras. Esse dado é um dos mais importantes para o processo de salvaguardas nucleares, pois fornece o enriquecimento do material no isótopo ${ }^{235} \mathrm{U}$.

A validação do método foi realizada com a análise do padrão CRM (Certified Reference Material - Material de Referência Certificado) 125-A, que é uma pastilha de $\mathrm{UO}_{2}$ certificada pelo NBL (New Brunswick Laboratory). O material usado para a composição desse padrão foi produzido em um único lote pela CNFD (Westinghouse Commercial Fuel Division), Columbia, Carolina do Sul. A fração atômica foi apresentada na Tabela 3. 
Tabela 3 - Valores certificados para a fração atômica da pastilha de $\mathrm{UO}_{2}$. Dados apresentados com suas incertezas expandidas $(U)$ em nível de confiança de $95 \%(k=2)$.

\begin{tabular}{c|c}
\hline Isótopo & fração atômica $\pm \mathbf{U}(\boldsymbol{\%})$ \\
\hline${ }^{\mathbf{2 3 5}} \mathbf{U}$ & $4,0574 \pm 0,0028$ \\
${ }^{\mathbf{2 3 8}} \mathbf{U}$ & $95,9049 \pm 0,0029$ \\
${ }^{234} \mathbf{U}$ & $0,0374 \pm 0,0003$ \\
${ }^{\mathbf{2 3 6}} \mathbf{U}$ & $0,0003 \pm 0,0002$ \\
\hline
\end{tabular}

\subsection{Amostras simuladas}

As amostras de esfregaço simuladas foram preparadas a partir de padrões de $\mathrm{UF}_{4} \mathrm{e}$ $\mathrm{U}_{3} \mathrm{Si}_{2}$, com a finalidade de se comparar com as amostras de esfregaço reais e para a validação das medidas de atividade radioativa e de composição isotópica (Amostra B). Elas também foram utilizadas para comparação das micrografias adquiridas por MEV. Nessas amostras, foram utilizadas diferentes massas de urânio, conforme a Tabela 4:

Tabela 4 - Massa de urânio utilizada nas amostras de esfregaço padrão preparadas em laboratório. Dados apresentados com suas incertezas expandidas $(U)$ em nível de confiança de $95 \%(k=2)$.

\begin{tabular}{c|c}
\hline Amostra & Massa (mg) $\pm \mathbf{U}$ \\
\hline $\mathbf{A}\left(\mathbf{U}_{\mathbf{3}} \mathbf{S i}_{\mathbf{2}}-\mathbf{I P E N}-\mathbf{1 9 , 8 5 \%}{ }^{\mathbf{2 3 5}} \mathbf{U}\right)$ & $11 \pm 2$ \\
$\mathbf{B}\left(\mathbf{U}_{\mathbf{3}} \mathbf{S i}_{\mathbf{2}}-\mathbf{I P E N}-\mathbf{0 , 7 9 5 \%}{ }^{\left.{ }^{235} \mathbf{U}\right)}\right.$ & $3 \pm 2$ \\
$\mathbf{C}\left(\mathbf{U F}_{\mathbf{4}}-\mathbf{C E A}-\mathbf{0 , 7 8 9 \%}{ }^{\left.{ }^{235} \mathbf{U}\right)}\right.$ & $9 \pm 2$ \\
$\mathbf{D}\left(\mathbf{U}_{\mathbf{3}} \mathbf{S i}_{\mathbf{2}}-\mathbf{I P E N}-\mathbf{1 9 , 8 5 \%}{ }^{\left.{ }^{\mathbf{2 3 5}} \mathbf{U}\right)}\right.$ & $3 \pm 2$ \\
\hline
\end{tabular}




\subsection{Amostragem real}

A coleta das amostras de esfregaço foi realizada no setor de processamento químico de urânio do CCN (Centro de Combustível Nuclear) do IPEN, que declara que manuseia urânio com porcentagem atômica de ${ }^{235} \mathrm{U}$ com até $20 \%$ em massa atômica $(25 ; 85)$. Nesse centro, o composto $\mathrm{UF}_{6}$ é convertido a $\mathrm{UF}_{4}$, que são os compostos utilizados na fabricação do combustível para o reator IEA-R1m. Numa etapa posterior o composto $\mathrm{UF}_{4}$ é transformado em urânio metálico pela adição de $\mathrm{Mg}^{0}$ e finalmente em $\mathrm{U}_{3} \mathrm{Si}_{2}$ pela adição de $\mathrm{Si}^{0}$ (Figura 32).

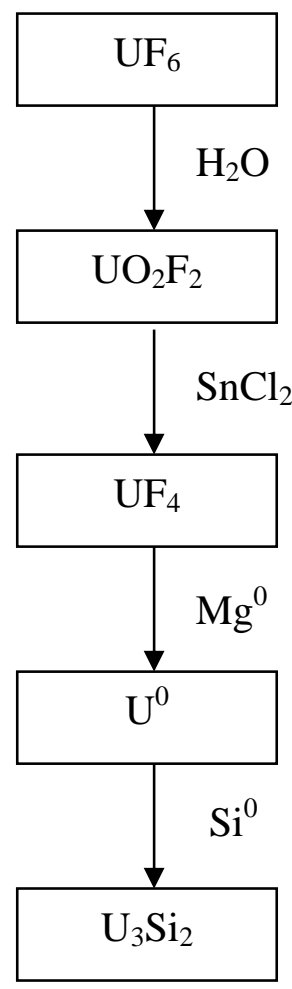

Figura 32 - Etapas de produção do U3Si2 efetuadas pelo CCN/IPEN.

As amostras foram coletadas em sete pontos distintos, desde o corredor que dá acesso à instalação até pontos mais internos nos quais se manuseiam os compostos de 
urânio. A Figura 33 apresenta o mapa da instalação que produz o $\mathrm{UF}_{4} \mathrm{e}$ os pontos onde foram coletadas as sete amostras de esfregaço:

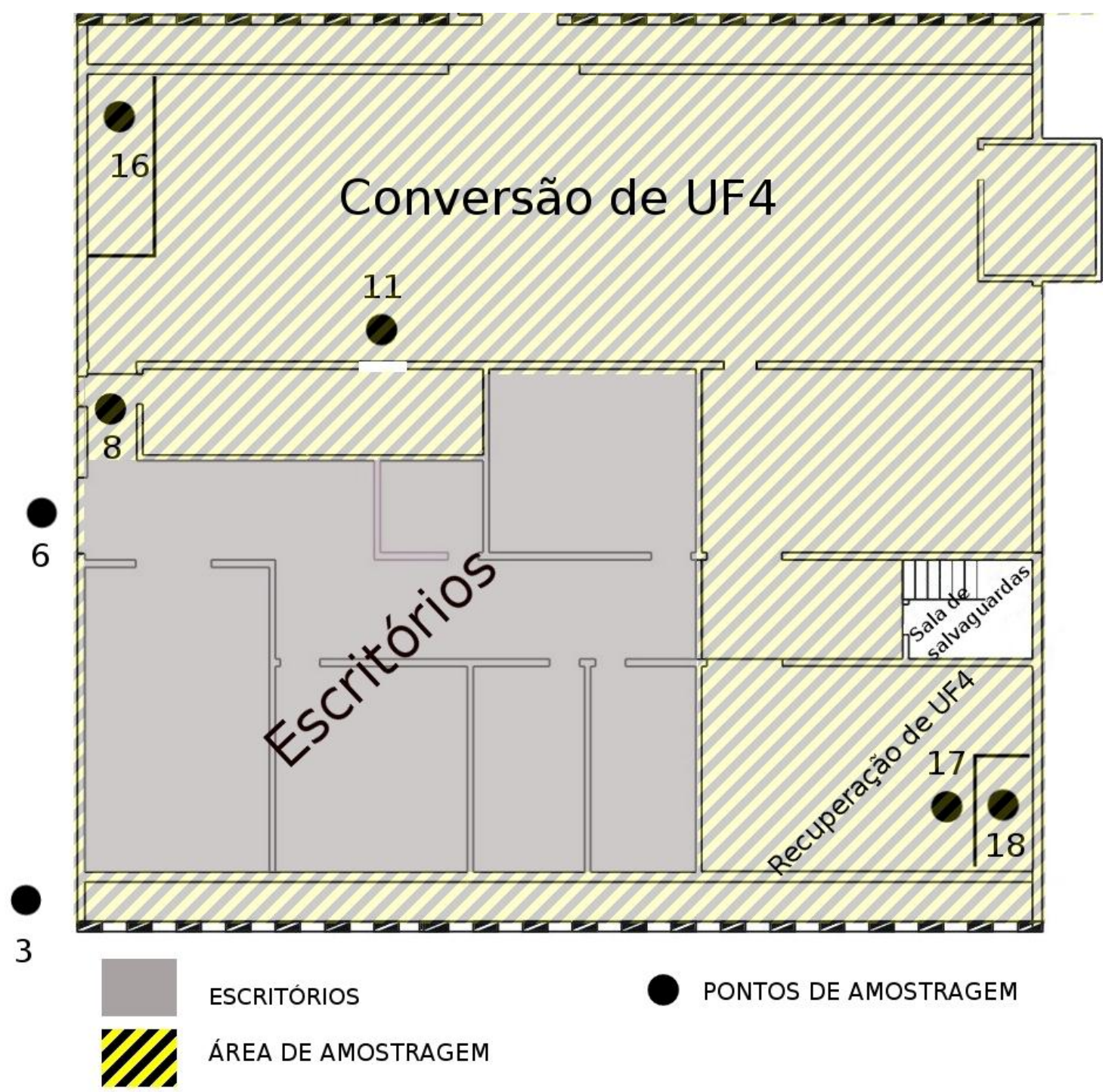

Figura 33 - Mapa da área de coleta com a localização do local em que foi realizado o esfregaço.

A coleta dos esfregaços foi realizada com filtros de papel de $5,1 \mathrm{~cm}$ de diâmetro, em uma área de $100 \mathrm{~cm}^{2}$. Uma vez coletados, eles foram armazenados em recipientes vedados e estéreis. A Figura 34 apresenta o kit para coleta das amostras e uma amostra de esfregaço real coletada na instalação. 


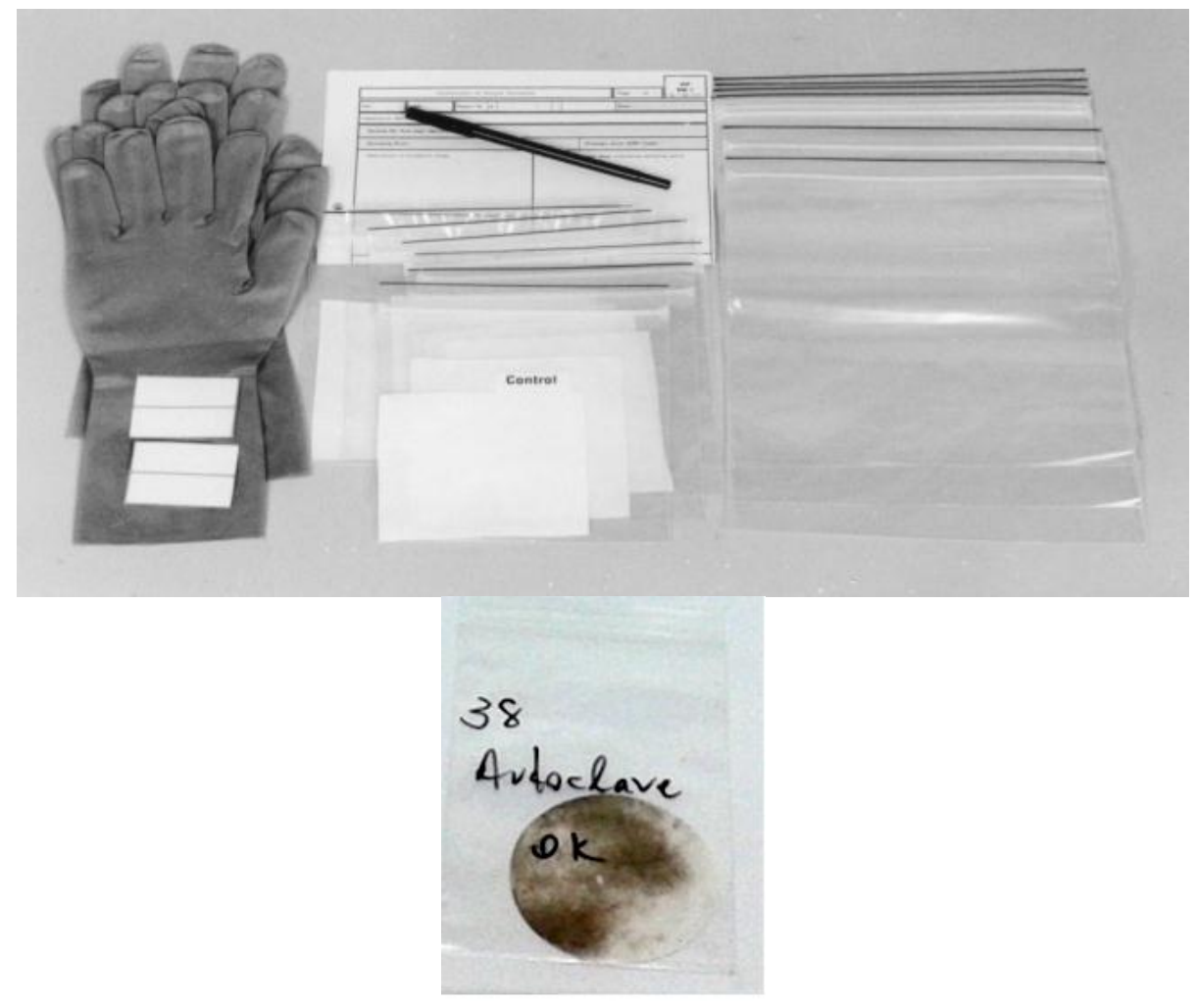

Figura 34 - Kit para a coleta das amostras de esfregaço (29) e uma amostra real.

As amostras reais foram comparadas com as amostras de referência que o laboratório possui, fornecidas pela ABACC; com o tetrafluoreto de urânio $\left(\mathrm{UF}_{4}\right)$ natural, que é um padrão químico levemente enriquecido - $(0,789 \pm 0,074) \%$ em massa de ${ }^{235} \mathrm{U}-$ proveniente do CEA (Commissariat a L'Énergie Atomique), França; siliceto de urânio $\left(\mathrm{U}_{3} \mathrm{Si}_{2}\right)-(19,848 \pm 0,051) \%$ em massa de ${ }^{235} \mathrm{U}(86)$ e proveniente do combustível nuclear produzido nas instalações do CCN do IPEN, que é caracterizado pelo LCQ/CQMA. Essas comparações foram efetuadas com o intuito de validar a metodologia proposta. 


\subsection{Instrumentos}

As medições de razão isotópica de urânio foram realizadas utilizando-se um HRICP-MS equipado com multiplicador de elétrons simples (ELEMENT1, Thermo Electron Corp., Bremen, Germany, 1996). Esse equipamento possui um sistema analisador de dupla focalização de íons com geometria reversa (Nier-Johnson), sendo um analisador magnético seguido de um analisador eletrostático. Em conjunto com o HR-ICP-MS, foi utilizado um instrumento de ablação a laser, modelo LUV-266X (New Wave Research - Merchantek, Carlsbad - CA, USA), equipado com um laser Nd:YAG com comprimento de onda de 266 nm. O material ablacionado foi transportado por um fluxo de argônio para o plasma.

Para a análise morfológica das partículas contidas no esfregaço, foi utilizada uma técnica de coleta com fita dupla-face para que se pudesse fixar a amostra no suporte (stub) do microscópio eletrônico de varredura. O instrumento utilizado foi um TableTop Hitachi TM 3000, com aceleração de $15 \mathrm{kV}$. Ele foi configurado para o modo de elétrons retroespalhados (backscattered electrons - BSE). A caracterização química foi realizada através da técnica de espectroscopia de energia dispersiva de raios-x (EDS), que utiliza um sensor SDD de $30 \mathrm{~mm}^{2}$ e possui resolução de $135 \mathrm{eV}$, por um sistema Quantax 70.

Para a medição das emissões alfa, foi utilizado um contador Ludlum 2929 em conjunto com o módulo 43-10-01 (Sweetwater, TX - USA). Esse instrumento conta com um cintilador $\mathrm{ZnS}(\mathrm{Ag})$, janela de $0,4 \mathrm{mg} / \mathrm{cm}^{2}$ e eficiência de $49 \%$ para ${ }^{238} \mathrm{U}$.

\subsection{Otimização do LA-HR-ICP-MS}

Os ajustes para o ICP-MS, como calibração de massa, foram realizados em baixa resolução, introduzindo as amostras por via úmida a uma concentração de $10 \mathrm{ngg}^{-1} \mathrm{de}$ solução de ${ }^{115}$ In, alcançando-se sensitividade de cerca de $1 \times 10^{6} \mathrm{cps}$.

As principais condições operacionais da técnica LA-HR-ICP-MS foram estabelecidas com a utilização do padrão de referência SRM (Standard Reference Material - Material de Referência Padrão) NIST 610, que possui concentração de $(461,5 \pm 1,1)$ $\mu g g^{-1}$ de urânio e foi preparado com forma de bastão e depois fatiado. Sua matriz é 
composta por $72 \% \mathrm{SiO}_{2}, 12 \% \mathrm{CaO}, 14 \% \mathrm{Na}_{2} \mathrm{O}$ e $2 \% \mathrm{Al}_{2} \mathrm{O}_{3}(32,38)$. Em cada uma das ablações foram alterados os principais parâmetros do sistema LA-HR-ICP-MS, tais como potência de rádio frequência $(\mathrm{RF})$, diâmetro do feixe do laser e posição do eixo z (foco do laser). Esses ajustes foram executados com tempo de pré-ablação e de aquisição de dados de 1 minuto em um único ponto.

Os parâmetros otimizados do sistema de ablação a laser foram: pré-ablation de 60s;

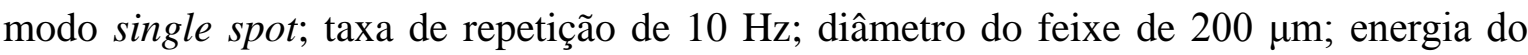
laser em $40 \%(0,096 \mathrm{~mJ})$; densidade de energia do laser a $0,31 \mathrm{~J} / \mathrm{cm}^{2}$ e posição do eixo $\mathrm{z}$ em 1,125 $\mathrm{mm}$ acima da superfície da amostra. Os parâmetros otimizados foram apresentados na Tabela 5, conforme procedimento descrito por Marin et al. $(87 ; 88)$.

Tabela 5 - Parâmetros otimizados para o sistema LA-HR-ICP-MS.

\begin{tabular}{|c|c|c|}
\hline Parâmetros & Via úmida* & Ablação a laser \\
\hline RF power $(W)$ & 1240 & 1000 \\
\hline Cooling gas $\left(\operatorname{lmin}^{-1}\right)$ & 16,00 & 16,00 \\
\hline Auxiliary gas $\left(\operatorname{lmin}^{-1}\right)$ & 0,91 & 0,96 \\
\hline Sample gas $\left(\operatorname{lmin}^{-1}\right)$ & 1,060 & 1,434 \\
\hline Resolution & LOW & LOW \\
\hline Run and passes & $3 \times 1$ & $10 \times 2$ \\
\hline Mass windows (\%) & $150 \%$ & $5 \%$ \\
\hline Samples per peak & 20 & 800 \\
\hline Search window (\%) & $100 \%$ & $150 \%$ \\
\hline Integration window (\%) & $100 \%$ & $100 \%$ \\
\hline Integration type & Average & Average \\
\hline Scan type & Escan & Escan \\
\hline Repetition rate $(\mathrm{Hz})$ & - & 10 \\
\hline Laser beam diameter $(\mu \mathrm{m})$ & - & 200 \\
\hline Laser energy $(\mathrm{mJ})$ & - & 0,096 \\
\hline Laser energy density $\left(\mathrm{Jcm}^{-2}\right)$ & - & 0,31 \\
\hline Defocusing (mm) & - & 1,125 \\
\hline
\end{tabular}

*Configuração para calibração do ICP-MS. 


\section{TRATAMENTO DOS DADOS}

\subsection{Atividade radioativa}

A atividade de um material nuclear é dada pela taxa de emissões, em um determinado intervalo de tempo, de partículas alfa, beta ou gama que são provenientes dos átomos que o compõe. A unidade do S.I. para atividade radioativa é o Becquerel (Bq), que corresponde a uma desintegração por segundo. O urânio emite principalmente partículas alfa, portanto para determinar sua atividade pode-se utilizar um detector do tipo Geiger acoplado com um contador.

\subsection{Atividade medida}

A expressão que foi utilizada para fornecer a atividade das amostras analisadas nesse estudo depende de parâmetros de construção do instrumento utilizado para a medição da taxa de decaimento e é dado pela seguinte equação:

$$
A=\frac{N-N o}{\text { Ei.Es.F.60 }}
$$

Em que:

$\mathrm{N}=$ contagens da amostra;

No $=$ contagens de fundo;

$\mathrm{Ei}=$ eficiência da sonda;

Es $=$ eficiência de emissão da fonte e

$\mathrm{F}=$ fator de transferência do esfregaço. 


\subsection{Fórmula empírica para atividade}

O urânio é frequentemente caracterizado no meio ambiente e no rejeito radioativo gerado pelas instalações nucleares, que processam esse elemento em diversos graus de enriquecimentos no isótopo ${ }^{235} \mathrm{U}$. Essas caracterizações compreendem: a espectrometria alfa para medições da atividade de cada isótopo do urânio; medida de massa total de urânio e medições das razões isotópicas por espectrometria gama e espectrometria de massas (89).

A partir de dados empíricos e interpolações matemáticas é possível ajustar uma função que forneça a atividade total de urânio devido às emissões alfa, partindo do nível de enriquecimento isotópico em ${ }^{235} \mathrm{U}$, conforme a equação abaixo proposta por Rucker et al. (89):

$$
A_{\text {empírica }}=0,19192+0,64333 .\left(w t \%{ }^{235} U\right)-0,00025 \cdot\left(w t \%{ }^{235} U\right)^{2}
$$

Em que:

$\mathrm{wt} \%{ }^{235} \mathrm{U}=$ porcentagem de enriquecimento isotópico em ${ }^{235} \mathrm{U}$.

\subsection{Fator de discriminação de massa nas medidas de razão isotópica}

A discriminação de massa ocorre quando os íons positivamente carregados formados no plasma sofrem ação da força repulsiva de Coulomb, resultando na perda de transmissão através das lentes ópticas iônicas. Isso ocorre devido aos íons mais leves serem mais defletidos que os pesados, tornando a força repulsiva dependente da diferença de massas entre os isótopos. Portanto, existe um fator de correção para cada isótopo, que pode ser calculado por leis lineares, exponenciais ou potencias. Esta correção é feita com a utilização de um padrão para corrigir os dados obtidos das medições das amostras. Nesse estudo foi utilizada a lei linear por se adequar melhor à técnica ICP-MS $(87 ; 90 ; 35 ; 34)$. Essa lei é expressa pelas seguintes equações:

$$
C F=\frac{\left(f_{m d}-1\right)}{\Delta m}
$$


Em que,

$\mathrm{CF}=$ discriminação de massa;

$\mathrm{f}_{\mathrm{md}}=$ fator de discriminação de massa e

$\Delta_{\mathrm{m}}=$ diferença nominal entre as massas.

Com:

$$
f_{m d}=\frac{R_{\text {certificado }}}{R_{\text {medido }}}
$$

Em que,

$\mathrm{f}_{\mathrm{md}}=$ fator de discriminação de massa;

$\mathrm{R}_{\text {certificado }}=$ razão isotópica certificada e

$\mathrm{R}_{\text {medido }}=$ razão isotópica medida.

Uma vez calculada a discriminação de massa, a razão isotópica é corrigida pela expressão (5):

$$
R_{c o r r}=R_{m}(1+C F)^{\delta m}
$$

Em que,

$\mathrm{R}_{\text {corr }}=$ razão isotópica medida corrigida pela discriminação de massa $(\mathrm{CF})$;

$\mathrm{R}_{\text {meas }}=$ razão isotópica medida;

$\mathrm{CF}=$ discriminação de massa e

$\delta_{\mathrm{m}}=$ diferença nominal de massa. 


\subsection{Fração atômica}

A fração atômica indica o grau de enriquecimento isotópico e é dada pela seguinte equação:

$$
F_{235}=100 x \frac{\frac{{ }^{235} U}{{ }^{238} U}}{1+\frac{{ }^{234} U}{{ }^{238} U}+\frac{{ }^{235} U}{{ }^{238} U}+\frac{{ }^{236} U}{{ }^{238} U}}
$$

Em que,

$$
\begin{aligned}
& \mathrm{F}^{235}=\text { fração atômica para o isótopo }{ }^{235} \mathrm{U}, \\
& { }^{234} \mathrm{U} /{ }^{238} \mathrm{U}=\text { razão isotópica }{ }^{234} \mathrm{U} /{ }^{238} \mathrm{U}, \\
& { }^{235} \mathrm{U} /{ }^{238} \mathrm{U}=\text { razão isotópica }{ }^{235} \mathrm{U} /{ }^{238} \mathrm{U} \text { e } \\
& { }^{236} \mathrm{U} /{ }^{238} \mathrm{U}=\text { razão isotópica }{ }^{236} \mathrm{U} /{ }^{238} \mathrm{U} .
\end{aligned}
$$

\subsection{Estimativa de incerteza}

Toda medição está sujeita a algum grau de variabilidade. Esta variabilidade pode vir de diferentes fontes, como: o instrumento de medição, o item medido, o ambiente, etc. e representam a incerteza analítica da medida. A estimativa da incerteza considera todas as fontes de erros do procedimento analítico. Portanto, ao ser associada com uma medida analítica permite um melhor entendimento do processo de medição. E torna-se uma parte essencial desse processo, pois facilita a inter-comparação de resultados obtidos por diferentes laboratórios e metodologias.

A estimativa da incerteza é comumente baseada no ISO GUM (91). Nela estão contempladas as incertezas de todas as componentes da padrão das medições, que são combinadas quadraticamente de forma a se obter a incerteza combinada (uc) (eq. 16).

$$
u_{c}=\sqrt{\sum_{i=1}^{n} u\left(x_{i}\right)^{2}}
$$


Em que,

$\mathrm{u}_{\mathrm{c}}=$ incerteza combinada;

$\mathrm{u}(\mathrm{xi})=$ incerteza padrão.

A incerteza padrão $\mathrm{u}\left(\mathrm{x}_{\mathrm{i}}\right)$ para cada entrada é avaliado pelos seguintes critérios: tipo A, que considera o desvio padrão da média de uma série de observações; tipo B, que considera todas as informações disponíveis, tais como as fontes externas, certificados de calibração, incerteza do fabricante e o julgamento baseado na experiência do especialista.

$O$ resultado final de uma medição é expresso de forma a permitir um fator de abrangência associado ao nível de confiança escolhido, que é determinado a partir do cálculo do grau de liberdade efetivo (eq. 17) e seu correspondente fator de abrangência dado pela distribuição t-Student. Isto se faz necessário para garantir que a distribuição de uma pequena população amostral seja Gaussiana.

$$
v_{e f f}=\frac{u_{c}^{4}}{\sum_{i=1} \frac{u_{i}^{4}}{v_{i}}}
$$

Em que,

$\nu_{\text {eff }}=$ grau de liberdade efetivo;

$\mathrm{u}_{\mathrm{c}}=$ incerteza combinada;

$\mathrm{u}_{\mathrm{i}}=$ incertezas padrões;

$v_{\mathrm{i}}=$ grau de liberdade de cada incerteza padrão.

Um nível de confiança de $95.45 \%$ corresponde a um fator de abrangência de $\mathrm{k}=2,00$ e um nível de confiança de 99.73 a um k=3,00. Portanto, a incerteza expandida (U) é calculada pela seguinte equação:

$$
U=u_{c} k
$$

Em que,

$\mathrm{U}=$ incerteza expandida; 


$$
\begin{aligned}
& \mathrm{u}_{\mathrm{c}}=\text { incerteza combinada; } \\
& \mathrm{k}=\text { fator de abrangência. }
\end{aligned}
$$

Os resultados das medições foram expressos como a média das medidas seguidos pelos valores de suas incertezas expandidas, na forma: $\bar{y} \pm U$ (91).

\subsection{Precisão}

O termo precisão é utilizado em circunstâncias específicas de medições. Ela pode ser expressa por meio da repetitividade de uma medida, considerando-se as mesmas condições de metodologia, instrumentação, observador e local. A repetitividade pode ser quantificada por meio do desvio padrão relativo (DPR). 


\section{RESULTADOS E DISCUSSÕES}

Todas as sete amostras $(3,6,8,11,16,17$ e 18) mais os quatro padrões (A, B, C e D) foram analisados conforme a metodologia descrita. Porém, serão apresentados e discutidos com maior ênfase os resultados das amostras 17 e 18, pois elas foram coletadas diretamente do local em que se manipula o urânio enriquecido - uma na bancada e a outra no chão em frente a esta bancada. Além disso, elas foram as que apresentaram as melhores estatísticas de contagens para o conjunto de técnicas utilizadas. Para a técnica de MEV/EDS foram apresentados apenas os resultados da amostra 18, pois o processo de identificação de partículas de urânio em amostras de esfregaço é extremamente demorado e o intuito foi utilizar esta técnica para complementar a análise das razões isotópicas.

As amostras 3, 6, 8, 11 e 16 apresentaram atividade radioativa muito baixa - da ordem de grandeza do ruído de fundo do contador Geiger utilizado. Com base nesta primeira avaliação o inspetor poderia decidir coletar outros testemunhos, aumentando o número de pontos de coleta e, consequentemente, a probabilidade de encontrar algum indício de atividade radioativa. No entanto, esses testemunhos que não apresentaram atividade ainda são representativos com respeito ao enriquecimento no isótopo ${ }^{235} \mathrm{U}$, pois mesmo apresentando baixas contagens alfa eles possuem algumas partículas de urânio e indícios de enriquecimento. Esses dois últimos parâmetros não podem ser determinados em campo pelo inspetor, que conta apenas com um contador Geiger portátil. Portanto, para estas amostras serão apresentados somente os resultados das medições de suas razões isotópicas.

\subsection{Medição da atividade radioativa}

Utilizando os valores empíricos fornecidos pela equação 11 e tendo conhecimento da massa de urânio contida em cada amostra simulada pôde-se estimar sua atividade em becquerel. Desta forma foi possível compará-las com os valores das atividades calculados pela equação 10 (atividade medida). A Tabela 6 apresenta os dados brutos das contagens do branco, das amostras padrão (A, B, C e D) e das amostras reais (17 e 18). 
Tabela 6 - Contagens de emissão, em contagens por minuto (cpm,) alfa do branco e das amostras $A, B, C, D, 17$ e 18. Dados apresentados com suas incertezas expandidas $(U)$ em nível de confiança de $95 \%(k=2)$ para as amostras sumuladas.

\begin{tabular}{c|c}
\hline & $($ contagens $\pm \boldsymbol{U}) \boldsymbol{c p m}$ \\
\hline Branco & $5 \pm 1$ \\
Amostra A & $20827 \pm 49$ \\
Amostra B & $151 \pm 1$ \\
Amostra C & $490 \pm 4$ \\
Amostra D & $3167 \pm 20$ \\
Amostra 17 & $902 \pm 11$ \\
Amostra 18 & $658 \pm 17$ \\
\hline
\end{tabular}

Segundo Rucker et al. (89), pode-se associar o enriquecimento isotópico em ${ }^{235} \mathrm{U}$ com a atividade total da amostra em $\mathrm{Bqg}^{-1}$ a partir de uma expressão empírica obtida por interpolações matemáticas (equação 11). Ao se relacionar a atividade medida, que é dada em $\mathrm{Bq}$, com a atividade total empírica $\left(\mathrm{Bqg}^{-1}\right)$, é possível estimar a massa de urânio existente em cada amostra de esfregaço real.

A Tabela 7 apresenta esses valores calculados $\left(\mathrm{A}_{\mathrm{m}}\right)$ e empíricos $\left(\mathrm{A}_{\text {empírica }}\right)$ para as amostras estudadas. Com base nessa tabela, verificou-se que a diferença relativa entre as atividades empírica e medida foram de - $0,21 \%, 6,9 \%, 5,5 \%$ e - $0,42 \%$, respectivamente para as amostras A, B, C e D. Esses valores foram considerados suficientes para a préavaliação dessas amostras, uma vez que representam bem a ordem de grandeza da quantidade de urânio presente. Além disso, deve-se considerar a qualidade das amostras, pois, conforme a Figura 33, as amostras de esfregaço são heterogêneas. Elas apresentam uma grande quantidade de partículas espúrias. A partir desses dados foi possível estimar a quantidade de urânio presente nas amostras de esfregaço. 
Tabela 7 - Dados da massa de urânio depositada (m), contagens por minuto (cpm), atividade medida (Am) e atividade total calculada (Aempírica) das amostras de esfregaço simuladas (A, B, C e D) e das amostras de esfregaço reais (17 e 18). Dados apresentados com suas incertezas expandidas ( $U$ ) em nível de confiança de $95 \%(k=2)$.

\begin{tabular}{c|ccccc}
\hline Amostra & $\mathbf{m} \pm \mathbf{U}(\mathbf{g})$ & $\mathbf{c p m} \pm \mathbf{U}$ & $\mathbf{A}_{\mathbf{m}} \pm \mathbf{U}(\mathbf{B q})$ & $\begin{array}{c}\mathbf{A}_{\text {empírica }} \\
\left(\mathbf{B q g} \mathbf{-}^{-1}\right)\end{array}$ & $\begin{array}{c}\mathbf{A}_{\text {empírica }} \\
(\mathbf{B q})\end{array}$ \\
\hline $\mathbf{A}\left(\mathbf{U}_{\mathbf{3}} \mathbf{S i}_{\mathbf{2}}-\mathbf{I P E N}-\mathbf{1 9 , 8 5 \%}{ }^{\mathbf{2 3 5}} \mathbf{U}\right)$ & $0,011 \pm 0,001$ & $20827 \pm 98$ & $5246 \pm 142$ & 475950 & $5235 \pm 476$ \\
$\mathbf{B}\left(\mathbf{U}_{\mathbf{3}} \mathbf{S i}_{\mathbf{2}}-\mathbf{I P E N}-\mathbf{0 , 7 9 5 \%}{ }^{\left.{ }^{235} \mathbf{U}\right)}\right.$ & $0,003 \pm 0,001$ & $151 \pm 2$ & $67 \pm 4$ & 24020 & $72 \pm 24$ \\
$\mathbf{C}\left(\mathbf{U F}_{\mathbf{4}}-\mathbf{C E A}-\mathbf{0 , 7 8 9 \%}{ }^{\left.{ }^{335} \mathbf{U}\right)}\right.$ & $0,009 \pm 0,001$ & $490 \pm 8$ & $220 \pm 6$ & 25876 & $233 \pm 24$ \\
$\mathbf{D}\left(\mathbf{U}_{\mathbf{3}} \mathbf{S i}_{\mathbf{2}}-\mathbf{I P E N}-\mathbf{1 9 , 8 5 \%}{ }^{\left.{ }^{235} \mathbf{U}\right)}\right.$ & $0,003 \pm 0,001$ & $3167 \pm 40$ & $1434 \pm 42$ & 475950 & $1428 \pm 476$ \\
$\mathbf{1 7}-\mathbf{2 0} \%$ & $0,00085 \pm 0,00008$ & $902 \pm 11$ & $407 \pm 15$ & 475950 & - \\
$\mathbf{1 8}-\mathbf{2 0} \%$ & $0,00062 \pm 0,00008$ & $658 \pm 17$ & $296 \pm 17$ & 475950 & - \\
\hline
\end{tabular}




\subsection{Caracterização por MEV e EDS}

A caracterização de amostras de esfregaço por MEV traz valiosas informações a respeito da presença de urânio e da rota de produção de matérias nucleares, que podem ser determinada pela forma da partícula encontrada.

As amostras de esfregaço apresentam uma grande quantidade e variedade de partículas normalmente presentes no meio ambiente. Dentre elas pode-se citar o urânio. Como esse elemento possui número atômico $(Z)$ elevado, o $\mathrm{MEV}$ foi configurado no modo de elétrons retroespalhados (backscattering - BSE), com aceleração de 15 kV e magnificação de 1200x. Esse modo favorece esses elementos, pois os elétrons provenientes da sonda do microscópio eletrônico são retroespalhados e captados por sensores específicos que deixam esses elementos em evidência. A Figura 35 (a) mostra claramente essa situação, na qual as partículas mais brilhantes são compostas de urânio, enquanto as menos brilhantes são compostas por outros elementos de número atômico menor. Nessa mesma figura, pode-se notar que há aglomerados de partículas de alto brilho e algumas partículas isoladas. Aumentando-se a magnificação do MEV sobre a área em que se encontrava uma única partícula de cerca de $60 \mu \mathrm{m}$, notou-se a presença de outras partículas mais escuras e menores em cima dela, conforme Figura 35 (b). 


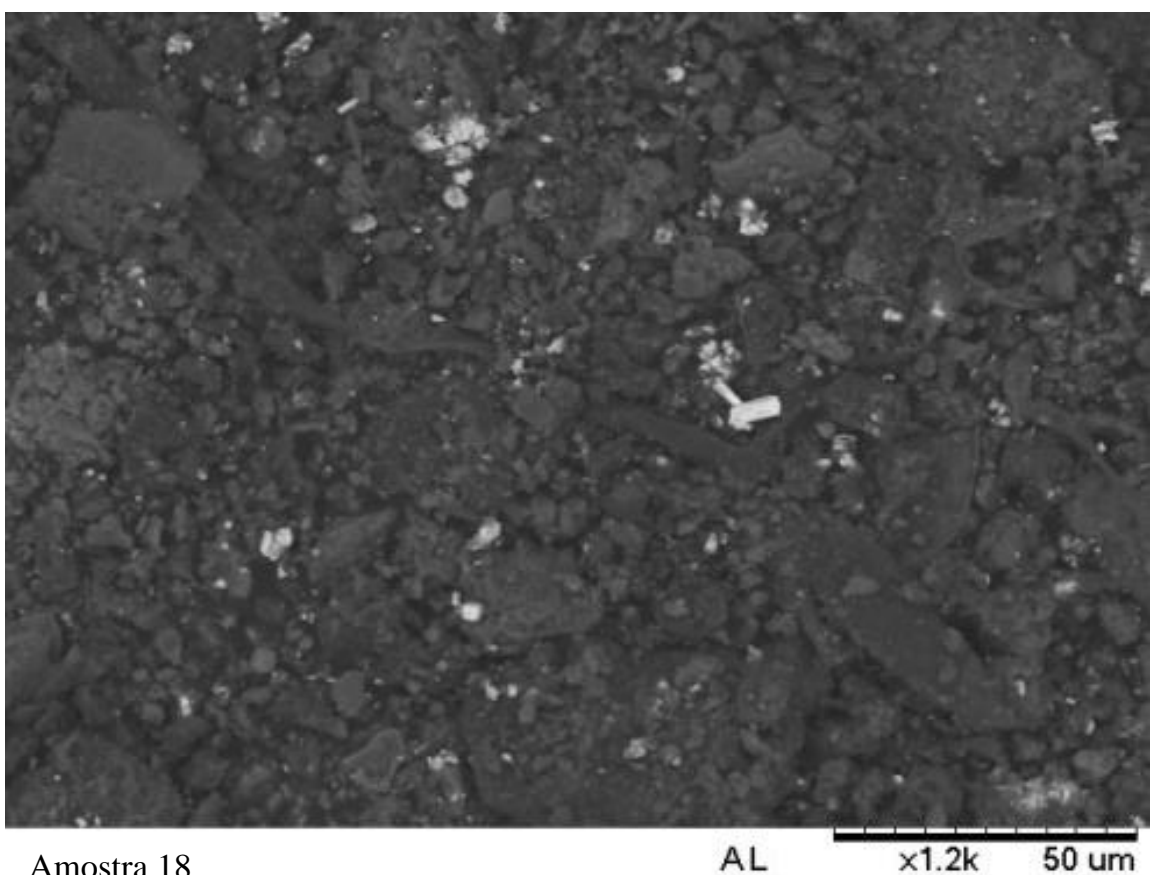

(a)

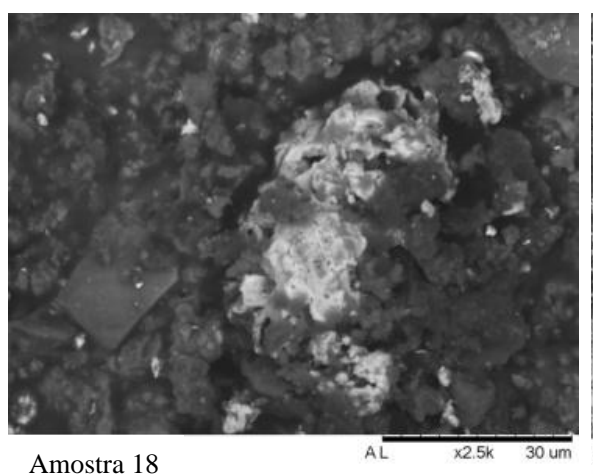

(b)

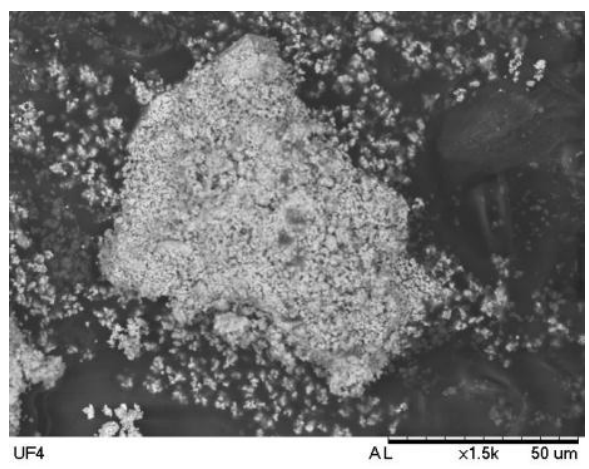

(c)

Figura 35 - Imagens obtidas por MEV: (a) amostra 18 com magnificação de 1200x; (b) amostra 18 com magnificação de 2500x e (c) padrão de UF $F_{4}$ com magnificação de 1500x.

A Figura 35 (c) representa a micrografia do padrão $\mathrm{UF}_{4}$ fornecido pela $\mathrm{CEA}$. Ao se comparar a morfologia dessa partícula padrão com as imagens obtidas para a amostra 18 (Figura 35 (b)), notou-se uma grande semelhança entre elas. A fim de se verificar essa semelhança de um modo qualitativo e semi-quantitativo, foi efetuada uma análise por EDS para composição atômica da amostra real 18 e do padrão de $\mathrm{UF}_{4}(\operatorname{amostra} \mathrm{C})$. 
A Figura 36 apresenta o espectro EDS e o mapa de distribuição dos elementos de uma das leituras observadas da amostra C. Nela, pôde-se notar qualitativamente a presença dos picos de U (3,164 keV - linha M e 3,3 keV) e F $(0,677 \mathrm{keV}$ - linha $\mathrm{K} \alpha)$ previamente selecionados, bem como do pico de $0 \mathrm{keV}$ que é intrínseco dessa técnica.

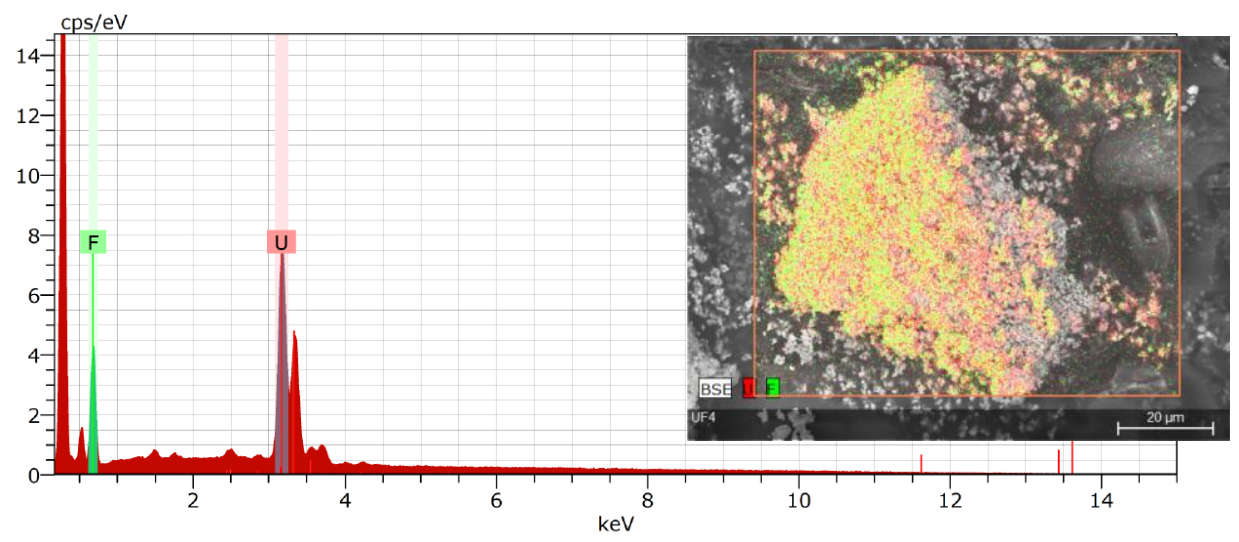

Figura 36 - Espectro EDS e mapa de distribuição dos elementos do padrão $\mathrm{UF}_{4}$ do CEA com os elementos $U$ e F selecionados.

Os valores obtidos para cada leitura da amostra $\mathrm{C}$ por MEV/EDS estão apresentados na Tabela 8. A média desses valores e a incerteza associada às leituras foram de $(22,13 \pm 0,10) \%$ para U e $(77,88 \pm 0,10) \%$ para F. Esses resultados representam uma diferença de 10,65 \% e 2,65 \%, respectivamente, para $\mathrm{U}$ e F, dos valores da composição atômica esperada teoricamente para uma partícula de $\mathrm{UF}_{4}$, que é de $20 \%$ de U e $80 \%$ de F. Ainda na Tabela 10 , estão apresentados os valores da composição atômica da amostra 18 (amostra de esfregaço real), cujas médias e incertezas expandidas foram $(20,62 \pm 0,26) \%$ para $U$ e $(79,38 \pm 0,26) \%$ para F. Esses valores apresentam uma diferença relativa ao padrão de 6,81\% para U e 1,93\% para F. Esses resultados reforçam os indícios de que a partícula analisada era de $\mathrm{UF}_{4}$. Portanto, pôde-se estimar com um bom grau de segurança, que a partícula da amostra real (amostra 18) tem a mesma composição atômica da amostra padrão $(\mathrm{C})$. 
Tabela 8 - Composição atômica do padrão $\mathrm{UF}_{4}$ e da amostra 18. Dados apresentados com suas incertezas expandidas $(U)$ em nível de confiança de $95 \%(k=2)$.

\begin{tabular}{cccc}
\hline Composição atômica $\pm \mathbf{U}(\%)$ & \multicolumn{2}{c}{ Composição atômica $\pm \mathbf{U}(\%)$} \\
\hline Padrão $\mathbf{U F}_{\mathbf{4}} \mathbf{C E A}-$ & \multicolumn{2}{c}{ Amostra 18} \\
$\left(\mathbf{0 , 7 8 9} \pm \mathbf{0 , 0 7 4 )} \%{ }^{235} \mathbf{U}\right.$ & $\mathbf{U}$ & $\mathbf{F}$ \\
$\mathbf{U}$ & $\mathbf{F}$ & $(20,62 \pm 0,26) \%$ & $(79,38 \pm 0,26) \%$ \\
\hline
\end{tabular}

Ao se aplicar a técnica de EDS sobre uma partícula isolada com cerca de $30 \mu \mathrm{m}$ encontrada na amostra 18, obteve-se a imagem e o espectro apresentado na Figura $37 . \mathrm{Na}$ imagem, pôde-se notar a presença de impurezas na superfície da partícula. Os elementos que compõem essas impurezas foram discriminados no espectro de EDS e são: $\mathrm{Na}, \mathrm{Al}, \mathrm{Si}, \mathrm{S}, \mathrm{N}$ e C. Esses elementos são comuns em amostras de esfregaço e representam uma importante fonte de interferência no sinal analítico para LA-HR-ICP-MS, causando instabilidade e, consequentemente, baixa precisão e acurácia.

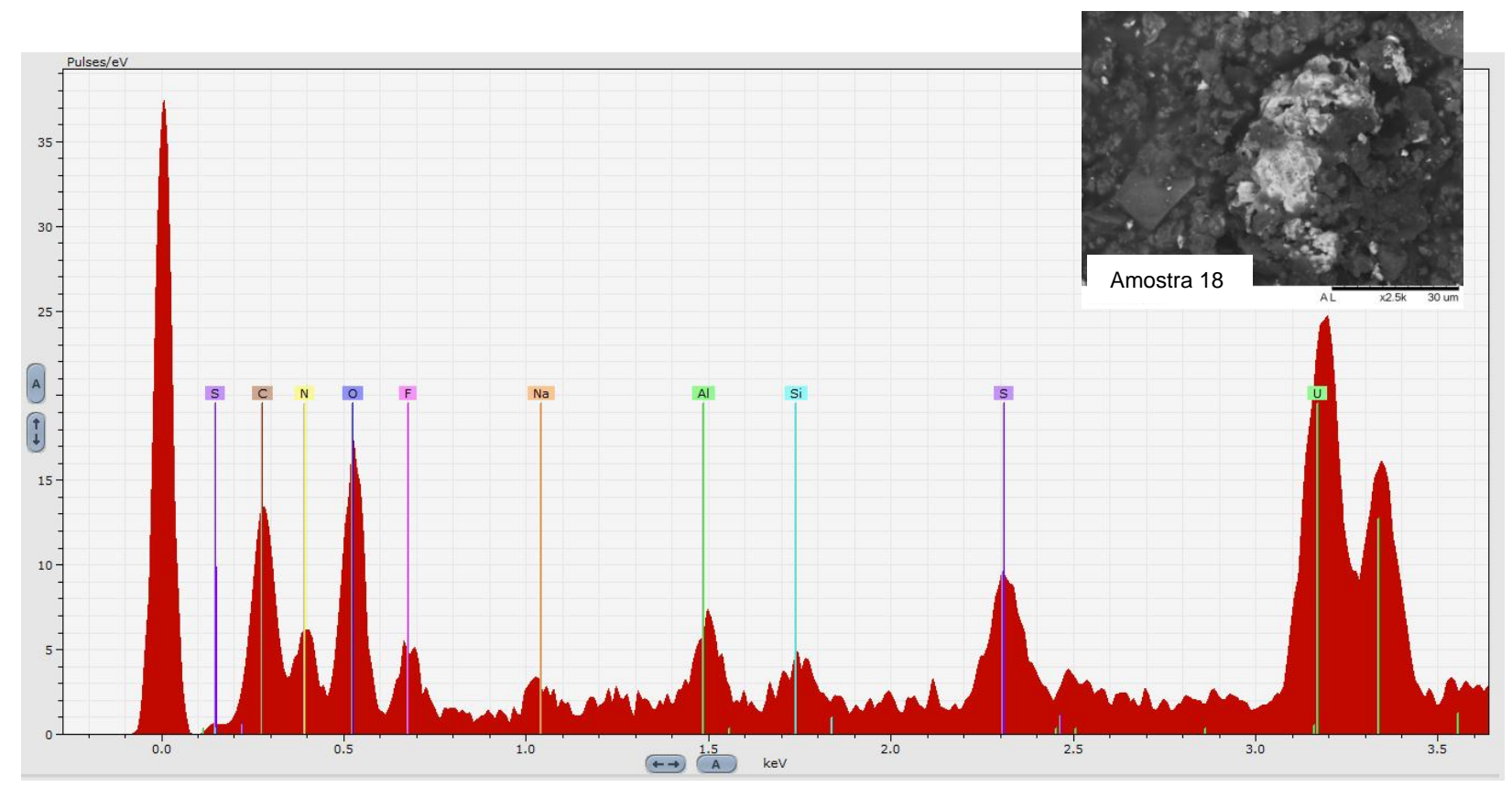

Figura 37 - Espectro EDS amostra 18 com todos os elementos. 


\subsection{Otimização do sistema LA-HR-ICP-MS}

O primeiro parâmetro avaliado foi a potência de RF. Dessa forma, a potência foi variada de $850 \mathrm{~W}$ a $1000 \mathrm{~W}$ com o intuito de se determinar qual valor de potência resultaria no menor DPR (Figura 38). Após este experimento pôde-se determinar que a potência ideal de trabalho seriam $1000 \mathrm{~W}$, pois nesse valor o DPR das medições foi de 5,4\% para o isótopo majoritário ${ }^{238} \mathrm{U}$.

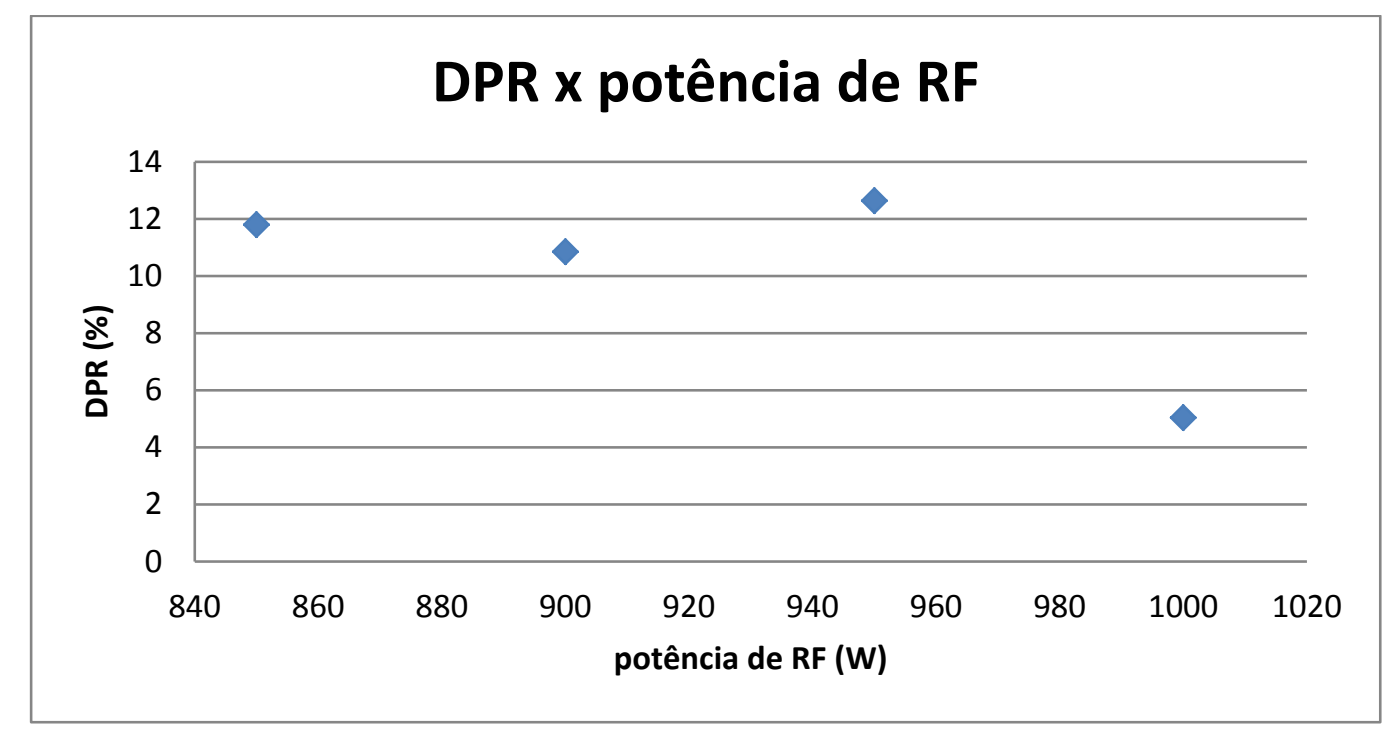

Figura 38-Dados do ajuste da potência de RF (rádio freqüência) do LA-HR-ICP-MS. 
Mantendo a potência de RF em 1000 W, foi investigada a posição do eixo x (Figura 39). Ela determina o foco do feixe do laser sobre a superfície da amostra. A posição do eixo z foi variada de 0 (foco na superfície da amostra) até $-3,285 \mathrm{~mm}$, ou seja, com o foco em 3,285 mm acima da superfície da amostra.

O ponto ótimo da posição do eixo x, com base no menor DPR $(7,2 \%)$ para o isótopo ${ }^{238} \mathrm{U}$, foi em $-1,125 \mathrm{~mm}$. Este ponto de foco faz com que uma quantidade menor do substrato seja arrancado durante o processo de ablação. Portanto, uma menor quantidade é levada para o plasma, causando menos interferência em sua estabilidade.

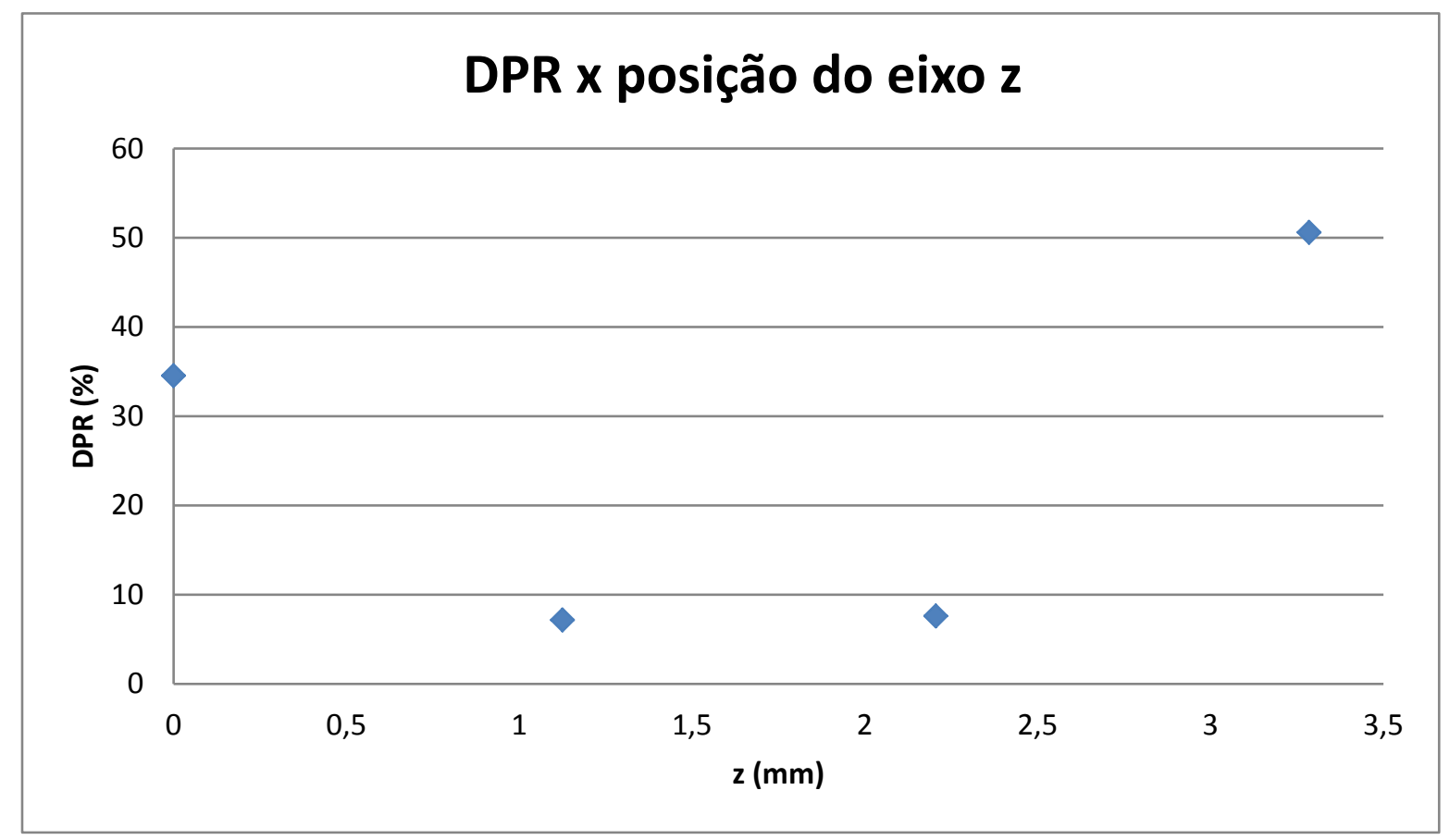

Figura 39 - Dados do ajuste do eixo z do sistema LA-HR-ICP-MS. Este eixo determina o ponto de foco do feixe de laser sobre a superfície da amostra.

Mantendo os dois últimos parâmetros constantes foi estudado o último parâmetro do sistema LA-HR-ICP-MS - o diâmetro do feixe do laser. Conforme a Figura 40, foi estabelecido o diâmetro de trabalho em $200 \mu \mathrm{m}$, pois o DPR referente a esse diâmetro foi de $9,2 \%$. 


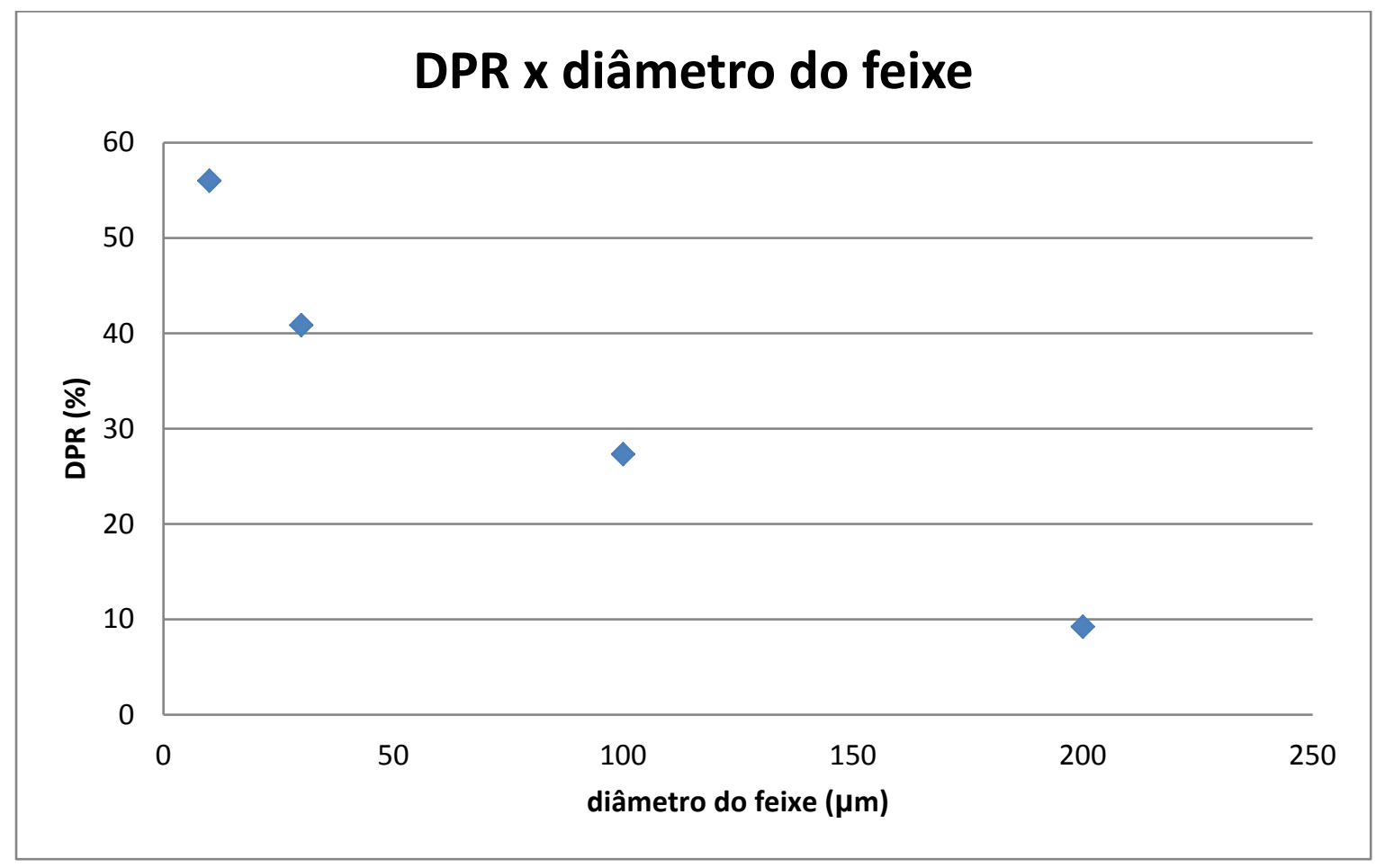

Figura 40 - Dados do ajuste do diâmetro do feixe do laser.

Esses ajustes preliminares foram de grande importância para que se garantisse a sensibilidade e a estabilidade desta técnica. Isso permitiu que se atingisse uma boa precisão, com DPR variando de $1,55 \%$ a 7,6 \% (Tabela 9) para a leitura do padrão de referência certificado (CRM 125-A), que foi realizada após essses ajustes. Esses valores estão de acordo com valores obtidos por outros autores $(77 ; 92 ; 93)$. Ao comparar os resultados das medições do padrão com o seu respectivo certificado encontrou-se uma diferença relativa de aproximadamente $-4,9 \%$, para a razão isotópica maioritária $\left({ }^{235} \mathrm{U} /{ }^{238} \mathrm{U}\right)$. Este é um outro indicativo da qualidade da técnica empregada. 
Tabela 9 - Dados das medições de razão isotópica do padrão CRM - 125-A.

\begin{tabular}{ccc}
\hline & Leituras & DPR $(\boldsymbol{\%})$ \\
\hline & 0,00045 & 2,08 \\
${ }^{234} \mathbf{U} /{ }^{\mathbf{2 3 8}} \mathbf{U}$ & 0,00044 & 1,96 \\
& 0,00045 & 2,17 \\
& 0,00045 & 2,33 \\
& 0,00047 & 2,51 \\
& 0,0420 & 1,55 \\
${ }^{235} \mathbf{U} /{ }^{\mathbf{2 3 8}} \mathbf{U}$ & 0,0418 & 1,76 \\
& 0,0422 & 2,45 \\
& 0,0423 & 1,91 \\
& 0,0419 & 2,06 \\
${ }^{236} \mathbf{U} /{ }^{\mathbf{2 3 8}} \mathbf{U}$ & 0,000036 & 7,60 \\
& 0,000033 & 6,14 \\
& 0,000030 & 6,25 \\
& 0,000033 & 6,14 \\
\hline
\end{tabular}

Ainda com base nos dados da Tabela 9 foram construídos os gráficos de DPR x razão isotópica, que foi apresentado na Figura 41. 


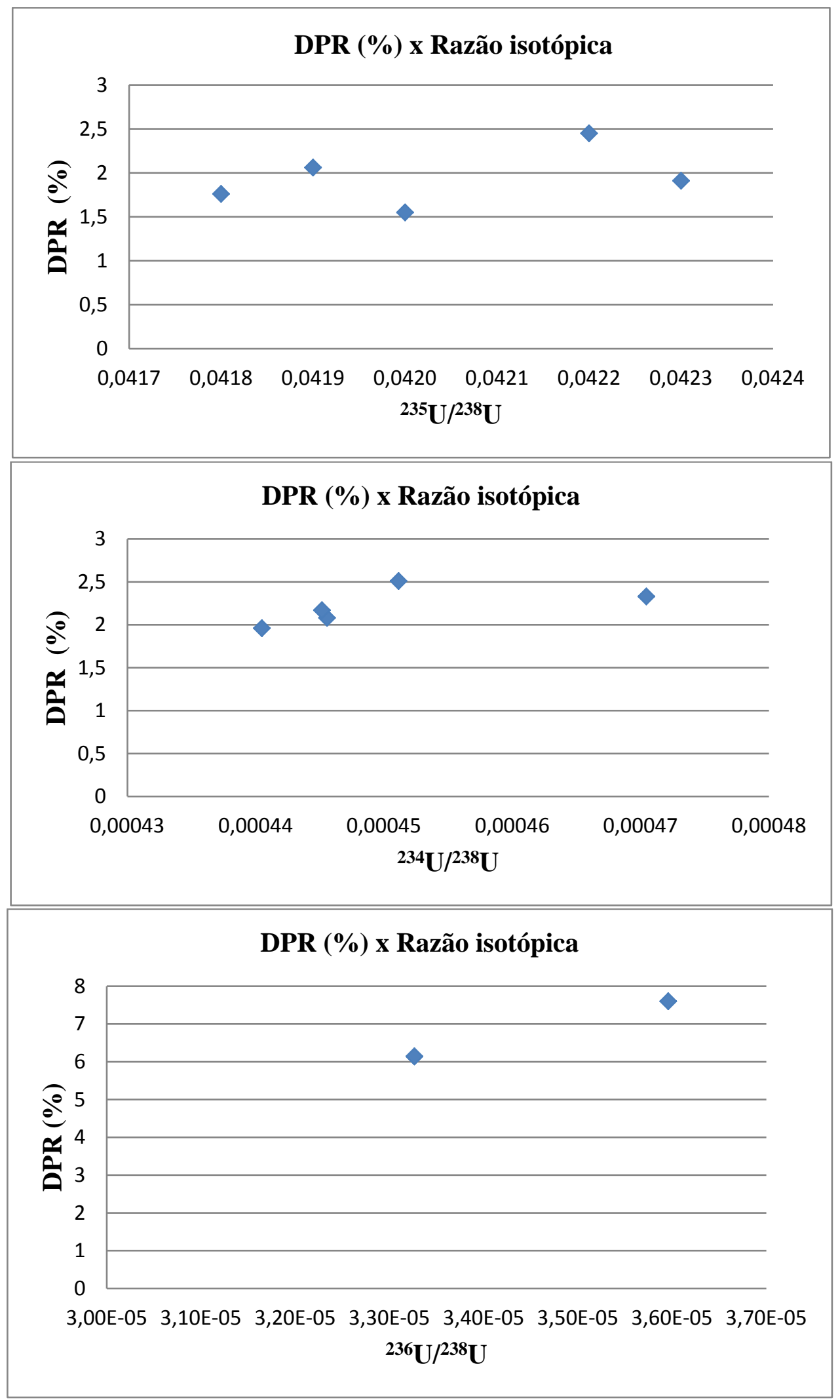

Figura 41 - DPR x razões isotópicas medidas do padrão certificado CRM-125A. 
Conforme pode ser observado na Figura 38, as razões isotópicas ${ }^{235} \mathrm{U} /{ }^{238} \mathrm{U}$ e ${ }^{234} \mathrm{U} /{ }^{238} \mathrm{U}$ apresentaram uma boa precisão e estabilidade para esse tipo de técnica. Isso demonstra a robustez da técnica LA-HR-ICP-MS para se medir a razão isotópica de urânio. Porém, ao se medir a razão ${ }^{236} \mathrm{U} /{ }^{238} \mathrm{U}$ obteve-se maior instabilidade que pode ser atribuída a sua baixa contagem estatística, devido à sua baixa concentração no padrão.

\subsection{Composição isotópica medida para a amostra de esfregaço simulada B}

Os resultados obtidos para as razões isotópicas ${ }^{234} \mathrm{U} /{ }^{238} \mathrm{U}$ e ${ }^{235} \mathrm{U} /{ }^{238} \mathrm{U}$ (Tabela 10) apresentaram desvio padrão relativo (DPR) de 3,0 \% e 1,2 \%, respectivamente. Já o isótopo

${ }^{236} \mathrm{U}$ não foi detectado. A precisão da razão ${ }^{235} \mathrm{U} /{ }^{238} \mathrm{U}$, representada pelo DPR, é compatível com a incerteza expandida percentual ( $u \%)$, pois eles estão na mesma ordem de grandeza. Esse valor está de acordo com aquelas reportadas por outros autores. Pointurier et al. divulgou DPR de 12,7 \% ao analisar amostras de partículas individuais de urânio (92) e 9,6 \% ao analisar uma amostra cedida durante um programa de comparação interlaboratorial (93). Já LLoyd et al. obteve DPR variando de 0,2 \% a 1,8 \% ao analisar urânio empobrecido em solos. (94).

Tabela 10 - Dados relativos à razão isotópica corrigida (Rt), incerteza expandida $(U)$, incerteza percentual (u\%), graus de liberdade efetivos (veff) e fator de abrangência ( $k$ ) para as medições da amostra simulada $B$ - cujo nível de enriquecimento é próximo do natural..

\begin{tabular}{ccccccc}
\hline & & $\mathbf{R}_{\mathrm{t}}$ & $\mathbf{U}(\mathbf{k}=\mathbf{2})$ & $\mathbf{u} \%(\boldsymbol{\%})$ & $\mathbf{v}_{\text {eff }}$ & $\begin{array}{c}\mathbf{k} \\
\text { (t-Student) }\end{array}$ \\
\hline Amostra & ${ }^{235} \mathbf{U} /{ }^{238} \mathbf{U}$ & 0,00719 & 0,00020 & 2.8 & 7 & 2,51 \\
simulada B & ${ }^{234} \mathbf{U} /{ }^{238} \mathbf{U}$ & 0,000076 & 0,000031 & 41 & 7 & 2,51 \\
\hline
\end{tabular}

A razão isotópica ${ }^{235} \mathrm{U} /{ }^{238} \mathrm{U}$ corrigida $(\mathrm{Rt})$ pelo fator de discriminação de massa foi $0,00719 \pm 0,00020$, que representa uma fração atômica de $(0,71 \pm 0,07) \%$. Este resultado 
representa uma diferença relativa de $-2,1 \%$ quando comparado com o valor recentemente recomendado $(0,7257 \%)$ para o urânio natural (94). Já a razão ${ }^{234} U /{ }^{238} U$ não está de acordo com os resultados obtidos por Kappel et al. (95) que também analisou urânio natural, porém pela técnica LA-MC-ICP-MS. A diferença relativa entre esses resultados foi de cerca de $37 \%$. Este resultado pode ser explicado pela baixa estatística de contagens.

Foi realizado um teste t-Student devido ao pequeno número de replicatas $(n=6)$, pois esse número é considerado baixo para garantir que a distribuição seja normal. Esse teste depende dos graus de liberdade efetivos $\left(v_{\text {eff }}\right)$ e da probabilidade da distribuição. O fator de abrangência $(\mathrm{k})$ obtido pelo teste $\mathrm{t}-$ Student foi 2,51 , indicando que a distribuição foi levemente diferente da distribuição normal.

\subsection{Análise isotópica das amostras reais}

Após a análise de morfologia e composição atômica por EDS foi realizada a análise da composição isotópica das amostras coletadas no CCR e do padrão CRM 125-A. Para tanto,

foram selecionados os isótopos ${ }^{234} \mathrm{U},{ }^{235} \mathrm{U},{ }^{236} \mathrm{U}$ e ${ }^{238} \mathrm{U}$ para o cálculo das razões ${ }^{234} \mathrm{U} /{ }^{238} \mathrm{U}$, ${ }^{235} \mathrm{U} /{ }^{238} \mathrm{U}$ e ${ }^{236} \mathrm{U} /{ }^{238} \mathrm{U}$. Foram realizadas seis replicatas em cada amostra, com tempo de ablação de quinze segundos.

Um efeito que deve ser considerado durante as medições de razões isotópicas de urânio é a discriminação de massa. Por esse motivo, a razão isotópica deve ser corrigida para cada isótopo. Os efeitos da discriminação de massa para o LA-HR-ICP-MS são devidos a uma complexa série de inter-relações entre as interações laser-alvo, eficiência de transporte e o comportamento da quantidade ablacionada no plasma. Quanto menor o comprimento de onda do feixe do laser, menos sensíveis são os efeitos da discriminação de massa. Isso se dá pelo fato de feixes mais energéticos promovem uma maior ionização do material, pois os efeitos devido à condução de calor são menores. Para minimizar esses efeitos, pode-se realizar a ablação com uma densidade de potência de $10^{9} \mathrm{Wcm}^{-2}$ (77) e utilizar do recurso de se desfocalizar o feixe do laser $(87 ; 88 ; 70)$, permitindo que apenas uma pequena quantidade de material da superfície da amostra seja retirada. A Tabela 11 apresenta os valores do fator de 
discriminação de massa obtidos.

Tabela 11 - Fator de discriminação de massa obtido pela análise do padrão CRM 125-A pela técnica LA-HR-ICP-MS. Dados apresentados com suas incertezas expandidas em nível de confiança de $95 \%(k=2)$.

\begin{tabular}{c|c}
\hline Razão & Fator de discriminação de massa $\left(\mathbf{f}_{\mathbf{m}}\right) \pm \mathbf{U}$ \\
\hline${ }^{234} \mathrm{U}^{238} \mathrm{U}$ & $0,7680 \pm 0,0031$ \\
${ }^{235} \mathrm{U}^{238} \mathrm{U}$ & $0,9790 \pm 0,0016$ \\
${ }^{236} \mathrm{U} /{ }^{238} \mathrm{U}$ & $0,32 \pm 0,11$ \\
\hline
\end{tabular}

É esperado que o fator de discriminação de massas (Tabela 11) seja o mais próximo possível da unidade, como foi obtido para a razão ${ }^{235} \mathrm{U} /{ }^{238} \mathrm{U}$. Entretanto, os valores do $\mathrm{f}_{\mathrm{m}}$ para as razões ${ }^{234} \mathrm{U} /{ }^{238} \mathrm{U}(0,7680 \pm 0,0031) \mathrm{e}^{236} \mathrm{U} /{ }^{238} \mathrm{U}(0,32 \pm 0,11)$ apresentaram valores muito diferentes da unidade, devido à baixa abundância desses isótopos que implica em uma baixa estatística de contagens e à instabilidade intrínseca ao LA-HR-ICP-MS. Porém, os valores do DPR dessas medidas foram 1,3\%, 0,2 \% e 7,6 \%, respectivamente ${ }^{234} \mathrm{U}{ }^{238} \mathrm{U},{ }^{235} \mathrm{U} /{ }^{238} \mathrm{U}$ e ${ }^{236} \mathrm{U} /{ }^{238} \mathrm{U}$. Esse baixo DPR para as razões ${ }^{234} \mathrm{U} /{ }^{238} \mathrm{U}$ e ${ }^{235} \mathrm{U} /{ }^{238} \mathrm{U}$ indicam a boa precisão da técnica utilizada, apesar da baixa exatidão.

Com o intuito de se obter dados metrologicamente rastreáveis foram calculadas as estimativas de incertezas de cada medida. Para a estimativa da incerteza expandida (U) foram consideradas as seguintes componentes: o desvio padrão da média das medições (incerteza do tipo A) e as incertezas das abundâncias isotópicas divulgadas no certificado de calibração do padrão CRM 125-A (incerteza do tipo B) como mostrado na Tabela 4. A contribuição da incerteza referente ao certificado de calibração do padrão tem distribuição normal, e seu divisor é o fator de abrangência $(\mathrm{k}=2)$. A Tabela 12 apresenta os valores das incertezas padrão $\left(\mathrm{u}_{\mathrm{i}}\right)$ que são utilizados para o cálculo da incerteza combinada $\left(\mathrm{u}_{\mathrm{c}}\right)$, o tipo de distribuição considerado, o tipo de incerteza, o divisor, o coeficiente de correlação $\left(\mathrm{c}_{\mathrm{i}}\right)$ e os graus de liberdade $\left(\mathrm{v}_{\mathrm{i}}\right)$, que são utilizados para o cálculo da incerteza expandida $(\mathrm{U})$. 
Tabela 12 - Tabela utilizada para a estimativa das incertezas, contendo os tipos de distribuição e incerteza, incertezas padrão (ui), o divisor, o coeficiente de correlação (ci) e os graus de liberdade (vi). Os dados nela contidos são referentes à amostra 17

\begin{tabular}{|c|c|c|c|c|c|c|c|c|}
\hline \multicolumn{9}{|c|}{ Componentes da incerteza } \\
\hline Nome & $\begin{array}{c}\text { Tipo de } \\
\text { incerteza }\end{array}$ & Dist. Prob. & Divisor & $\mathbf{c}_{\mathbf{i}}$ & $\mathbf{u}_{\mathrm{i}}{ }^{235} \mathrm{U} /{ }^{238} \mathrm{U}$ & $u_{i}{ }^{234} U /{ }^{238} U$ & $\mathbf{u}_{\mathbf{i}}{ }^{236} \mathrm{U} /{ }^{238} \mathrm{U}$ & $v_{i}$ \\
\hline $\begin{array}{c}\text { Medida Padrão } \\
\text { CRM }\end{array}$ & A & $\mathrm{N}$ & 1 & 1 & 0,00006667 & 0 & 0,00000045 & 5 \\
\hline $\begin{array}{c}\text { Medida da } \\
\text { Amostra }\end{array}$ & A & $\mathrm{N}$ & 1 & 1 & 0,016 & 0,00009 & 0,00015 & 5 \\
\hline $\begin{array}{l}\text { Certificado CRM } \\
\text { isótopo de urânio } \\
\text { de interesse }\end{array}$ & B & $\mathrm{N}$ & 1 & 1 & 0,0014 & 0,00015 & 0,0001 & $\infty$ \\
\hline $\begin{array}{c}\text { Certificado CRM } \\
\text { do isótopo }{ }^{238} \mathbf{U}\end{array}$ & B & $\mathrm{N}$ & 1 & 1 & 0,000145 & 0,000145 & 0,00145 & $\infty$ \\
\hline
\end{tabular}


A incerteza devido às medições das amostras, ou seja, a repetitividade das medidas foi a maior contribuição para a incerteza da razão ${ }^{235} U /{ }^{238} U$. Isso se deve à variabilidade nas medições. Para os outros isótopos, apesar das baixas contagens estatísticas, a incerteza foi menor em razão da precisão obtida nessas medições, mas ainda assim uma das componentes mais significativas.

A Tabela 13 apresenta o valor da razão isotópica corrigida (Rt), a incerteza expandida $(\mathrm{U})$, a incerteza percentual ( $\mathrm{u} \%)$, o grau de liberdade efetivo $\left(v_{\text {eff }}\right)$ e o fator de abrangência $(\mathrm{k})$ que foram calculados com base nos dados da Tabela 11 para todas as amostras analisadas:

Tabela 13 - Dados relativos à razão isotópica corrigida (Rt), incerteza expandida $(U)$, incerteza percentual ( $u \%)$, graus de liberdade efetivos (veff) e fator de abrangência $(k)$.

\begin{tabular}{|c|c|c|c|c|c|c|}
\hline & & $\mathbf{R t}$ & $\mathbf{U}$ & $\mathrm{u} \%(\%)$ & $v_{\text {eff }}$ & $\mathbf{k}$ \\
\hline \multirow{2}{*}{ Amostra 3} & ${ }^{235} \mathrm{U} /{ }^{238} \mathrm{U}$ & 0,023 & 0,007 & 29,8 & 4 & 2,87 \\
\hline & ${ }^{234} \mathrm{U} /{ }^{238} \mathrm{U}$ & 0,00054 & 0,00011 & 20,4 & 6 & 2,65 \\
\hline \multirow{2}{*}{ Amostra 6} & ${ }^{235} \mathrm{U} /{ }^{238} \mathrm{U}$ & 0,064 & 0,006 & 9,4 & 4 & 2,87 \\
\hline & ${ }^{234} \mathrm{U} /{ }^{238} \mathrm{U}$ & 0,0019 & 0,0008 & 42,9 & 4 & 2,87 \\
\hline \multirow{2}{*}{ Amostra 8} & ${ }^{235} \mathrm{U} /{ }^{238} \mathrm{U}$ & 0,132 & 0,019 & 14,4 & 4 & 2,87 \\
\hline & ${ }^{234} \mathrm{U} /{ }^{238} \mathrm{U}$ & 0,00146 & 0,00030 & 20,6 & 4 & 2,87 \\
\hline \multirow{2}{*}{ Amostra 11} & ${ }^{235} \mathrm{U} /{ }^{238} \mathrm{U}$ & 0,145 & 0,005 & 3,5 & 4 & 2,87 \\
\hline & ${ }^{234} \mathrm{U} /{ }^{238} \mathrm{U}$ & 0,00197 & 0,00034 & 17,3 & 4 & 2,87 \\
\hline \multirow{2}{*}{ Amostra 16} & ${ }^{235} \mathrm{U} /{ }^{238} \mathrm{U}$ & 0,159 & 0,024 & 15,1 & 4 & 2,87 \\
\hline & ${ }^{234} \mathrm{U} /{ }^{238} \mathrm{U}$ & 0,0016 & 0,0004 & 24,6 & 4 & 2,87 \\
\hline \multirow{2}{*}{ Amostra 17} & ${ }^{235} \mathrm{U} /{ }^{238} \mathrm{U}$ & 0,195 & 0,032 & 16,4 & 5 & 2,65 \\
\hline & ${ }^{234} \mathrm{U} /{ }^{238} \mathrm{U}$ & 0,001749 & 0,00029 & 16,6 & $\infty$ & 2,00 \\
\hline \multirow{2}{*}{ Amostra 18} & ${ }^{235} \mathrm{U} /{ }^{238} \mathrm{U}$ & 0,211 & 0,034 & 15,8 & 5 & 2,65 \\
\hline & ${ }^{234} \mathrm{U} /{ }^{238} \mathrm{U}$ & 0,001734 & 0,00029 & 16,7 & $\infty$ & 2,00 \\
\hline
\end{tabular}


Nessa tabela, observa-se que os valores de incerteza em alguns casos estão extremamente elevados, chegando a 42,9 \% para isótopos minoritários e 29,8 \% para os majoritários. A principal razão desses resultados está associada à instabilidade da técnica frente à heterogeneidade das amostras de esfregaço. Uma melhoria nesses resultados pode ser obtida aumentando-se o número de medições realizadas por amostra. Com isso os graus de liberdade efetivos ( $\mathrm{v}_{\text {eff }}$ ) aumentariam e consequentemente $\mathrm{o}$ fator de abrangência se aproximaria mais de $\mathrm{k}=2$, garantindo uma distribuição normal. Entretanto, no escopo desse trabalho há de se considerar que a instalação declara que trabalha com urânio enriquecido em até $20 \%$. Portanto, qualquer valor obtido abaixo desse nível, fora da abrangência da incerteza pode ser considerado válido para fins de salvaguarda. Nos casos em que o valor obtido esteja dentro do fator de abrangência da incerteza da medição faz-se necessário a busca de métodos mais precisos ou de etapas complementares de purificação de amostra e separação química.

As razões isotópicas corrigidas (Rt 5/8) e exibidas na Tabela 13 não apresentaram correções elevadas para os isótopos majoritários, pois os fatores de discriminação de massa deles foram próximos à unidade. Entretanto, os isótopos minoritários apresentaram uma correção maior devido às suas baixas abundâncias e, consequentemente, baixa estatística de contagens. Um modo de melhorar essas medições seria utilizar um ICP-MS com detector do tipo multicoletor, que detecta todos os isótopos ao mesmo instante, diferentemente do utilizado nesse trabalho que detecta os isótopos de maneira sequencial.

Ao se analisar os valores das razões isotópicas e incertezas respectivas às amostras que apresentaram baixa emissão alfa $(3,6,8,11$ e 16), notou-se que elas apresentam enriquecimento no isótopo ${ }^{235} \mathrm{U}$. Desta forma, estes testemunhos não podem ser invalidados. Principalmente as amostras coletadas no exterior da instalação (3 e 6). Elas são de extrema importância para investigações forenses nucleares, pois representam uma avaliação não intrusiva e possibilitaria que se inferisse que a instalação trabalha com urânio enriquecido.

Como não há instruções para valores-alvo dos níveis de incerteza para a análise das amostras de esfregaço por qualquer técnica analítica, comparou-se a incerteza alcançada nesse estudo com aquelas alcançadas em outros estudos $(77$; 92) que utilizam a mesma técnica, conforme a Tabela 14. 
Tabela 14 - Comparação entre as incertezas expandidas percentuais (u\%) obtidas em três estudos a respeito da análise de amostras de esfregaço pela técnica LA-HR-ICP-MS.

\begin{tabular}{c|c}
\hline & $\mathbf{u \%} \mathbf{( \% )}$ \\
\hline Estudo presente & $3,5 \%$ a $29,8 \%$ \\
Varga, Z. & $1,8 \%$ a $3,0 \%$ \\
Pointurier, F. et al. & $20,7 \%$ a $28,2 \%$ \\
\hline
\end{tabular}

Comparando-se os dados da Tabela 14 notou-se que as incertezas encontradas por Pointurier et al. (41), que foram obtidas por análises de amostras de esfregaço reais, estão compatíveis com aquelas que foram encontradas nesse trabalho. Já os valores encontrados por Varga (77) (obtidos por análises de amostras de esfregaço simuladas, ou seja, sem a heterogeneidade comum às amostras reais) apresentaram uma incerteza menor, porém ainda compatível com a incerteza obtida para a amostra 11. É importante notar que a maior incerteza encontrada foi referente à amostra 3 que foi coletada fora da instalação e, além de apresentar uma extensa gama de partículas espúrias conta, com uma quantidade muito baixa de urânio. E à medida que se entra na instalação notou-se uma melhoria na estatística de contagens, com consequente diminuição da incerteza.

Com o intuito de se verificar a qualidade dos dados obtidos, foram construídos os gráficos da razão ${ }^{235} \mathrm{U} /{ }^{238} \mathrm{U}$ versus cada aquisição para as amostras 17 e 18, conforme a Figura 42. Nela nota-se que os dados estão compatíveis entre si, dentro de suas respectivas incertezas mesmo para a aquisição 3 da Figura 42 (a), que apresenta razão isotópica um pouco abaixo das demais. A linha sólida representa o padrão NIST U200 (razão ${ }^{235} \mathrm{U} /{ }^{238} \mathrm{U}=0,25126$ ), que se for comparado com a razão isotópica obtida para as amostras 17 (Figura 42 (a)) e 18 (Figura 42 (b)) nota-se que são resultados compatíveis, uma vez que a barra de incerteza dos dados obtidos sobrepõe a linha do padrão em até três vezes a incerteza. Por outro lado, essa figura também demonstra que a instalação está operando dentro do nível de enriquecimento isotópico declarado, pois a abrangência das incertezas não sobrepõe a linha do padrão enriquecido em $20 \%$. 


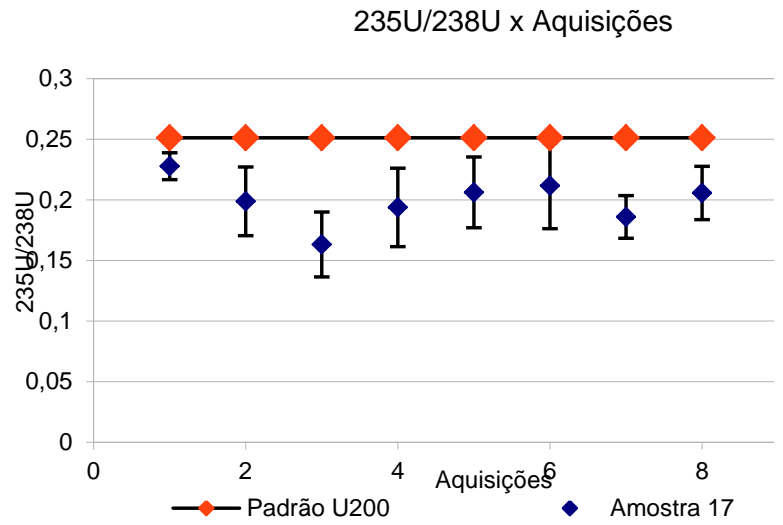

(a)

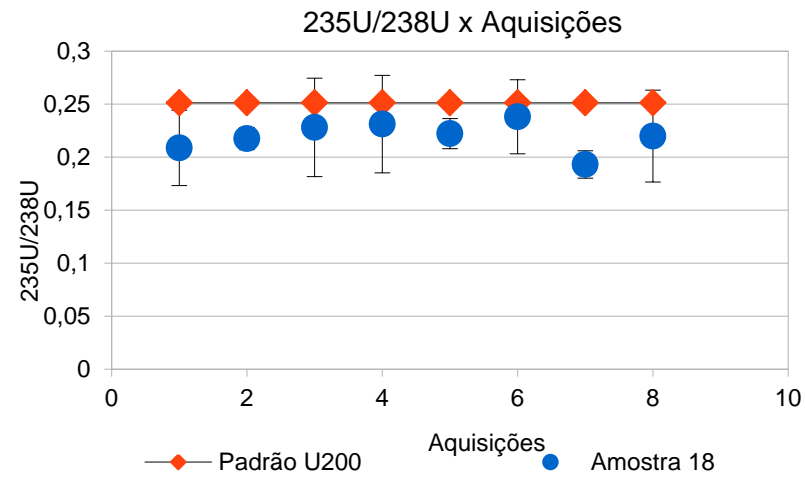

(b)

Figura 42 - Razões ${ }^{235} U{ }^{238} U$ medidas e suas respectivas incertezas expandidas $(k=2)$ para as amostras 17 (a) e 18 (b) em comparação com o padrão NIST U200.

A fim de se obter alguma informação relevante sobre a assinatura da composição isotópica de urânio da instalação construiu-se o gráfico da razão ${ }^{234} \mathrm{U} /{ }^{238} \mathrm{U}$ pela razão ${ }^{235} \mathrm{U} /{ }^{238} \mathrm{U}$ para as amostras 17 e 18, conforme Figura 43. Nela observa-se o agrupamento de suas distribuições, ou seja, elas possuem graus de enriquecimento compatíveis entre si, que era o esperado, pois elas foram coletadas no mesmo local. Essa última informação é importante para uma inspeção de salvaguarda real, pois segundo Donohue, D. L. (29) permite determinar a o processo de produção do material. O ponto mais disperso dentre as aquisições é referente à terceira replicata da amostra 17 , porém sua incerteza o torna compatível com as demais aquisições. 


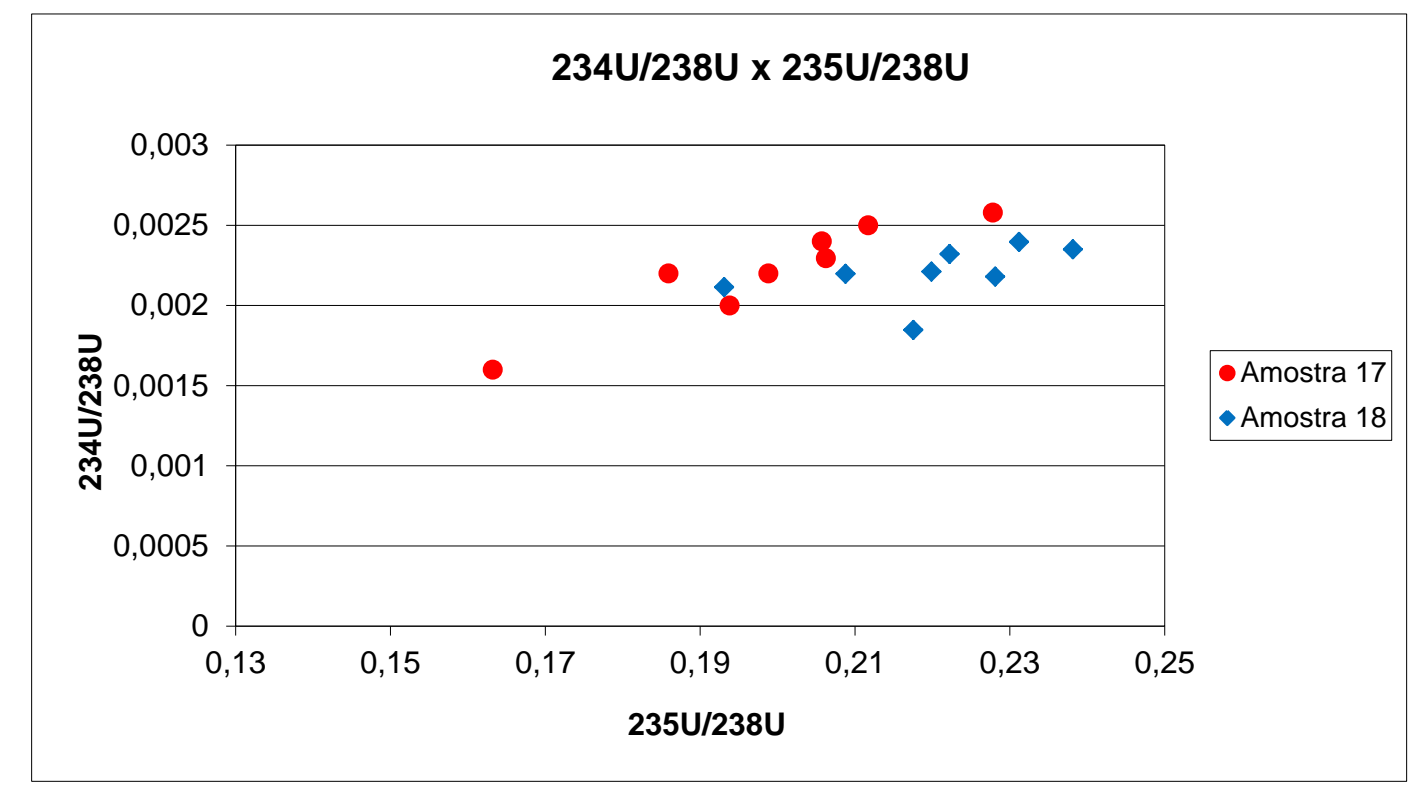

Figura 43 - Gráfico da razão isotópica ${ }^{234} U{ }^{238} U x^{235} U /^{238}$ U para as amostras 17 e 18.

Baseado nos valores das razões isotópicas apresentados na Tabela 13 a fração atômica foi calculada conforme descrito por Marin et al. $(87 ; 88)$. Esses resultados estão consolidados na Tabela 15. Os valores corrigidos das amostras 17 e 18, que apresentaram o maior nível de enriquecimento, foram de $(16,1 \pm 2,7) \%$ e $(17,3 \pm 2,8) \%$, respectivamente. Esta diferença pode ocorrer em razão da heterogeneidade da amostra e pelo fato de não se conseguir ablacionar uma partícula individualmente. Durante as análises foram ablacionados alguns aglomerados de partículas, devido limitações de resolução do conjunto óptico do sistema de ablação à laser. Isto causou instabilidade do sinal e consequente alteração na razão isotópica medida, que é diferente da situação ideal: analisar uma partícula individual. Tal procedimento permitiria medir o grau de enriquecimento sem que houvesse contaminação por partículas espúrias ou de urânio natural de origem ambiental. 
Tabela 15 - Dados consolidados dos valores de fração atômica medida $\left(F_{235}\right.$ medida $)$. Dados apresentados com suas incertezas expandidas em nível de confiança de 95\% ( $k=2$ ).

\begin{tabular}{c|c}
\hline Amostras & $\mathbf{F}_{\mathbf{2 3 5} \text { medido }} \pm \mathbf{U}(\boldsymbol{\%})$ \\
\hline $\mathbf{3}$ & $2,3 \pm 0,7$ \\
$\mathbf{6}$ & $6,0 \pm 0,6$ \\
$\mathbf{8}$ & $11,6 \pm 1,7$ \\
$\mathbf{1 1}$ & $12,61 \pm 0,44$ \\
$\mathbf{1 6}$ & $13,7 \pm 2,1$ \\
$\mathbf{1 7}$ & $16,1 \pm 2,7$ \\
$\mathbf{1 8}$ & $17,3 \pm 2,8$ \\
\hline
\end{tabular}

Analisando-se os dados de fração atômica de todas as amostras apresentados na Tabela 15 , notou-se um aumento no nível de enriquecimento no isótopo ${ }^{235} \mathrm{U}$ (Figura 44) conforme se adentra na instalação. Com base nas amostras 3 e 6, que foram coletadas fora da instalação, comprova-se a importância das amostras de esfregaço para investigações forenses e como um método de investigação e monitoração não intrusivo. 


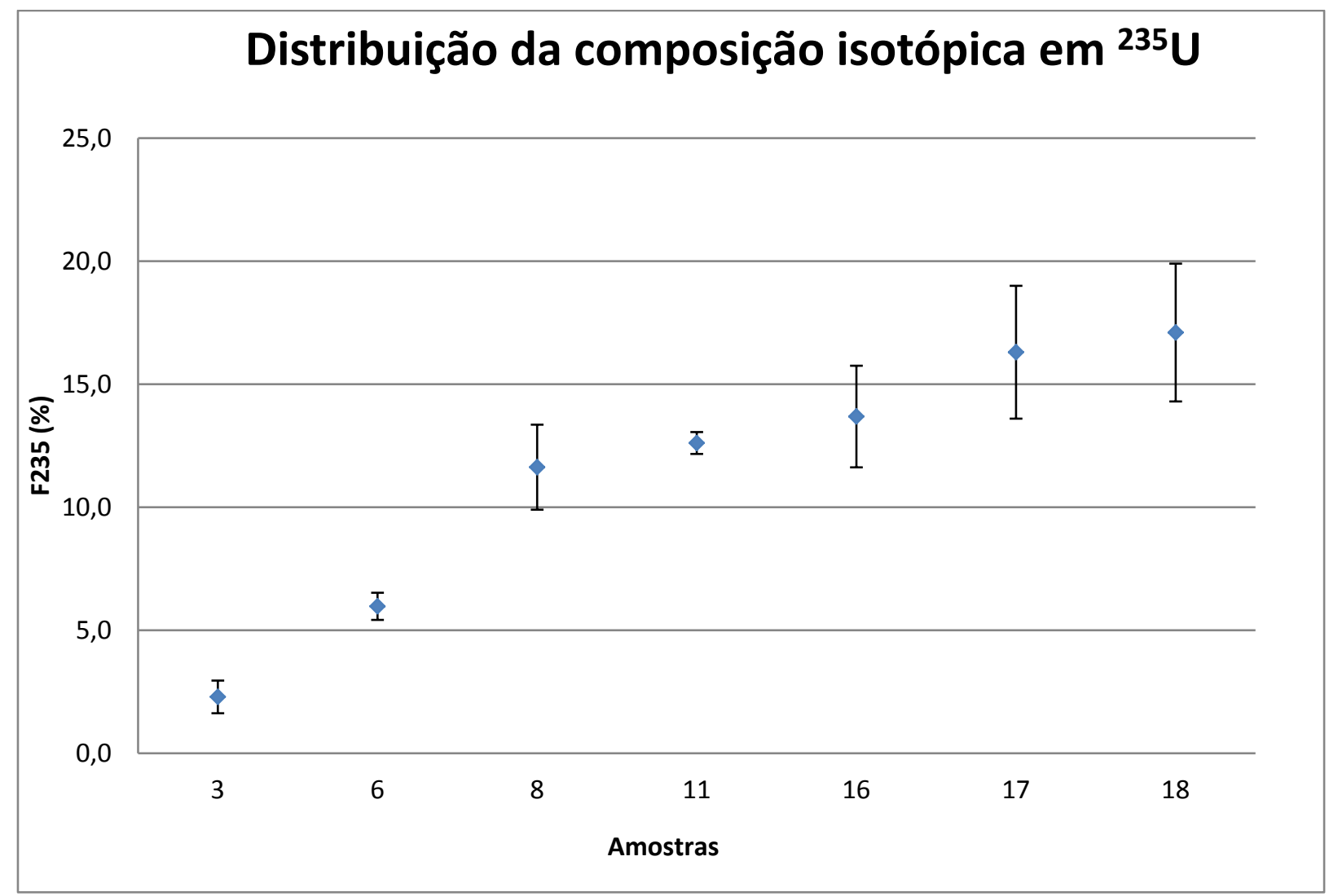

Figura 44 - Distribuição da fração atômica para as amostras analisadas. Dados apresentados com suas incertezas expandidas em nível de confiança de $95 \%(k=2)$.

Na Figura 44, observa-se claramente que a amostra coletada no exterior da instalação (amostra 3) apresenta um valor de enriquecimento mais baixo, que pode ser atribuído à presença de urânio natural ou alguma contaminação. Também foi notado que o valor do enriquecimento aumentou conforme aproxima-se dos pontos em que se trabalha com urânio enriquecido. Ainda nessa figura, pode-se observar que, dentro das suas incertezas, as amostras 8, 11, 16, 17 e 18 possuem níveis de enriquecimento compatíveis entre si (dentro de suas barras de incerteza) e conforme declarado pelo operador da instalação (20 \%). Do ponto de vista das salvaguardas nucleares, o importante é verificar que a instalação não esteja trabalhando com enriquecimento acima do permitido. No entanto, do ponto de vista de uma investigação forense nuclear, a informação da fração atômica do isótopo ${ }^{235} \mathrm{U}$ (Tabela 15), em conjunto com aquelas fornecidas pelas imagens da morfologia da partícula contribuem para a determinação do tipo de processo e do grau de enriquecimento real em que a instalação opera. 
Caso fossem analisados outros elementos, como as terras raras (86), poderia ser identificado uma impressão digital, por exemplo, química, desse tipo de material e, consequentemente, conhecer sua origem (atribuição nuclear) (44). Isso permitiria que se demonstrasse a consistência, ou não, de uma hipótese construída após um evento de interceptação de material nuclear ilicitamente transportado ou não declarado.

Apesar da enorme dificuldade de se encontrar partículas individuais utilizando somente o conjunto óptico do sistema de ablação à laser foram encontradas três partículas ao acaso, sendo uma na amostra 8 e duas na amostra 11. Essas partículas tinham cerca de $30 \mu \mathrm{m}$ (partículas grandes) e suas razões isotópicas estão apresentadas na Tabela 16.

Tabela 16 - Razões isotópicas corrigidas para as partículas encontradas nas amostras 8 e 11. Dados apresentados com suas incertezas expandidas em nível de confiança de $95 \%(k=2)$.

\begin{tabular}{c|c}
\hline Amostra & Rt 5/8 \\
\hline Amostra 8 - Partícula 1 & $0,0230 \pm 0,0020$ \\
Amostra 11 - Partícula 1 & $0,135 \pm 0,005$ \\
Amostra 11 - Partícula 2 & $0,150 \pm 0,007$ \\
\hline
\end{tabular}

Com base nessa tabela e na Tabela 13 pode-se notar que a razão isotópica ${ }^{235} \mathrm{U} /{ }^{238} \mathrm{U}$ da partícula encontrada na amostra 8 é muito menor do que aquela encontrada em sua análise total, demonstrando a sua heterogeneidade. O mesmo não ocorre com as partículas 1 e 2 da amostra 11, que são compatíveis entre si e com a razão isotópica ${ }^{235} \mathrm{U} /{ }^{238} \mathrm{U}$ obtida em sua análise total. Essa informação está mais ressaltada na Figura 45, que apresenta um gráfico das razões isotópicas de todas as amostras. 


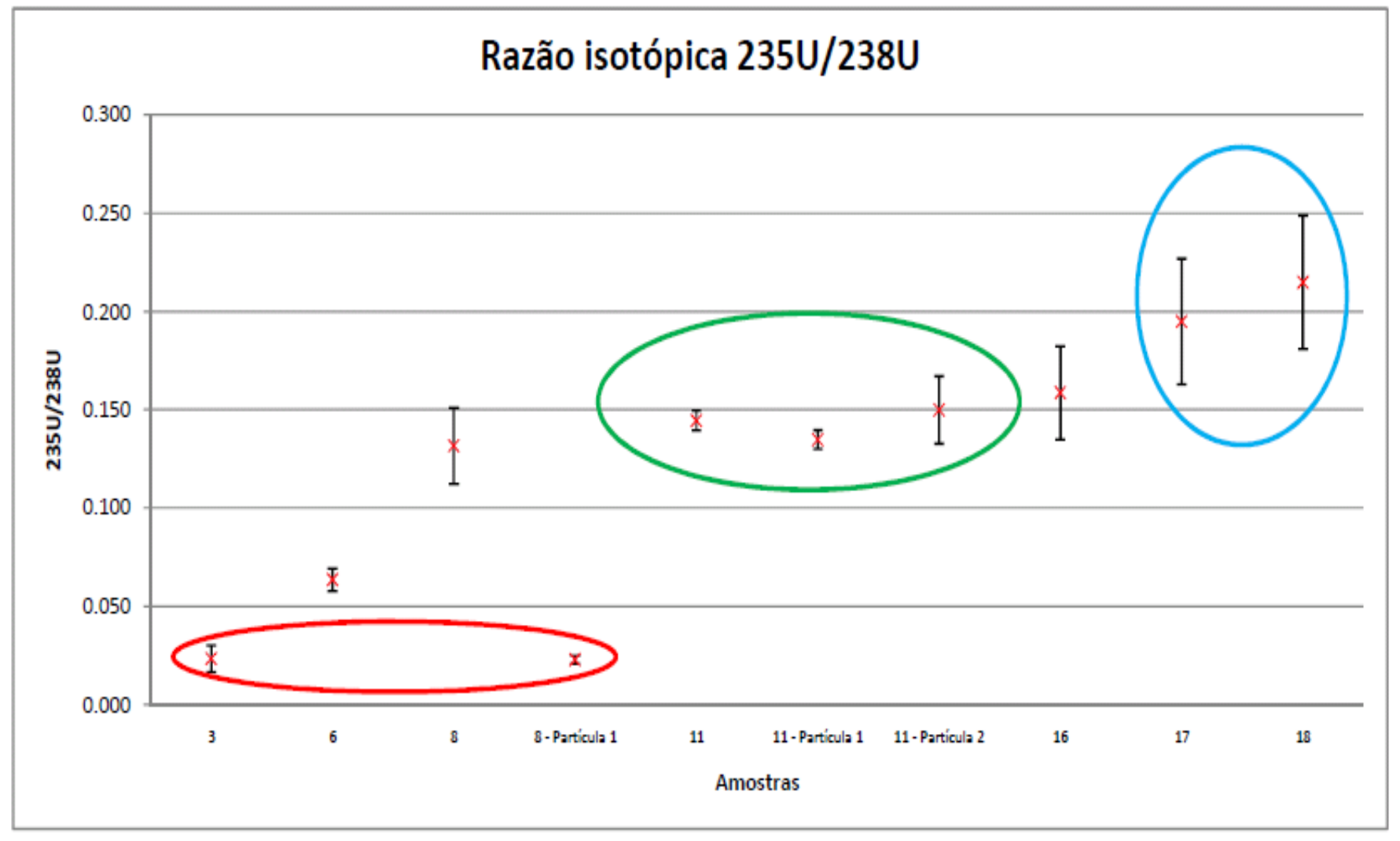

Figura 45 - Razões isotópicas ${ }^{235} U{ }^{238} U$ das amostras coletadas no CCR/IPEN. Dados apresentados com suas incertezas expandidas em nível de confiança de 95\% ( $k=2)$. Amostra 3 - Corredor de acesso ao prédio; Amostra 6 - porta de acesso ao prédio; Amostra 8 - ponto de troca de sapatos; Amostra 11 - ponto de checagem de radiação; Amostra 16 - capela de $U_{4}$; Amostra 17 - chão em frente à capela de recuperação de UF 4 ; Amostra 18 - capela de recuperação de $U F_{4}$.

Na figura 45 nota-se que a partícula 1 da amostra 8 possui um nível de enriquecimento compatível com o da amostra 3 (círculo vermelho). Isso mostra que a análise integral da amostra pode mascarar a análise da razão isotópica, pois assim como foi encontrada uma partícula com baixo enriquecimento, poderia ter sido encontrada um partícula de enriquecimento elevado que estaria diluída entre diversas outras com baixo enriquecimento. $\mathrm{O}$ círculo verde mostra o agrupamento entre os valores das razões isotópicas da amostra 11 integral e das partículas nela encontradas, que se leva a concluir que essas razões são compatíveis dentro de suas incertezas e apresentam certa homogeneidade com respeito à razão 
${ }^{235} \mathrm{U} /{ }^{238} \mathrm{U}$. O círculo azul mostra que as amostras 17 e 18 possuem graus de enriquecimento compatíveis e que, provavelmente, são de pontos próximos. Essa última análise reforça a importância da utilização de técnicas analíticas capazes de analisar partículas individuais e coloca a LA-HR-ICP-MS como uma técnica promissora e robusta para análises das swipes samples. Além disso, os esfregaços têm área de aproximadamente $20,4 \mathrm{~cm}^{2}$ e apenas uma ínfima fração (algumas dezenas de $\mu \mathrm{m}$ ) são utilizados para a análise. Isto a torna uma técnica praticamente não destrutiva, pois preserva uma parte considerável do testemunho.

\subsection{Comparação entre as incertezas da razão isotópica ${ }^{235} U{ }^{238} U$ da amostra simulada e das amostras reais}

Foram selecionadas algumas amostras que apresentaram as menores incertezas expandidas percentuais (u \%) para a razão isotópica ${ }^{235} \mathrm{U} /{ }^{238} \mathrm{U}$ e compiladas em na Tabela 17 , com o intuito de se comparar com a amostra simulada B (esfregaço simulado analisado por LA-HR-ICP-MS). A partir disso pôde-se notar que as u \%, quando se consegue analisar partículas individuais (amostras 8 e 11), são da mesma ordem de grandeza da u \% da amostra simulada, que é homogênea. No entanto, quando se compara com os dados das amostras de esfregaço reais analisadas como um todo (amostras 8 , e 18), a situação já muda por completo devido a sua heterogeneidade intrínseca, pois trata-se de um tipo de amostra ambiental que contém diversos detritos.

Uma exceção é o caso da amostra 11 analisada integralmente (bulk), em que pôde-se notar que a sua incerteza expandida percentual é da mesma ordem de grandeza da u \% da amostra simulada. Isso pode indicar que a área ablacionada nessa amostra apresentou maior homogeneidade. 
Tabela 17 - Comparação entre as incertezas expandidas percentuais ( $u$ \%) da razão isotópica ${ }^{235} U{ }^{238} U$ obtidas para as amostras reais e simuladas.

\begin{tabular}{c|cc}
\hline & Amostras & u \% (\%) \\
\hline \multirow{4}{*}{ Esfregaço real } & 8 & 14,4 \\
& 11 & 3,5 \\
& 18 & 15,8 \\
& 8 - Partícula 1 & 8,7 \\
& 11 - Partícula 1 & 3,7 \\
Esfregaço simulado & 11- Partícula 2 & 4,7 \\
\hline
\end{tabular}




\section{Conclusão}

O estudo comparativo entre as atividades radioativas medidas e as atividades empíricas de enriquecimento isotópico no isótopo ${ }^{235} \mathrm{U}$ mostraram-se uma ferramenta importante para a estimativa da massa de urânio contida na amostra, pois os valores obtidos para o padrão e para as amostras estudadas apresentaram uma diferença relativa, variando de 0,21 \% a 6,9\%. Esse tipo de estudo preliminar também permite uma avaliação inicial dos melhores pontos de amostragem e o estabelecimento da melhor estratégia analítica para a análise das amostras de esfregaço. Isto permitiu que se escolhessem outras técnicas complementares, que trouxessem maior confiabilidade e segurança ao protocolo proposto.

A identificação da partícula por MEV e sua análise semi-quantitativa por EDS mostram-se muito eficientes na identificação da morfologia e composição atômica das partículas encontradas e analisadas, pois foi possível compará-las com padrões de mesma composição, constatar a compatibilidade de suas características morfológicas e também contatar que os compostos de urânio encontrados nos esfregaços são compatíveis com a atividade declarada. Essa metodologia possui um potencial muito grande para ser implementada em processos de salvaguardas e forense nuclear, porém ainda precisa de melhorias no que diz respeito às análises quantitativas por EDS, pois as amostras reais de esfregaço contém elementos como: $\mathrm{Na}, \mathrm{Al}, \mathrm{Si}, \mathrm{S}, \mathrm{N}$ e C.

Os dados obtidos pela análise de razão isotópica demonstram a aplicabilidade, robustez e agilidade que a técnica LA-HR-ICP-MS implementa à análise de amostras de esfregaço. A estratégia adotada de se utilizar o feixe de laser desfocalizado e a utilização de replicatas proporcionou uma melhor precisão na análise, alcançando níveis DPR de até $1,1 \%$, que estão em conformidade com artigos divulgados na literatura $(77 ; 92)$. No entanto, esta técnica não atinge a precisão especificada pela AIEA para medições de razão isotópica de urânio para fins de salvaguarda. Mesmo assim, foram obtidos resultados muito consistentes com o material que está sendo manipulado na instalação. Já no caso de uma investigação forense nuclear seria possível determinar que a instalação trabalha com urânio enriquecido.

As amostras que apresentaram maior nível de enriquecimento (amostras 17 e 18) foram comparadas com o valor em que a instalação opera, apresentando diferença relativa percentual de $18,9 \%$ e $12,9 \%$, respectivamente. Essa diferença pode ser atribuída à presença de urânio 
natural nas áreas de coleta. A utilização da técnica LA-HR-ICP-MS reduz o tempo de análise, exclui procedimentos de preparação de amostras demorados e com grande possibilidade de contaminação e consome apenas uma pequena quantidade de material do testemunho, que é de suma importância para a ciência forense nuclear.

Apesar dos resultados satisfatórios obtidos com a utilização dessa técnica, faz-se necessário a melhoria dos procedimentos de identificação e localização de partículas individuais para análises pontuais Isto eliminaria o problema de heterogeneidade e proporcionaria maior confiabilidade às medidas do nível de enriquecimento com o qual a instalação opera, pois aumentaria a robustez das informações obtidas. Satisfeitas estas condições, a LA-HR-ICP-MS poderia ser considerada uma técnica alternativa para ser utilizada para fins de salvaguardas e de investigações forenses nucleares. 


\section{Bibliografia}

1. IBRAM. IBRAM - Instituto Brasileiro de Mineração. [Online] IBRAM. [Citado em: 10 de janeiro de 2013.] Informações e Análises da Economia Mineral Brasileira. http://www.ibram.org.br/sites/1300/1382/00001461.pdf.

2. Agência Internacional de Energia Atômica (AIEA). Climate change and nuclear power 2011. [Online] [Citado em: 10 de 10 de 2012.] http://www.iaea.org/OurWork/ST/NE/Pess/assets/11-43751_ccnp_brochure.pdf. 3. Almeida, E. S. Teoria Atômica Grega. [Online] [Citado em: 10 de 10 de 2013.] http://www.sbfisica.org.br/rbef/pdf/vol05a15.pdf.

4. Martins, R. A. Como Becquerel não descobriu a radioatividade. Caderno Catarinense de Ensino de Física. 1990, Vol. 7, pp. 24-45.

5. Grupo de Ensino de Física da Universidade Federal de Santa Maria. Física Moderna. [Online] [Citado em: 10 de janeiro de 2013.] Física Moderna.

http://coral.ufsm.br/gef/Moderna/moderna08.pdf.

6. biodieselbr. [Online] [Citado em: 10 de janeiro de 2013.] O Primeiro Reator Nuclear. http://www.biodieselbr.com/energia/nuclear/primeiro-reator-nuclear.htm.

7. Jonter, Thomas. Nuclear Non-Proliferation - a Brief Historical background. [A. do livro] ESARDA. [ed.] G. Janssens-Maenhout. Nuclear Safeguards and Non-Proliferation - Course Syllabus. Luxemburgo : European Comunity, 2009, pp. 9 - 17.

8. Indústrias Nucleares Brasileiras. INB - Indústrias Nucleares do Brasil. [Online] [Citado em: 10 de janeiro de 2013.] http://inb.gov.br.

9. Indústrias Nucleares do Brasil. FAQ. [Online] [Citado em: 10 de janeiro de 2013.] http://www.inb.gov.br/pt-br/LeiAcesso/FAQ.pdf.

10. CRC Press. Handbook of Chemistry and Physics. [A. do livro] C. R. Hammond. [ed.] W. M. Haynes. The Elements. Oxford : CRC Press, 2013, Vol. 93, pp. 4-39 - 4-40.

11. Barbosa, V. INFO EXAME. [Online] [Citado em: 2013 de janeiro de 10.] http://info.abril.com.br/noticias/tecnologias-verdes/fotonoticias/quem-sao-os-10-senhoresmundiais-do-uranio.shtml.

12. Granjeiro, C. et al. O CICLO DE COMBUSTÍVEL. [Online] [Citado em: 10 de janeiro de 2013.] http://nuclear.com.sapo.pt/index_ficheiros/Page1834.htm.

13. Marinha do Brasil. [Online] [Citado em: 10 de janeiro de 2013.]

www.cgee.org.br/atividades/redirect.php?idProduto $=2069$.

14. Grupo de Ensino de Física da Universidade Federal de Santa Maria. [Online] [Citado em: 12 de janeiro de 2013.] Fissão Nuclear. http://www.ufsm.br/gef/Nuclear/nuclear12.pdf. 15. Soares, H. V. et al. Ciclo do combustível nuclear. [Online] [Citado em: 10 de janeiro de 2013.] http://www.cctn.nuclear.ufmg.br/wp-content/uploads/2012/06/Palestra_ciclos.pdf. 16. Jankowitsch-Prevor, O. International Norms against Nulear Weapons, an overview? Treaties, Conventions, Agreements and 'Initiatives` regarding non-proliferation of nuclear weapons, disarmament and arms control. [A. do livro] ESARDA. Nuclear Safeguards and Non-Proliferation - Course Syllabus. Luxemburgo : European Comunity, 2009, pp. 69-71. 17. International Atomic Energy Agency (IAEA). INFCIRC/153. Viena : s.n., 1972. 18. Janssens-Maenhout, G. Nuclear Material Subject to Safeguards. [A. do livro] ESARDA. Nuclear Safeguards and Non-Proliferation - Course Syllabus. Luxemburgo : European Comunity, 2009, pp. 45 - 52. 
19. Burrows, B. The principles of nuclear material management. [A. do livro] ESARDA. Nuclear Safegurds and Non-Proliferation - Course Syllabus. Luxemburgo : European Community, 2009, pp. 44-66.

20. Instituto de Radioproteção e Dosimetria (IRD). Instituto de Radioproteção e Dosimetria. [Online] [Citado em: 10 de 01 de 2012.] http://ird.gov.br.

21. Agência Brasileiro-Argentina de Contabilidade e Controle de Materiais Nucleares (ABACC). Agência Brasileiro-Argentina de Contabilidade e Controle de Materiais Nucleares (ABACC). [Online] [Citado em: 22 de 10 de 2010.] http://www.abacc.org.

22. Khater, A. E. M. Recent Development in Radiochemical Analysis for Safeguards Purposes - A Review Article. Cairo : s.n., 2005.

23. International Atomic Energy Agency (IAEA). INFCIRC/26. Viena : s.n., 1961. 24. International Atomic Energy Agency (IAEA). INFCIRC/66. Viena : s.n., 1965. 25. International Atomic Energy Agency (IAEA). INFCIRC/140. Viena : s.n., 1970. 26. ABACC. ACORDO ENTRE A REPÚBLICA FEDERATIVA DO BRASIL, A REPÚBLICA ARGENTINA, A AGÊNCIA BRASILEIRO-ARGENTINA DE CONTABILIDADE E CONTROLE DE MATERIAIS NUCLEARES (ABACC) E A AGÊNCIA INTERNACIONAL DE ENERGIA ATÔMICA(AIEA) PARA A APLICAÇÃO DE SALVAGUARDAS. Agência Brasileiro-Argentina de Contabilidade e Controle de Materiais Nucleares. [Online] [Citado em: 14 de Dezembro de 2013.] http://www.abacc.org.br/wpcontent/uploads/2009/10/quadripartite_portugues.pdf.

27. IAEA. International Atomic Energy Agency Board of Governors, Model Protocol Additional to the Agreement(s) and the International Atomic Energy Agency for the Application of Safeguards. Vienna : s.n., 1997. INFCIRC/540 - Corrected.

28. Hooper, Richard. The IAEA's Additional Protocol. Disarmament Forum - On-site Inspections: Common Problems, Different Solutions. 1999, Vol. 3, pp. 7 - 16.

29. Donohue, D. L. Strenghtening IAEA safeguards through environmental sampling and analysis. Journal of Alloys and Compounds. 1998, Vols. 11-18, pp. 271-273.

30. Moyland, Suzanna van. The IAEA's Programme 93+2. Londres : VERTIC, 1997. ISBN 1-899548-08-4.

31. The changing nature of safeguards. Hooper, Richard. 1, 2003, IAEA Bulletin, Vol. 45, pp. 7-11.

32. Hooper, Richard. Strengthening IAEA Safeguards in an Era of Cooperation. Arms Control Today. 1995, Vol. 25, pp. 14-18.

33. Monteiro, R. L. Desenvolvimento e validação de uma metodologia de análise multielementar em amostras de soro sanguíneo por espectrometria de massas de alta resolução com fonte de plasma indutivo. São Paulo : Instituto de Pesquisas Energéticas e Nucleares (IPEN), 1999. Dissertação(Mestrado).

34. Buchmann, J. H. et al. Environmental monitoring as an important tool for safeguards of nuclear material and nuclear forensics. journal of Radioanalytical and Nuclear Chemistry. 2006, Vol. 270, pp. 291-298.

35. Furusawa, H. A. et al. Uranium isotopic analysis by using Sector Field Inductively Mass Spectrometer. Journal of Radioanalytical and Nuclear Chemistry. 1999, Vol. 242, pp. 647651.

36. Godoy, M. L. D. P. et. al. Application of ICP-QMS for the determination of plutonium in environmental sample for safeguards purposes. Journal of Environmental Radioactivity. 2007, Vol. 97, pp. 124-136.

37. Esaka, F. et al. Comparison of ICP-MS and SIMS techniques for determining uranium 
isotope ratios in individual particles. Talanta. 78, 2009, pp. 290-294.

38. Shen, Y. et. al. Study on analysis of isotopic ratio of uranium-bearing particle in swipe samples by Ft-TIMS. Radiation Measurements. 2008, Vol. 43, pp. 299-302.

39. Zhang, X. Z. et. al. Application of Inductively Coupled Plasma Mass Spectrometry to the determination of uranium isotope ratios in individual particles for nuclear safeguards.

Spectrochimica Acta Part B. 2007, Vol. 62, pp. 1130-1134.

40. Degueldre, C. et. al. Uranium colloid analysis by single particle inductively coupled plasma mass spectrometry. Talanta. 2006, Vol. 68, pp. 623-628.

41. Wallenius, M. Nuclear Forensic investigations: Two case studies. Forensic Science International. 2006, pp. 55-62.

42. Mayer, K. et al. Nuclear forensics - a methodology providing clues on the origin of illicitly trafficked nuclear materials. Analyst. 2005, Vol. 130, pp. 433-441.

43. IAEA (International Atomic Energy Agency). Incidents of nuclear and other radioactive material out of regulatory control - 2013 Fact Sheet. Vienna : s.n., 2013.

44. (AIEA), Agência Internacional de Energia Atômica. Nuclear Forensic Support, Technical Guidance - Reference Manual. s.l. : IAEA Nuclear Security Series, n²2, 2006. 45. Joint Working Group of the American Physical Society and the American Association for the Advancement of Science. Nuclear Forensics Role, State of the Art, Program Needs. Washington, D.C. : s.n., 2005.

46. Pajo, L. UO2 Fuel pellet impurities, pellet surface roughness and $\mathrm{n}(18 \mathrm{O}) / \mathrm{n}(16 \mathrm{O})$ ratios, applied to nuclear forensic science. Dissertação (Mestrado). s.l. : Universidade de Helsinki, 2001. ISBN 952-10-0122-4.

47. Capannesi, G. et al. Characterization of a suspect nuclear fuel rod in a case of illegal international traffic of fissile material. Forensic Science International. 2010, pp. 15-21.

48. Mayer, K. e Wallenius, M. Nuclear Forensic Methods in Safeguards. ESARDA BULLETIN. 2008, Vol. 38, pp. 44-51.

49. Aplicação da Técnica de Correlação Isotópica na Determinação da Concentração dos Nuclídeos 241 Am E 243 Am em Combustíveis Nucleares Irradiados. SARKIS, J. E. S. ET AL. Rio de Janeiro : s.n., 1996. Anais do VI Congresso Geral de Energia Nuclear. VI Congresso Geral de Energia Nuclear.

50. Correlações Isotópicas em Combustíveis Nucleares Irradiados. SARKIS, J. E. S. et al. Rio de Janeiro : s.n., 1996. Anais VI Congresso Geral de Energia Nuclear. VI Congresso Geral de Energia Nuclear.

51. Wallenius, M. et al. Origin Determination of Plutonium Material in Nuclear Forensics. Journal of Radioanalytical and Nuclear Chemistry. 2000, Vol. 246, pp. 317-321.

52. Nicolaou, G. Provenance of unknown plutonium material. Journal of Environmental Radioactivity. 99, 2008, pp. 1708-1710.

53. Robel, Martin e Kristo, Michael J. Discrimination of source reactor type by multivariate statistical analysis of uranium and plutonium isotopic concentrations in unknown irradiated nuclear fuel material. Journal of Environmental Radioactivity. 99, 2008, pp. 1789-1797.

54. Švedkauskaitè-LeGore, J. et al. Investigation of the isotopic composition of lead and of trace element concentration in natural uranium materials as a signature in nuclear forensics. Radiochimica Acta. 2007, Vol. 95, pp. 601-605.

55. Sarkis, J.E.S. et al. Ciência Forense Nuclear. [A. do livro] R.P.O. Branco. Químioca Forense: Ampliando o Horizonte da Perícia. Campinas : Millennium, 2012, Vol. II. ISBN 978-85-7325-252-8.

56. Becker, Johanna Sabine. Inorganic Mass Spectrometry. West Sussex : Wiley, 2007. pp. 7 
- 38 e 150 - 153. ISSN 978-0-470-01200-0.

57. Thomas, Robert. Practical Guide to ICP-MS. New York : Marcel Dekker, 2004. pp. 1 61. ISBN 0-8247-5319-4.

58. Sarkis, JES. Espectrometria de massas. [A. do livro] R.P.O. et al. BRANCO. Química Forense Sob Olhares Eletrônicos. s.l. : Millennium Editora, 2006, pp. 43-72.

59. Thermo Scientific. [Online] [Citado em: 10 de janeiro de 2013.] http://www.thermo.com/eThermo/CMA/PDFs/Various/File_2512.pdf.

60. Becker, J. S. et al. Inorganic trace analysis by mass spectrometry. Spectrochimica Acta B. 53, 1998, pp. 1475-1506.

61. Thermo Fisher Scientific. ELEMENT2/ELEMENT XR - Hardware Manual. Bremen : s.n., 2009.

62. Einstein, A. On the quantum theory of radiation. Phys. Z. 1917, Vol. 18, p. 121. 63. Shibuya, Elisa. ACOPLAMENTO LASER - ESPECTRÔMETRO DE MASSA DE DUPLA FOCALIZAÇÃO COM FONTE DE PLASMA INDUZIDO (LA-HR-ICP-MS): ESTUDOS FUNDAMENTAIS E ANÁLISES QUANTITATIVAS EM AMOSTRAS SÓLIDAS. São Paulo : Dissertação de mestrado, 1999.

64. Maillet, Henry. O laser - Princípios e técnicas de aplicação. São Paulo : Manole, 1987. pp. 1 - 12.

65. Russo, Richard, Mao, Xianglei e Gonzales, Jhanis. Laser Ablation. [A. do livro] Jagdish P. Singh e Surya Narayan Thakur. Laser-Induced Breakdown Spectroscopy. Amsterdam : Elsevier, 2007, pp. 49 - 82.

66. Leme, A. et al. [Online] http://www.ebah.com.br/content/ABAAABY_cAC/seminariocores-1.

67. Richard, Russo, et al., et al. Laser ablation in analytical chemistry - a review. Talanta. 2002, Vol. 57, pp. 425 - 451.

68. Russo, Richard E. e Mao, Xianglei. Chemical analysis by Laser Ablation. [A. do livro] John C. Miller e Richard F. Haglund. Laser Ablation and Desorption. s.1. : Academic Press, 1998, Vol. 30, pp. 375 - 405.

69. Becker, J. S. et al. Laser ablation inductively coupled plasma mass spectrometry for the trace, ultratrace and isotope analysis of long-lived radionuclides in solid samples. Int. J. Mass Spectrom. 1-3, 2000, Vol. 202, pp. 531-539.

70. Pickhardt, C. et al. Laser ablation inductively coupled plasma mass spectrometry for direct isotope ratio measurements on solid samples. International Journal of Mass Spectrometry. 2005, Vol. 242, pp. 273-280.

71. Széles, E. Laboratory for nuclear forensics and environmental analysis. Seminar on $R \& D$ activities at the Institute of Isotopes Related to Nuclear Security. Viena : s.n., 2010.

72. Becker, Johanna Sabine. State-of-art and progress in precise and accurate isotope ratio measurements by ICP-MS and LA-ICP-MS. JAAS. 2002, Vol. 17, pp. 1172 - 1185.

73. Russo, R. et al. Influence of wavelength on fractionation in laser ablation ICP-MS. JAAS. 2000, Vol. 15, p. 1115.

74. Gunther, D. et al. Wavelength dependant ablation rates for metals and silicate glasses using homogenized laser beam profiles-implications for LA-ICP-MS. Applied Surface Science. 2001, Vol. 182, p. 91.

75. Gray, A.L. Solid sample introduction by laser ablation for inductively coupled plasma. Analyst. 1985, Vol. 110, pp. 551-556.

76. Aregbe, Y. et al. Report on the Workshop on Direct Analysis of Solid Samples Using Laser Ablation-Inductively Coupled Plasma-Mass Spectrometry (LA-ICP-MS). s.1. : ESARDA 
BULLETIN No 46, 2011. pp. 136-145.

77. Varga, Z. Application of laser ablation inductively coupled plasma mass spectrometry for the isotopic analysis of single uranium particle. Analytica Chimica Acta. 2008, Vol. 625, pp. 17.

78. Bürger, S. e Riciputi, L. R. A rapid isotope ratio analysis protocol for nuclear solid materials using nano second laser ablation time of flight ICP-MS. Journal of Environmental Radioactivity. 11, 2009, Vol. 100, pp. 970-976.

79. Boulyga, S. F. and Prohaska, T. Determining the isotopic compositions of uranium and fission products in radioactive environmental microsamples using laser ablation ICP-MS with multiple ion counters. Anal. Bioanal. Chem. 2008, Vol. 390, pp. 531-539.

80. Alamelu, D. et al. Determination of impurities in thoria (ThO2) using Laser Ablation Inductively Coupled Plasma Mass Spectrometry (LA-ICP-MS). Journal of Nuclear Materials. 406, 2010, pp. 356-359.

81. Boulyga, S. et al. Plutonium and americium determination in mosses by laser ablation ICP-MS combined with isotope dilution technique. International Journal of Mass Spectrometry. 2003, Vol. 226, pp. 329-339.

82. Williams, D. e Carter, C. Transmission Electron Microscopy - A Textbook for Materials Science. Nova Iorque : s.n., 2009. ISBN 978-0-387-76501-3.

83. Kuo, Y. et al. Silicon photodiodes for electron beam position and drift detection in scanning electron microscopy and electron beam lithography system. Nuclear Instruments and Methods in Physics Research Section A: Accelerators, Spectrometers, Detectors and Associated Equipment. 2011, Vol. 645, 1, pp. 84-89.

84. Wittke, J. Universidade do Arizona. [Online] 2008. [Citado em: 10 de 01 de 2013.] http://www4.nau.edu/microanalysis/Microprobe-SEM/Instrumentation.html.

85. Saliba-Silva, A. M. et al. Fabrication of U3Si2 powder for fuels used in IEA-R1 Nuclear Research Reactor. Materials Forum. Vols. 591-593, pp. 194-199.

86. Rosa, D. S. Caracterização química, física e isotópica de U3Si2 para fins forenses nucleares. Instituto de Pesquisas Energéticas e Nucleares. São Paulo : s.n., 2011. Dissertação (Mestrado).

87. Marin, R. C., Sarkis, J. E. S. and Nascimento, M. R. The use of LA-SF-ICP-MS for nuclear forensics purposes: uranium isotope ratio analysis. Journal of Radioanalytical and Nuclear Chemistry. 2013, Vol. 295, pp. 99-104.

88. Isotope ratio measurements of uranium by LA-HR-ICP-MS. Marin, R. C. and Sarkis, J. E. S. Belo Horizonte : s.n., 2011. INAC.

89. Rucker, T. L. e Johnson Jr., C. M. Relationship between isotopic uranium activities and total uranium at various uranium enrichments. Journal of radioanalytical and Nuclear Chemistry. 1998, Vol. 235, 1-2, pp. 47-52.

90. Bürger, S. F. et al. Implementation of Guide to the Espression of uncertainty in Measurement. International Journal of Mass Spectrometry. 2010, Vol. 294, pp. 65-76.

91. Joint Comitee for Guides in Metrology. Evaluation of measurement data - guide to the expression of uncertainty in measurements. s.l. : JCGM 100, 2008.

92. Pointurier, F, et al. Application of Nanosecond-UV Laser Ablation Inductively Coupled Plasma Mass Spectrometry for the Isotopic Analysis of Single Submicrometer-Size Uranium Particles. Analytical Chemistry. 2011, Vol. 83, pp. 7841-7848.

93. Pointurier, F. e Hubert, A. Performance of laser ablation: quadrupole-b ased ICP-MS coupling for the analysis of single micrometric uranium particles. Journal of Radioanalytical and Nuclear Chemistry. 2012, Vol. 296, pp. 609-616. 
94. Lloyd, N.S. et al. Precise and accurate isotopic analysis of microscopic uranium-oxide grains using LA-MC-ICP-MS. JAAS. 2009, Vol. 24, pp. 752-758.

95. Kappel, $\mathbf{S}$. et al. Direct uranium isotope ratio analyusis of single micrometer-sized glass particles. Journal of Environmental Radioactivity. 2012, Vol. 113, pp. 8-15. 